\title{
Studies of Premixed and Non-Premixed Hydrogen Flames
}

\author{
Okjoo Park, ${ }^{1}$ Peter S. Veloo, ${ }^{2}$ Hugo Burbano, ${ }^{1}$ Fokion N. Egolfopoulos ${ }^{1}$ \\ ${ }^{I}$ Department of Aerospace and Mechanical Engineering \\ University of Southern California, Los Angeles, CA 90089-1453, USA \\ ${ }^{2}$ Exponent, Failure Analysis Associates, Los Angeles, CA 90066, USA
}

Full-length article submitted to Combustion and Flame

Running title: Studies of Premixed and Non-Premixed Hydrogen Flames

\section{Corresponding Author:}

Fokion N. Egolfopoulos

Department of Aerospace and Mechanical Engineering,

University of Southern California

Los Angeles, California 90089-1453, USA

Phone: 213-740-0480

Fax: 213-740-8071

Email: egolfopo@usc.edu 


\title{
Studies of Premixed and Non-Premixed Hydrogen Flames
}

\author{
Okjoo Park ${ }^{\mathrm{a}}$, Peter S. Veloo ${ }^{\mathrm{b}}$, Hugo Burbano ${ }^{\mathrm{a}}$, Fokion N. Egolfopoulos ${ }^{\mathrm{a}, *}$ \\ ${ }^{a}$ Department of Aerospace and Mechanical Engineering \\ University of Southern California, Los Angeles, CA 90089-1453, USA \\ ${ }^{b}$ Exponent, Failure Analysis Associates, Los Angeles, CA 90066, USA
}

\begin{abstract}
The hydrogen oxidation chemistry constitutes the foundation of the kinetics of all carbon- and hydrogencontaining fuels. The validation of rate constants of hydrogen-related reactions can be complicated by uncertainties associated with experimental data caused by the high reactivity and diffusivity of hydrogen. In the present investigation accurate experimental data on flame propagation and extinction were determined for premixed and non-premixed hydrogen flames at pressures between $p=1$ and $7 \mathrm{~atm}$. The experiments were designed to sensitize the three-body $\mathrm{H}+\mathrm{O}_{2}+\mathrm{M} \rightarrow \mathrm{HO}_{2}+\mathrm{M}$ reaction, whose rate is subject to notable uncertainty. This was achieved by increasing the pressure and by adding to the reactants $\mathrm{H}_{2} \mathrm{O}$ and $\mathrm{CO}_{2}$ whose collision efficiencies are high compared to other species. In the present study, directly measured flame properties were compared against computed ones, in order to eliminate uncertainties associated with extrapolations, as is the case for laminar flame speeds. The measured extinction strain rates exhibit both a positive and negative dependence on pressure with and without weighting with the density, and this non-monotonic behavior is caused by the competition between the $\mathrm{H}+\mathrm{O}_{2} \rightarrow \mathrm{O}+\mathrm{OH}$ and $\mathrm{H}+\mathrm{O}_{2}+\mathrm{M} \rightarrow \mathrm{HO}_{2}+\mathrm{M}$ reactions as well as the $\mathrm{HO}_{2}$ kinetic pathways as pressure increases. The various kinetic models considered in this investigation did not reproduce equally well the non-premixed flame extinction data with added $\mathrm{H}_{2} \mathrm{O}$. On the other hand, the predicted extinction strain rates were consistent between the various models in the case of added $\mathrm{CO}_{2}$. Finally, it was shown that the formulation of binary diffusion coefficient pairs including $\mathrm{H}-\mathrm{N}_{2}$ and $\mathrm{H}_{2}-\mathrm{N}_{2}$ has a first order effect on the prediction of extinction strain rates of non-premixed $\mathrm{H}_{2}$ flames.
\end{abstract}

Keywords: Flame propagation, flame extinction, pressure effects, kinetic modeling, hydrogen kinetics 


\section{Introduction}

The study and development of kinetic models for the oxidation of hydrogen has historically been motivated by its hierarchical importance in combustion chemistry. Recent interest in utilizing synthesis gas (syngas) as a fuel for Integrated Gasification Combined Cycle (IGCC) will require the validation of existing $\mathrm{H}_{2} / \mathrm{CO}$ chemical kinetic reaction models at conditions relevant to those encountered in gas turbines. This will require accurate experimental results at elevated pressures and low flame temperatures (e.g., [1,2]). Adding to challenges in accurately modeling syngas oxidation is the possibility of significant $\mathrm{H}_{2} \mathrm{O}$ vapor and $\mathrm{CO}_{2}$ present in the fuel stream after coal gasification. Nitrogen oxide $\left(\mathrm{NO}_{\mathrm{x}}\right)$ mitigation strategies for stationary gas turbines include $\mathrm{H}_{2} \mathrm{O}$ vapor injected into gas turbine combustors or the utilization of exhaust gas recirculation (e.g., [3-6]).

The development of accurate syngas oxidation chemical kinetic models has been the focus of a number of recent investigations (e.g., [7-12]). The kinetics of $\mathrm{H}_{2}$ oxidation at elevated pressures was recently studied by Burke et al. [2], and a negative pressure dependence of the mass burning rate was derived for flames of $\mathrm{H}_{2} /$ oxidizer and $\mathrm{H}_{2} / \mathrm{CO}$ /oxidizer at low flame temperatures and pressures between $p=1$ and $25 \mathrm{~atm}$. It was shown also that predictions made using the majority of existing models for $\mathrm{H}_{2}$ oxidation (e.g., [7-11]) fail to predict closely the reported data. Recently, an updated $\mathrm{H}_{2} / \mathrm{O}_{2}$ kinetic model was developed [12], by incorporating improvements in elementary rate coefficients, in order to provide better predictions of the high-pressure data of Ref. 2. Sheen [13] demonstrated that the inability to predict the data of Ref. 2 stems from the uncertainties inherent in the rate parameters and not from errors in kinetic pathways. Using USC Mech II [8] optimized using the Method of Uncertainty Minimization using Polynomial Chaos Expansion (MUM-PCE) Sheen [13] was able to reproduce the experimental measurements from Burke et al. [2]. In Refs. 2 and 13, the need for additional experimental flame data for $\mathrm{H}_{2}$ oxidation to better constrain kinetic models is highlighted also.

Laminar flame speed, $S_{\mathrm{u}}^{\circ}$, data with accurately quantified uncertainties are also essential in constraining kinetic models. There is a large body of literature $S_{\mathrm{u}}^{\mathrm{o}}$ results for $\mathrm{H}_{2} /$ air flames at atmospheric pressure (e.g., [14-20]). The difficulty with utilizing this data is the large spread in these measurements and the little consensus between $S_{\mathrm{u}}^{\mathrm{o}}$ values at a fixed equivalence ratio, $\phi$. The principal difficulty encountered in experimental measurements of atmospheric pressure $\mathrm{H}_{2}$ /air flames is that, $S_{\mathrm{u}}^{0}$ 's for such mixtures range from the order of $\mathrm{cm} / \mathrm{s}$ to $\mathrm{m} / \mathrm{s}$. At such large flow field velocities, there is large uncertainty in flow velocity measurements using either particle image velocimetry (PIV) or laser Doppler velocimetry (LDV). Another complicating factor is that the extrapolation of the strained flame velocity to zero stretch, to determine $S_{\mathrm{u}}^{\mathrm{o}}$, introduces additional uncertainties depending on the 
extrapolation method. Fuel lean $\mathrm{H}_{2}$ /air mixtures have a sub-unity Lewis number $(L e)$ and are thermodiffusionally unstable, adding thus ambiguity to the so-called measured $S_{\mathrm{u}}^{\mathrm{o}}$ 's of fuel lean $\mathrm{H}_{2} /$ air flames that cannot physically exist at the zero stretch limit due to cellular instabilities. Positive stretch suppresses cellular instabilities therefore reducing the dimensionality of the system (e.g., [21,22,23]). Thus, for lean premixed $\mathrm{H}_{2} /$ air flames, extinction strain rates, $K_{\text {ext }}$ 's, measured in the counterflow configuration provide a more meaningful experimental validation for kinetic models compared to $S_{\mathrm{u}}^{\mathrm{o}}$,s. Dong et al. [24] measured $K_{\text {ext }}$ 's of premixed $\mathrm{H}_{2}$ /air flames and results showed that the sensitivity of $K_{\text {ext }}$ to molecular transport could be as large as to kinetics.

The first goal of this present study was to provide experimental $S_{\mathrm{u}}^{\mathrm{o}}$ data for $\mathrm{H}_{2}$ flames with systematically quantified uncertainties. Using a modified $\mathrm{O}_{2} / \mathrm{N}_{2}$ oxidizer with a larger $\mathrm{N}_{2}$ dilution ratio relative to air, $S_{\mathrm{u}}^{\mathrm{o}}$ 's of $\mathrm{H}_{2} / \mathrm{O}_{2} / \mathrm{N}_{2}$ flames at near stoichiometric conditions were measured accurately by avoiding large flow velocities needed to stabilize $\mathrm{H}_{2}$ /air flames. Both extrapolated $S_{\mathrm{u}}^{\mathrm{o}}$ 's and the directly measured reference flame speeds, $S_{\mathrm{u}, \mathrm{ref}}$, were used to evaluate a number of recently developed kinetic models for $\mathrm{H}_{2}$ oxidation. The kinetics of ultra-fuel lean $\mathrm{H}_{2} /$ air were investigated further by the measurement of $K_{\text {ext }}$ 's for the same mixtures.

There exists an extensive literature body of work on the extinction of non-premixed $\mathrm{H}_{2}$ flames of motivated primarily by their relevance to high-speed propulsion applications (e.g., [25-30]). Pellett and coworkers [25-27] determined $K_{\text {ext }}$ 's of $\mathrm{N}_{2}$ diluted, atmospheric pressure, opposed-jet non-premixed $\mathrm{H}_{2}$ flames.

The effect of pressure on extinction limits of non-premixed $\mathrm{H}_{2}$ flames has been addressed to a limited extent in available literature (e.g., [28-32]). Papas et al. [28] measured local $K_{\text {ext }}$ 's as a function of $\mathrm{H}_{2}$ dilution between $p=0.5$ and $1 \mathrm{~atm}$ and noted that flame temperatures exhibit a non-monotonic pressure dependence. Recently, Niemann et al. [32] studied the pressure dependence of global extinction limits of non-premixed $\mathrm{H}_{2}$ flames between $p=1$ and $15 \mathrm{~atm}$. They confirmed the nonmonotonic pressure dependent behavior of computed $K_{\text {ext }}$ 's of non-premixed $\mathrm{H}_{2}$ flames previously observed by Sohn and Chung [30].

The second goal of this study relates to the relative scarcity of $\mathrm{H}_{2}$ flame data at elevated pressures with systematically quantified uncertainties. Extinction limits of non-premixed $\mathrm{H}_{2}$ flames at atmospheric and elevated pressures over a wide range of fuel concentrations were measured and modeled.

Syngas combustion in stationary gas turbines at elevated pressures and in the presence of notable quantities of $\mathrm{H}_{2} \mathrm{O}$ and $\mathrm{CO}_{2}$ will readily result in the production of the hydroperoxyl radicals $\left(\mathrm{HO}_{2}\right)$. The 
main source of $\mathrm{HO}_{2}$ is via a three-body main termination reaction between $\mathrm{H}$ and $\mathrm{O}_{2} . \mathrm{H}_{2} \mathrm{O}$, and to a lesser extent $\mathrm{CO}_{2}$, exhibit large chaperon efficiencies when participating in three-body termination reactions. There is a well-known, large uncertainty (e.g., [12,13]) associated with the rate parameter used to express this three-body reaction in existing $\mathrm{H}_{2}$ oxidation models. Adding to this uncertainty is the modeling of the associated collisional efficiency of the three body molecules $\mathrm{H}_{2} \mathrm{O}$ and $\mathrm{CO}_{2}$. Reducing this uncertainty has driven recent studies with wet $\mathrm{H}_{2}$ flames (e.g., [33-39]).

Seiser and Seshadri [31] studied the influence of $\mathrm{H}_{2} \mathrm{O}$ addition on the measured global $K_{\text {ext }}$ of premixed and non-premixed $\mathrm{H}_{2}$ flames at $p=1 \mathrm{~atm}$. They highlighted the need for accurate chaperon efficiency of $\mathrm{H}_{2} \mathrm{O}$ in three body reactions including $\mathrm{H}+\mathrm{O}_{2} \rightarrow \mathrm{HO}_{2}+\mathrm{M}, \mathrm{H}+\mathrm{OH}+\mathrm{M} \rightarrow \mathrm{H}_{2} \mathrm{O}+\mathrm{M}$, and $\mathrm{H}+\mathrm{H}+\mathrm{M} \rightarrow \mathrm{H}_{2}+\mathrm{M}$. Das et al. [33] investigated the effect of $\mathrm{H}_{2} \mathrm{O}$ on $S_{\mathrm{u}}^{\mathrm{o}}$ of $\mathrm{H}_{2} / \mathrm{CO} /$ air mixtures at $p=1 \mathrm{~atm}$ in the counterflow configuration, and it was recommended that the rate parameters for $\mathrm{H}_{2}+\mathrm{OH} \rightarrow \mathrm{H}_{2} \mathrm{O}+\mathrm{H}$ need to be revisited. Singh et al. [34] studied the effect of $\mathrm{H}_{2} \mathrm{O}$ on $S_{\mathrm{u}}^{0}$ of syngas/air mixtures using spherically expanding flames. Santner et al. [35] studied the effect of $\mathrm{H}_{2} \mathrm{O}$ dilution on the propagation of spherically expanding flames of $\mathrm{H}_{2}$ /oxidizer and $\mathrm{H}_{2} / \mathrm{CO}$ /oxidizer mixtures at pressures up to $p=10 \mathrm{~atm}$., and it was found that the negative pressure dependence of the burning rate shifts to lower pressures with $\mathrm{H}_{2} \mathrm{O}$ addition.

The final goal of this study was to perform systematic flame experiments by sensitizing important three-body reactions through $\mathrm{H}_{2} \mathrm{O}$ and $\mathrm{CO}_{2}$ additions and for flame temperatures in the $1000 \mathrm{~K}$ to $1400 \mathrm{~K}$ range. The present data can be used as targets to constrain kinetic models with emphasis on the main termination reaction involving $\mathrm{H}_{2} \mathrm{O}$ or $\mathrm{CO}_{2}$, i.e. $\mathrm{H}+\mathrm{O}_{2}+\left(\mathrm{H}_{2} \mathrm{O} / \mathrm{CO}_{2}\right)=\mathrm{HO}_{2}+\left(\mathrm{H}_{2} \mathrm{O} / \mathrm{CO}_{2}\right)$. 


\section{Experimental approach}

The opposed-jet counterflow configuration was used in both the propagation and extinction studies [24, 40-50], and the schematics are shown in Figs. 1 and 2 for atmospheric and high-pressure conditions respectively.

In order to determine $S_{\mathrm{u}}^{\mathrm{o}}$, the axial velocity profile along the system centerline is first measured. The minimum point of the axial velocity profile just upstream of the flame is defined as the reference flame speed, $S_{\mathrm{u}, \text { ref }}$, and the absolute value of the maximum velocity gradient in the hydrodynamic zone is defined as the imposed strain, $K$ [40], as shown in Fig. S1 of the supplementary material. Plotting $S_{\mathrm{u} \text {,ref }}$ against $K, S_{\mathrm{u}}^{\mathrm{o}}$ could be determined, in principle, by linearly extrapolating $S_{\mathrm{u}, \text { ref }}$ to zero imposed strain, i.e., $K=0$ [40]. In this study the computationally assisted non-linear extrapolation technique to $K=0$ was utilized $[42,43,47]$.

$K_{\text {ext }}$ 's of premixed flames were measured using the single-flame configuration by counterflowing fuel/air mixtures against an ambient temperature $\mathrm{N}_{2}$ jet. For $\mathrm{H}_{2} /$ air flames, a flame was established at a near extinction condition and the $\mathrm{H}_{2}$ flow rate was slightly reduced for fuel-lean mixtures to achieve extinction and determine $K_{\text {ext }}$ (e.g., [50]). For mixtures of $\mathrm{H}_{2} / \mathrm{air} / \mathrm{H}_{2} \mathrm{O}$, a flame was established at a fixed $\phi$ and a given $K, \mathrm{H}_{2} \mathrm{O}$ concentration was slightly increased to achieve extinction and determine $K_{\text {ext }}$.

$K_{\text {ext }}$ 's were measured also for non-premixed $\mathrm{H}_{2}$ flames established by counterflowing an air or air/ $\mathrm{H}_{2} \mathrm{O}$ jet against a $\mathrm{H}_{2} / \mathrm{N}_{2}$ jet. $\mathrm{H}_{2} \mathrm{O}$ was added to the oxidizer jet to sensitize more effectively the main termination reaction compared. Extinction was achieved by slightly decreasing the $\mathrm{H}_{2}$ concentration for dry non-premixed $\mathrm{H}_{2}$ flames. To achieve extinction for wet non-premixed flames, $\mathrm{H}_{2} \mathrm{O}$ concentration was increased until extinction was observed. Table 2 lists the experimental boundary conditions.

For all studies, the diameter of the burner nozzles $(D)$ were, $D=14 \mathrm{~mm}$ for $K \leq 400 \mathrm{~s}^{-1}$ and $D=10 \mathrm{~mm}$ for $K>400 \mathrm{~s}^{-1}$ at atmospheric conditions. The burner separation distance, $L$ was equal to $D$. The experimental boundary conditions are shown in Table 1.

Both PIV and LDV were used to quantify accurately flow velocities. The flow was seeded using micron size silicone oil droplets. Figure 1 depicts the schematic of the experimental configuration for premixed $\mathrm{H}_{2}$ /air flames at atmospheric pressure conditions that is integrated to a PIV system. Since $\mathrm{H}_{2}$ flames are invisible to the naked eye, a shadowgraph technique was utilized to observe the flame.

Experiments in which $\mathrm{H}_{2} \mathrm{O}$ (ACS de-ionized reagent grade) was introduced into the gas phase required the use of a vaporization system. The vaporization system consists of a syringe pump, nebulizer, and heated vaporization chamber shown in Fig. 2. $\mathrm{H}_{2} \mathrm{O}$ mass flow rates were controlled using 
high precision syringe pumps; a Harvard Apparatus ${ }^{\circledR}$ PHD 2000 for $p=1 \mathrm{~atm}$ experiments and a Chemyx ${ }^{\circledR}$ Nexus 6000 syringe pump for elevated pressure experiments.

To assist vaporization, air or $\mathrm{N}_{2}$ were preheated above the boiling temperature of $\mathrm{H}_{2} \mathrm{O}$ was co-flowed into the vaporization chamber. Additionally, the walls of the vaporization chamber were maintained at least $50 \mathrm{~K}$ above the boiling temperature of $\mathrm{H}_{2} \mathrm{O}$ using a combination of heating tapes, insulation, and thermocouples. The vaporization chamber was connected to the burner using heated and insulated stainless steel tubing. The temperature of the gas was elevated throughout the system to the nozzle exit such that the partial pressure was consistently below the vapor pressure of $\mathrm{H}_{2} \mathrm{O}$ at the prevailing ambient temperature and pressure.

Overall, the uncertainty in $\phi$ or mole fraction was determined to be no larger than $0.5 \%$. The temperature of the fuel streams, measured at the center of the burner nozzle exit, fluctuated within $\pm 2{ }^{\circ} \mathrm{C}$. The sampling errors in $K$ were determined and their $2 \sigma$ standard deviations are indicated with uncertainty bars.

\section{Numerical approach}

$S_{\mathrm{u}}^{\mathrm{o}}$ 's were computed using the PREMIX code [51,52]. Stretched flames in the counterflow configuration were numerically modeled using an opposed-jet code [53]. The original opposed-jet code has been modified to allow for the simulation of asymmetric boundary conditions [54]. Both PREMIX and opposed-jet codes have been modified to account for thermal radiation from $\mathrm{CH}_{4}, \mathrm{CO}, \mathrm{CO}_{2}$, and $\mathrm{H}_{2} \mathrm{O}$ at the optically thin limit [54,55]. The code is integrated with CHEMKIN [56] and the Sandia Transport [57] subroutine libraries.

$K_{\text {ext }}$ is computed by first establishing a vigorously burning flame at a given $K . K$ is then increased by increasing the flow velocities at the burner exits to the point of extinction. At the extinction state, the response of any flame property to $K$ is characterized by a turning-point behavior that introduces a singularity, if $K$ is considered as the independent variable (e.g., [58,59]). The opposed-jet code has been modified to capture this singular behavior, and to allow for a more precise determination of $K_{\text {ext }}$ [58]. More specifically, a two-point continuation approach is implemented by imposing a predetermined temperature or species mass fraction at two points in the flow field; thus $K$ becomes the dependent variable.

In order to accurately compute $K_{\text {ext }}$ and compare against the data, the experimental values of $L$ (e.g., [54]) and the axial velocity gradient at the nozzle exit, $\alpha$, (e.g., [43]) are necessary boundary conditions for all simulations. Egolfopoulos [54] numerically demonstrated that $K_{\text {ext }}$ increases with nozzle 
separation distance as a result of the reduction of the strain rate distribution within the reaction zone. In a recent study by $\mathrm{Ji}$ et al. [43], $\alpha$ was also found to have a considerable effect on the numerically determined $K_{\text {ext. }}$. The values of $\alpha$ for premixed flames at $1 \mathrm{~atm}$ were $15 \pm 10 \mathrm{~s}^{-1}$. For non-premixed flames, the values of $\alpha$ are listed in Table 3 .

Full multi-component transport coefficient formulations were used in all simulations for $S_{\mathrm{u}}^{\mathrm{o}}$ 's, $S_{\mathrm{u}, \mathrm{ref}}$ 's, and $K_{\text {ext }}$ 's along with the Soret effect. All simulation results are grid independent and utilized approximately 2000 grid points.

Five kinetic models were used to simulate experimental data, which are summarized in Table 4. The first model is the $\mathrm{H}_{2} / \mathrm{CO}$ sub-model of USC Mech II [8]. This model will be referred to as Model I hereafter. Model II is the $\mathrm{H}_{2} / \mathrm{CO}$ sub-model of Li et al. [7]. Model III is a recently updated $\mathrm{H}_{2} / \mathrm{O}_{2}$ model by Burke et al. [12]. Model Ia is the model by Davis et al. [10]. Model Ia is identical to Model I with the exception of the reaction rate parameter for the chain termination reaction, $\mathrm{HO}_{2}+\mathrm{OH} \rightarrow \mathrm{H}_{2} \mathrm{O}+\mathrm{O}_{2}$. In Model IIa, the transport parameters and formulation of Model II have been replaced by those of Model I.

The diffusion coefficients for Models I, Ia, IIa, and III were implemented in the simulations using updated $\mathrm{H}$ and $\mathrm{H}_{2}$ diffusion coefficients for several key pairs based on a re-evaluated set of LennardJones parameters by Wang and coworkers [24,54]. The elementary reactions common to all models in Table 4 are listed in a consistent manner in Table 5 to facilitate the proceeding analysis and discussion. Rate parameters and references for the elementary reactions listed in Table 4 are tabulated for Models I, II, and III in Tables S1 and S2 of the supplementary material. 


\section{Results and discussion}

\subsection{Laminar flame speeds of $\mathrm{H}_{2} /$ oxidizer mixtures}

Figure 3 depicts literature data [14-20,61] and computed $S_{\mathrm{u}}^{\mathrm{o}}$ 's of $\mathrm{H}_{2} /$ air mixtures at $p=1$ atm and unburned mixture temperature, $T_{\mathrm{u}}=298 \mathrm{~K}$. The calculations were performed using Models I, II, and III. Between $0.5 \leq \phi \leq 1.2$ (Fig. 3a) there is reasonably good agreement between all eight sets of experimental data. Within this $\phi$ range there is less than $30 \mathrm{~cm} / \mathrm{s}$ difference between maximum and minimum measured $S_{\mathrm{u}}^{\mathrm{o}}$ that is within $18 \%$ of the mean (or nominal) value. The spread between the various experimental measurements significantly increases at larger $\phi$ 's as shown in Fig. 3b. For example, at $\phi=2.6$, there is a $55 \mathrm{~cm} / \mathrm{s}(28 \%)$ spread in the measured $S_{\mathrm{u}}^{\circ}$. There is much less spread between the numerical calculations of $S_{\mathrm{u}}^{\mathrm{o}}$ in both Figs. $3 \mathrm{a}$ and $3 \mathrm{~b}$ relative to experimental results. The $S_{\mathrm{u}}^{\mathrm{o}}$ predictions by Models I and II are nearly identical. For $\phi \leq 1.2$ Model III's predictions are in close agreement with those obtained using Models I and II. At larger $\phi$ 's, using Model III results consistently in higher $S_{\mathrm{u}}^{\mathrm{o}}$ 's. For all three models, $\phi$ at which $S_{\mathrm{u}}^{\mathrm{o}}$ peaks is nearly identical, $\phi \approx 1.75$, which coincides with the experimental observations.

Most of the literature results in Fig. 3 were determined using the spherically expanding flame technique except for the measurements performed by Egolfopoulos and Law [61], which were determined using flames established in the counterflow configuration. It should be noted that it is difficult to perform meaningful comparisons between existing literature results, depicted in Fig. 3, as there is a distinct lack of meaningful quantification of experimental uncertainties for these measurements. Nevertheless, from Figs. 3a and 3b, it can be observed that the present calculations lie well within the range (or scatter) of experimental results.

A new set of experimental measurements of $S_{\mathrm{u}}^{\mathrm{o}}$ 's of $\mathrm{H}_{2} /\left(9.5 \% \mathrm{O}_{2}+90.5 \% \mathrm{~N}_{2}\right)$ mixtures with carefully quantified experimental uncertainties were determined at $T_{\mathrm{u}}=298 \mathrm{~K}$ and $p=1 \mathrm{~atm}$. The percentage of diluent, $\mathrm{N}_{2}$, was determined in order to maintain a maximum $S_{\mathrm{u} \text {,ref }}$ below $90 \mathrm{~cm} / \mathrm{s}$. Reducing $S_{\mathrm{u} \text {,ref }}$ resulted in a lower propensity for the mixture to flash back and lower Reynolds numbers at the burner exit, thus minimizing flow instabilities and data uncertainty. The $S_{\mathrm{u}}^{\mathrm{o}}$ uncertainties in this study were

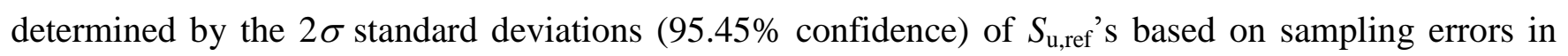
$S_{\mathrm{u}, \mathrm{ref}}$, and have been systematically quantified by the authors in Ref. 62 .

Figure 4a compares literature results [61,63] and numerical calculations for $S_{\mathrm{u}}^{\mathrm{o}}$ 's of $\mathrm{H}_{2} /\left(7.7 \% \mathrm{O}_{2}+92.3 \% \mathrm{~N}_{2}\right)$ mixtures at $T_{\mathrm{u}}=298 \mathrm{~K}$ and $p=1 \mathrm{~atm}$. There is closer agreement between the two literature data sets over a wide range of $\phi$ 's compared to Fig. 3. For $\phi \geq 2.0$, the results from 
Egolfopoulos and Law [61] are generally lower than those from Ref. 63. Figure 4b compares the present experimental results and numerical calculations for $\mathrm{H}_{2} /\left(9.5 \% \mathrm{O}_{2}+90.5 \% \mathrm{~N}_{2}\right)$ mixtures.

Comparing model predictions of $S_{\mathrm{u}}^{\mathrm{o}}$ 's for flames of the two $\mathrm{H}_{2} / \mathrm{O}_{2} / \mathrm{N}_{2}$ mixtures in Figs. $4 \mathrm{a}$ and $4 \mathrm{~b}$, reveals that there are now observable differences between predictions made using all three models. Detailed analysis, presented later in this section, demonstrates that this difference is kinetic in nature and stems from the various treatments of the $3^{\text {rd }}$ body collision efficiency of $\mathrm{N}_{2}$. From Fig. $4 \mathrm{~b}$, it can be seen that for $\phi \leq 2.0$ results obtained using Model III agree best with the present data. At larger $\phi$ 's, calculations using Model II reproduce best the present data. Overall, with increasing diluent fraction in the oxidizer stream, all three models have a tendency to under-predict the measured $S_{\mathrm{u}}^{\mathrm{o}} \mathrm{s}$.

Sensitivity analysis and computed flame structures highlight the kinetic similarities and differences between $\mathrm{H}_{2} /$ air and diluted $\mathrm{H}_{2} / \mathrm{O}_{2} / \mathrm{N}_{2}$ flames that have a reduced adiabatic flame temperature, $T_{\text {ad. }}$.

The logarithmic sensitivity coefficients of $S_{\mathrm{u}}^{\mathrm{o}}$ to kinetics for $\mathrm{H}_{2} /$ air (Figs. 5a and 5c) and $\mathrm{H}_{2} /\left(9.5 \% \mathrm{O}_{2}+90.5 \% \mathrm{~N}_{2}\right.$ ) (Figs. $5 \mathrm{~b}$ and $5 \mathrm{~d}$ ) flames at $\phi=1.1$ (Figs. 5a and 5b), and $\phi=1.75$ (Figs. 5c and 5d) are shown in Fig. 5. Comparing the sensitivity coefficients of $\mathrm{H}_{2} /$ air and $\mathrm{H}_{2} /\left(9.5 \% \mathrm{O}_{2}+90.5 \% \mathrm{~N}_{2}\right)$ flames reveals that these two sets of mixtures appear to exhibit similar behavior. There is notable sensitivity to the chain branching (R1, R3, and R5), propagating (R4), and termination (R2, R10) reactions for all three models apparent in Fig. 5. The key difference in the sensitivity analysis results between these two flames is in their sensitivity to the main termination reaction, R2. For the $\mathrm{H}_{2} /$ air flames considered in this analysis, increasing the rate of $\mathrm{R} 2$ has a positive effect on reactivity, whereas for $\mathrm{H}_{2} /\left(9.5 \% \mathrm{O}_{2}+90.5 \% \mathrm{~N}_{2}\right)$ flames, increasing the rate of $\mathrm{R} 2$ will have a strongly negative effect on the overall reactivity. To better understand this observation, computed species mole fraction profiles and reaction rates within these flames are analyzed.

Figure 6 depicts the concentrations of the important radicals $\mathrm{H}, \mathrm{OH}, \mathrm{HO}_{2}$, and $\mathrm{O}$ (Figs. 6a and 6c) and the reaction rates for $\mathrm{R} 1, \mathrm{R} 2$, and $\mathrm{R} 5$ (Figs. $6 \mathrm{~b}$ and $6 \mathrm{~d}$ ) for $\mathrm{H}_{2} /$ air and $\mathrm{H}_{2} /\left(9.5 \% \mathrm{O}_{2}+90.5 \% \mathrm{~N}_{2}\right.$ ) flames at $\phi=1.1$. Figure 6 clearly demonstrates some of the key differences between these two flames caused by increasing diluent ratio in the oxidizer stream. First, the concentration ratios of $\mathrm{HO}_{2}: \mathrm{H}_{,} \mathrm{HO}_{2}: \mathrm{OH}$, and $\mathrm{HO}_{2}: \mathrm{O}$ are larger in the $\mathrm{H}_{2} /\left(9.5 \% \mathrm{O}_{2}+90.5 \% \mathrm{~N}_{2}\right)$ flame. Second, there is a change in the reaction rate ratio between $\mathrm{R} 1$ and $\mathrm{R} 2$. For the $\mathrm{H}_{2}$ /air flame, the reaction rate of $\mathrm{R} 1$ is greater than $\mathrm{R} 2$, whereas the opposite is true for the $\mathrm{H}_{2} /\left(9.5 \% \mathrm{O}_{2}+90.5 \% \mathrm{~N}_{2}\right)$ flame. Finally, the reaction rate of R5 is an order of magnitude lower in the $\mathrm{H}_{2} /\left(9.5 \% \mathrm{O}_{2}+90.5 \% \mathrm{~N}_{2}\right)$ flame compared to the $\mathrm{H}_{2} /$ air flame. The differences in the characteristics of the radical pools and elementary reaction rates between these two flames factor into the sensitivity of $S_{\mathrm{u}}^{\mathrm{o}}$ to $\mathrm{R} 2$ observed in Fig. 5. For $\mathrm{H}_{2}$ /air flames, approximately $70 \%$ of $\mathrm{HO}_{2}$, a 
large majority of which is produced via R2, is consumed through R5. For the $\mathrm{H}_{2} /\left(9.5 \% \mathrm{O}_{2}+90.5 \% \mathrm{~N}_{2}\right)$ flame the reaction rate of $\mathrm{R} 5$ is reduced by an order of magnitude relative to the $\mathrm{H}_{2} /$ air flame greatly reducing the net flux of $\mathrm{HO}_{2}$ through this pathway that would produce the highly reactive $\mathrm{OH}$. These results and analysis demonstrate some key differences and similarities between the detailed flame structure for $\mathrm{H}_{2}$ /air and $\mathrm{H}_{2}$ /oxidizer flames whereby the oxidizer has been diluted relative to air to reduce the overall reactivity of the mixture and make experiments more tractable. An alternative approach to this analysis has been previously presented in Ref. 2. In Ref. 2 analysis was performed by identifying the explosion limit temperature and subsequently comparing the predicted flame structure. This analysis has been performed and is included as supplementary material.

\subsection{Experimental results and numerical calculations of stretched $\mathrm{H}_{2} /$ air and $\mathrm{H}_{2} /\left(9.5 \% \mathrm{O}_{2}+90.5 \% \mathrm{~N}_{2}\right)$} flames

There is ongoing debate regarding the value of modeling $S_{\mathrm{u}}^{\mathrm{o}}$ vs. modeling non-extrapolated directly measured data. Figures $7 \mathrm{a}$ and $7 \mathrm{~b}$ compare linear vs. non-linear extrapolation methodologies to determine $S_{\mathrm{u}}^{\mathrm{o}}$ 's for $\mathrm{H}_{2} /$ air and $\mathrm{H}_{2} /\left(9.5 \% \mathrm{O}_{2}+90.5 \% \mathrm{~N}_{2}\right)$ flames over a range of $\phi$ 's. Clearly at the conditions depicted in Fig. 7b there is little discrepancy between $S_{\mathrm{u}}^{\mathrm{o}}$ 's determined using either extrapolation technique. For the fuel lean mixtures depicted in Fig. 7a, there can be as large as a $10 \mathrm{~cm} / \mathrm{s}$ difference between linearly extrapolated $S_{\mathrm{u}}^{\mathrm{o}}$ 's compared with non-linearly extrapolated $S_{\mathrm{u}}^{\mathrm{o}}$ 's. In the present study the $S_{\mathrm{u}, \text { ref }}$ vs. $K$ data are directly modeled using the opposed-jet code eliminating uncertainties associated with extrapolations similar to Natarajan et al. [37].

Figures 8a to $8 \mathrm{f}$ depict the $S_{\mathrm{u} \text {,ref }}$ as a function of strain rate for a subset of the experimental results for $\mathrm{H}_{2} /$ air and $\mathrm{H}_{2} /\left(9.5 \% \mathrm{O}_{2}+90.5 \% \mathrm{~N}_{2}\right)$ flames at $\phi=0.32,0.35,0.45,1.10,1.75$, and 2.40 respectively. For the $\phi<1$ cases depicted in Figs. 8a, 8b, and 8c, there is a notably large gradient (i.e., large Markstein length) in the $S_{\mathrm{u}, \text { ref }}$ vs. $K$ data. For $\phi>1$, Figs. $8 \mathrm{e}$ and $8 \mathrm{f}$ show that there is a much weaker dependence of $S_{\text {u,ref }}$ to $K$ relative to the aforementioned fuel lean cases (smaller Markstein lengths). This is to be expected as $\phi>1$ mixture result in more vigorously burning flames that are less sensitive to stretch than the weaker burning $\phi<1$ flames. Additionally, as mentioned in the Introduction, for $\phi<1 \mathrm{H}_{2} /$ air mixtures $L e<1.0$ and thus the overall reactivity increases with (positive) stretch.

Figures 8a to 8f also compare numerical calculations using Models I, II, and III against the present directly measured data. At all $\phi$ 's considered, the present models reproduce to a very high degree the Markstein lengths in the experimentally determined $S_{\text {u,ref }}$ vs. $K$ data. This is as expected since it has been demonstrated (e.g., $[42,47])$ that the balance of momentum and heat, upstream of the preheat zone 
where $S_{\mathrm{u}, \text { ref }}$ is determined, should not depend, to the first order, on kinetics or transport of the chemical kinetic model. This agreement also provides confidence in the underlying physical model used in the numerical formulation of the opposed-jet. Results obtained using Model I consistently under-predict the measured $S_{\mathrm{u}, \text { ref }}$, while for very fuel lean $(\phi=0.35)$ and very fuel rich $(\phi=2.4)$ conditions, Model II provides good agreements with the present data. Between $0.35<\phi<2.1$, calculations using Model II under-predict the measured $S_{\mathrm{u}, \text { ref. }}$. Calculations using Model III under-predict the data for the $\phi=0.32$, 0.35 , and 0.45 cases. Model III predicts a much stronger positive effect of increasing $\phi$ on the reactivity of $\mathrm{H}_{2} /$ oxidizer mixtures compared with Models I and II. Therefore, computed $S_{\text {u,ref }}$ 's using Model III under-predict the data for the leanest case (Fig. 8a) and over-predict them for the richest case (Fig. 8f).

\subsection{Extinction limits of premixed fuel lean $\mathrm{H}_{2}$ /air flames}

Figure 9 compares the measured and computed $K_{\text {ext }}$ 's for premixed $\mathrm{H}_{2} / a$ air flames in the $0.28 \leq \phi \leq 0.35$ range. There is excellent agreement between the experimental and computed results using Model II for all $\phi$ 's considered. Predicted $K_{\text {ext }}$ 's by Models I and III are identical, and 20 to $55 \%$ lower than the predictions by Model II.

The overall trends between experimental and computed $K_{\text {ext }}$ 's of premixed $\mathrm{H}_{2} /$ air flames are identical to the trends observed in Figs. 8a $(\phi=0.32)$ and $8 \mathrm{~b}$ (at $\phi=0.35$ ). That is, Model II reproduces the experimental results, and predictions made using Models I and III are identical but notably under-predict the experimental results. This is a different trend compared to that seen in Fig. 3a. Specifically, for $S_{\mathrm{u}}^{\mathrm{o}}$ 's of $\mathrm{H}_{2}$ /air flames, Model III exhibits the strongest reactivity, and computed $S_{\mathrm{u}}^{\mathrm{o}}$ 's by Models I and II are identical and lower than Model III. This demonstrates that some of the kinetic pathways are sensitized at extinction differently compared to propagation, since extinction limits probe kinetic regimes for ultra-lean premixed flames for which propagation studies of fundamental value are not feasible due to cellular instabilities.

Figure 10 depicts the logarithmic sensitivity coefficients of $K_{\text {ext }}$ to reaction rate coefficients computed using Models I, II, and III for $\mathrm{H}_{2} /$ air flames at $\phi=0.28$. There is notable sensitivity to the chain propagation $\mathrm{R} 4$, chain termination $\mathrm{R} 2$, and chain branching $\mathrm{R} 1$ reactions for all three models. Additionally, there is large sensitivity to chain branching reactions R3 and R5. Compared to the sensitivity coefficients of $S_{\mathrm{u}}^{\mathrm{o}}$ 's at $\phi=1.1$ or 1.75 shown in Fig. $5, K_{\text {ext }}$ 's at $\phi=0.28$ are not sensitive to $\mathrm{R} 10$ and R11, which are chain termination reactions involving $\mathrm{H}$. There is instead increased sensitivity to reactions involving $\mathrm{HO}_{2}$, such as $\mathrm{HO}_{2}$ consumption by $\mathrm{O}, \mathrm{R} 7$. The key difference between the 
kinetics of $S_{\mathrm{u}}^{\mathrm{o}}$ and $K_{\mathrm{ext}}$ is the large negative sensitivity of $K_{\mathrm{ext}}$ 's to R2. In Fig. 5a, a small positive sensitivity of $S_{\mathrm{u}}^{\mathrm{o}}$ 's to R2 can be seen, but for extinction phenomena this sensitivity is strongly negative.

In order to understand better the differences observed between the numerical predictions of the three models considered presently, it is important to look closer at the choices of the rate parameters for the elementary reactions. R1 is a relatively well-understood and extensively studied reaction, and therefore it is consistently parameterized in all three models. Most recently, Hong et al. [64] proposed a new rate coefficient for R1 with improved uncertainty bounds and this rate is used in Model III. Although all three models have selected slightly different values for the $\mathrm{R} 1$ rate, the resulting net reaction rate is within $7 \%$ for all three models between $1000-1400 \mathrm{~K}$ and within $15 \%$ between $1400-2500 \mathrm{~K}$. Thus, discrepancies observed in predictions using these three models are unlikely due to the choice of the rate coefficient for R1.

From the results depicted in Fig. 10, it is clear that for ultra-lean $\mathrm{H}_{2}$ /air flames, the ratio of the rates $\mathrm{R} 2: \mathrm{R} 1$ plays a prominent role in dictating the overall predicted reactivity. Figure 11 depicts the branching ratio of $\mathrm{R} 2$ and $\mathrm{R} 1$ for Models I, II, and III between $800<T<2000$ and at $p=1$ and $7 \mathrm{~atm}$ using (a) $\mathrm{N}_{2}$ and (b) $\mathrm{H}_{2} \mathrm{O}$ as the third body respectively. Note that $\mathrm{R} 1$ is effectively independent of pressure due to the $\mathrm{HO}_{2}$ complex having sufficiently high energy to dissociate into $\mathrm{OH}+\mathrm{O}$ before collision with any third body (e.g., [12]). The branching ratios, R2:R1, for Models I and III are almost identical for $\mathrm{M}=\mathrm{H}_{2} \mathrm{O}$ and Models II and III have strong agreement in predictions for the case of $M=N_{2}$. Model II has, overall, the lowest ratio of R2:R1, especially for $M=\mathrm{H}_{2} \mathrm{O}$, resulting in increased overall reactivity for calculations of fuel lean flames. The reactivity of ultra-lean mixtures predicted by all three models follows closely the trends shown in Fig. 11.

Compared to R1, there exists notable uncertainty in the rate constants of R2. This is especially the case for the $3^{\text {rd }}$ body collisional efficiency of $\mathrm{H}_{2} \mathrm{O}$. Models II and III use the same value for the low pressure limit rate coefficient for R2 proposed by Michael et al [65] but have changed the centering factor and $3^{\text {rd }}$ body efficiency of $\mathrm{H}_{2} \mathrm{O}$ [2]. Between Models II and III, the centering factor was changed from 0.8 to 0.5 and the collisional efficiency of $\mathrm{H}_{2} \mathrm{O}$ was updated. The collisional efficiency of $\mathrm{H}_{2} \mathrm{O}$ relative to $\mathrm{N}_{2}$ in $\mathrm{R} 2$ has been assigned a value of 11.89, 11.0, and 14 for Models I, II, and III respectively. The result of this analysis is that although Model I uses a different rate constant for R2 $[10,66]$ compared to Models II and III, the resulting overall reaction rate for R2 between Models I and III are nearly identical. This explains the similar predictions using Models I and III, as shown in Fig. 9. Models I and III adopt the high pressure limit rate coefficient expression of R2 proposed by Troe [66]. 
In Model I, the pre-exponential Arrhenius factor has been optimized by a factor of 1.1. In Model II, the high-pressure limit rate constants were taken from Ref. 67.

\subsection{Extinction limits of 'wet' premixed $\mathrm{H}_{2}$ /air flames}

The results shown in Fig. 12 illustrate the effect of $\mathrm{H}_{2} \mathrm{O}$ addition on the extinction of premixed $\mathrm{H}_{2} /$ air flames. A $\mathrm{H}_{2}$ /air jet is co-flowed against a $\mathrm{N}_{2}$ jet with $\mathrm{H}_{2} \mathrm{O}$ added to the $\mathrm{H}_{2}$ /air jet. Experiments in Fig. 12 were performed at $\phi=0.38, p=1 \mathrm{~atm}$, and $T_{\mathrm{u}}=343 \mathrm{~K}$. The $x$-axis indicates the mole fraction of $\mathrm{H}_{2} \mathrm{O}$ in the $\mathrm{H}_{2} /$ air $/ \mathrm{H}_{2} \mathrm{O}$ mixture. The agreements between the data and numerical predictions are consistent with the results of Fig. 9 for premixed ultra-lean $\mathrm{H}_{2}$ /air flames. That is, predictions using Model II are in excellent agreement with the data and the computed $K_{\text {ext }}$ 's using Models I and III are consistently lower than the data.

To understand better the effect of $\mathrm{H}_{2} \mathrm{O}$ as a third body molecule, the main termination reaction was separated into R2 and R2a,

$$
\begin{aligned}
& \mathrm{H}+\mathrm{O}_{2}+\mathrm{M} \rightarrow \mathrm{HO}_{2}+\mathrm{M} \quad\left(\mathrm{M} \neq \mathrm{H}_{2} \mathrm{O}\right) \\
& \mathrm{H}+\mathrm{O}_{2}+\mathrm{H}_{2} \mathrm{O} \rightarrow \mathrm{HO}_{2}+\mathrm{H}_{2} \mathrm{O} .
\end{aligned}
$$

The logarithmic sensitivity coefficients of $K_{\text {ext }}$ of $\mathrm{H}_{2} / \mathrm{H}_{2} \mathrm{O} /$ air flames to kinetics computed using Model I, are shown in Fig. 13. At $X_{\mathrm{H}_{2} \mathrm{O}}=0.17$, the $K_{\text {ext }}$ sensitivity to R2a is larger compared to R1 suggesting that these data can be used as targets to constrain the uncertainty associated with the collisional efficiency of $\mathrm{H}_{2} \mathrm{O} . \quad \mathrm{H}_{2} \mathrm{O}$ dissociation, upstream of the flame, is not important under the conditions considered.

\subsection{Extinction limits of non-premixed $\mathrm{H}_{2}$ flames}

Figure 14a depicts the experimental and computed $K_{\text {ext }}$ 's as a function of $\mathrm{H}_{2}$ mole fraction, $X_{\mathrm{H}_{2}}$, in the $\mathrm{H}_{2} / \mathrm{N}_{2}$ jet for non-premixed counterflow $\mathrm{H}_{2}$ flames with unburned fuel stream temperature, $T_{\mathrm{H}_{2} / \mathrm{N}_{2}}=298 \mathrm{~K}$, oxidizer stream temperature, $T_{\text {air }}=298 \mathrm{~K}$, and $p=1 \mathrm{~atm}$.

Numerical calculations were performed using Models I, II, and III. For $X_{\mathrm{H}_{2}}<0.16$, Model II accurately reproduces the data similarly to the premixed flame results shown in Figs. 9 and 12. With increasing $X_{\mathrm{H}_{2}}$, Model II slightly over-predicts the data. At $X_{\mathrm{H}_{2}}>0.175$ Models I and III predictions agree well with the experimental results. 
Figure $14 \mathrm{~b}$ depicts the experimental and computed $K_{\text {ext }}$ 's for 'wet' non-premixed $\mathrm{H}_{2}$ flames. The experimental conditions for these flames are $X_{\mathrm{H}_{2}}=0.17, T_{\mathrm{H}_{2} / \mathrm{N}_{2}}=298 \mathrm{~K}, T_{\mathrm{air} / \mathrm{H}_{2} \mathrm{O}}=353 \mathrm{~K}$, and $p=1 \mathrm{~atm}$. As in Figs. 12 and 14a, using Model II provides the best agreements with the data while using Models I and III the data are under-predicted.

\subsection{Pressure effects on extinction limits of non-premixed $\mathrm{H}_{2}$ flames}

Figure 15 depicts the experimental and computed $K_{\text {ext }}$ 's for non-premixed $\mathrm{H}_{2}$ flames for $p=1,4$, and $7 \mathrm{~atm}, T_{\mathrm{H}_{2} / \mathrm{N}_{2}}=298 \mathrm{~K}$, and $T_{\text {air }}=298 \mathrm{~K}$. Numerical calculations were performed using Models I, Ia, II, and III. As stated earlier, Model Ia is nearly identical to Model I with the exception of the rate constants of R6. Calculated $K_{\text {ext }}$ 's using Models I, Ia, and III are identical at $p=1 \mathrm{~atm}$. For all three conditions namely $p=1,4$, and 7 atm, using Model II results in the largest $K_{\text {ext }}$ 's. Predicted $K_{\text {ext }}$ 's using Model II are in good agreement with the data at $p=1 \mathrm{~atm}$, as discussed in the previous section, but notably overpredict, by a factor of two, the data at $p=4$ and 7 atm. It is apparent from these results that Model II is unable to capture the pressure dependence. Additional simulations were performed using Model II with a $\mathrm{H}_{2} \mathrm{O}$ collision efficiency of 14.0 (from Model III) with a center-broadening factor of 0.5 [2]. The results predicted that $K_{\text {ext }}$ will decrease $5 \%$ from the original result at $p=4$ atm, but it is still $38 \%$ larger than predictions using Model III and 60\% higher than the experimental values. There are minor differences between computed $K_{\text {ext }}$ 's using Models I and III at all pressures. There is good agreement between calculations using Models I, Ia, and III and experimental results at $p=4 \mathrm{~atm}$. At $p=7 \mathrm{~atm}$, calculations using Models I and III over-predict the data but predictions using Model Ia are in excellent agreement with the data. Clearly, the pressure dependence is best captured by Model Ia relative to the other three models considered.

The only difference between Models I and Ia is in the rate expression of R6, which has been established to increase in importance with pressure (e.g., [68]). The rate constant for R6 in Model Ia is expressed by the combination of two Arrhenius forms [unit: $\mathrm{cm}^{3} \mathrm{~mol}^{-1} \mathrm{~s}^{-1}$ ]:

$$
k_{R 6}=\left(2.375 \times 10^{13}\right)\left(T^{0}\right) \exp \left(\frac{500}{R T}\right)+\left(10^{16}\right)\left(T^{0}\right) \exp \left(-\frac{17330}{R T}\right)
$$

$T$ : temperature, $\mathrm{K} ; R$ : universal gas constant, cal $\mathrm{mol}^{-1} \mathrm{~K}^{-1}$.

The first term in the above rate expression is from Keyser [69] with the original pre-exponential factor optimized by a factor of 0.82 . This portion of the rate represents the low temperature portion of the rate constant. The second term in the above rate expression of R6 is from Hippler et al. [70] and represents 
the intermediate and high temperature regimes. Model I uses a combination of four Arrhenius forms developed by Sivaramakrishnan et al. [68],

$$
\begin{aligned}
k_{R 6}= & 1.41 \times 10^{18} T^{-1.76} \exp \left(-\frac{60}{R T}\right)+1.12 \times 10^{85} T^{-22.3} \exp \left(-\frac{26900}{R T}\right) \\
& +5.37 \times 10^{70} T^{-16.72} \exp \left(-\frac{32900}{R T}\right)+2.51 \times 10^{12} T^{2} \exp \left(-\frac{40000}{R T}\right) \\
& +10^{136} T^{-40} \exp \left(-\frac{34800}{R T}\right)
\end{aligned}
$$

Models II and III use only the singular rate constant expression developed by Keyser [69]:

$$
k_{R 6}=2.89 \times 10^{13} T^{0} \exp \left(\frac{497}{R T}\right)
$$

Although replacing R6 in Model I with the expression from Model Ia improves the data predictions at elevated pressures, this is not the case for Models II and III. Simply replacing R6 in Models II and III with the rate parameter for R6 from Model Ia does not result in improved predictions. Each elementary reaction in $\mathrm{a} \mathrm{H}_{2}-\mathrm{O}_{2}$ system is tightly coupled with significant sensitivities of global flame phenomena. The challenges associated with the determination of the R6 rate constants stem from the lack of consistent experimental results and its unusual apparent temperature dependence (e.g., [71,72]). To parameterize correctly the non-Arrhenius expression for R6 over a wide range of conditions, additional experimental data are needed.

In Fig. 16, $K_{\text {ext }}$ 's are depicted as a function of pressure for a fixed $X_{\mathrm{H}_{2}}=0.14$. The pressure range is between $p=1$ and 7 atm and the calculations were made using Models I, Ia, and III. Calculations using Model II are not shown as its performance in Fig. 15 precludes it. Experimentally, $K_{\text {ext }}$ increases with pressure up to $p=3 \mathrm{~atm}$. Above $p=3 \mathrm{~atm}, K_{\mathrm{ext}}$ decreases with pressure. For all experimental conditions depicted in Fig. 16 only calculations using Model Ia are in excellent agreement with the data. Models I and III capture the pressure dependence of $K_{\text {ext }}$ but over-predict the reactivity above $p=2 \mathrm{~atm}$.

A more fundamental approach, however, is considering the variation of the density-weighted extinction strain rate $\rho_{\mathrm{u}} K_{\mathrm{ext}}$ as a function of pressure [73,74,75], where $\rho_{\mathrm{u}}$ is the unburned mixture density. Law [74] and Birkan and Law [75] used a chain mechanism model to demonstrate the importance of the branching-termination coupling in flame modeling and its influence predicting pressure dependence. From the Damköhler number definition, the relevant strain rate was demonstrated to be $\rho K$ instead of $K[74]$. This has also been demonstrated for the pressure dependence of the mass 
burning rates of $\mathrm{CH}_{4}$ /air flames (e.g., [76]), $\mathrm{H}_{2}$ /air flames (e.g., [2,77]), and $\rho_{\mathrm{u}} K_{\text {ext }}$ 's of non-premixed $\mathrm{CH}_{4}$ flames (e.g., $\left.[73,74]\right)$.

Figure 17 depicts $\rho_{\mathrm{u}} K_{\text {ext }}$ as a function of pressure for $X_{\mathrm{H}_{2}}=0.14$. From Fig. 17 it can be seen that the negative pressure dependence shifts to $p=5 \mathrm{~atm}$. The turning point is still captured by Model Ia and is shifted to higher pressures, i.e. $p=6$ and 7 atm for Models III and I respectively. The phenomena of the negative effect of pressure on the overall reactivity have been reported and discussed in number of previous studies (e.g., [2,29,30,32,73,76]).

Sohn and Chung [30] and most recently Niemann et al. [32] have discussed the negative pressure dependence of extinction limits of non-premixed $\mathrm{H}_{2}$ flames; the former study [30] primarily expanded upon the work by Balakrishnan et al. [78]. In Refs. 30 and 32 these phenomena are explained by defining a crossover temperature, $T_{\mathrm{c}},[78]$. When the maximum (peak) flame temperature at extinction, $T_{f, \max , \mathrm{E}}$, is above $T_{\mathrm{c}}$ the magnitude of the rate for $\mathrm{R} 1$ is larger than $\mathrm{R} 2$, as a result there will be a positive dependence of $K_{\text {ext }}$ on pressure. Conversely, when $T_{f, \max , \mathrm{E}}$ is below $T_{\mathrm{c}}, \mathrm{R} 2$ has a larger rate compared to R1 and increasing pressure will retard reactivity. In Refs. 30 and 32 it has been shown that $K_{\text {ext }}$ first increases and then decreases with pressure. The pressure at the turning point corresponds to the pressure at which $T_{\mathrm{c}}>T_{f \text {,max,E. }}$ This phenomenon corresponds to the turning point pressure dependence of $\rho_{\mathrm{u}} K_{\mathrm{ext}}$ and not $K_{\text {ext }}$ as shown in Fig. 18. Figure 18 depicts the computed $T_{f, \max , \mathrm{E}}$ and $T_{\mathrm{c}}$ as a function of $p$ using Models I, Ia, and III. $T_{\mathrm{c}}$ is identical for Models I and Ia because rate parameters for R1 and R2 are same for both models. For $X_{\mathrm{H}_{2}}=0.14, T_{\mathrm{c}}>T_{f, \max , \mathrm{E}}$ occurs at $p=5 \sim 5.5 \mathrm{~atm}$ for Models I and Ia and $p \approx 4 \mathrm{~atm}$ for Model III. Model Ia has a predicted turning point of $\rho_{\mathrm{u}} K_{\mathrm{ext}}$ at $p=5$ atm as shown in Fig.17.

To understand better the kinetics involved in the phenomena modeled in Figs. 15-17 the sensitivity of $K_{\text {ext }}$ to kinetics for a $X_{\mathrm{H}_{2}}=0.14$ non-premixed $\mathrm{H}_{2}$ flame was computed using Model Ia at various pressure conditions and is depicted in Fig. 19. At $p=1$ atm the chain branching R1 and R3,, and chain propagation $\mathrm{R} 4$ reactions involving $\mathrm{H}, \mathrm{O}$, and $\mathrm{OH}$ dominate the sensitivity spectrum. At $p=3$ atm, reactions involving $\mathrm{HO}_{2}$ are increasingly sensitized. Conversely, the sensitivities to R3 and R4 substantially decrease. At $p=5 \mathrm{~atm}$, the rate ratio of $\mathrm{R} 2$ to $\mathrm{R} 1$ has significantly increased compared to $p=1 \mathrm{~atm}$.

The primary cause for the pressure dependence of $\rho_{\mathrm{u}} K_{\mathrm{ext}}$ is the competing consumption pathways of $\mathrm{H}$ between $\mathrm{R} 1$ and R2. The results of Fig. 19 illustrate that reactions involving $\mathrm{HO}_{2}$ become increasingly rate limiting at elevated pressures. In Fig. 20, $\mathrm{H}$ concentration decreases but $\mathrm{HO}_{2}$ concentration is notably higher relative to $\mathrm{H}$ with increasing pressure. Higher $\mathrm{HO}_{2}$ concentration, as a result, leads to increased flux through $\mathrm{R} 5$ and $\mathrm{R} 8$ that compete with $\mathrm{R} 1$ for the consumption of $\mathrm{H}$. The 
chain branching $\mathrm{R} 5$ is the dominant $\mathrm{HO}_{2}$ consumption pathway. $\mathrm{OH}$ concentration also decreases with increasing pressure; however R9 plays an increasingly important role in $\mathrm{OH}$ generation at elevated pressures. Although R5 is still the dominant pathways for both $\mathrm{HO}_{2}$ consumption and $\mathrm{OH}$ generation at increasing pressures, it gradually decreases in importance in favor of the chain terminating R6, as shown in Figs. 19 and 21. Furthermore, the consumption pathway of $\mathrm{O}$ through R9, which competes with R3, notably increases with increasing pressure, which has been previously discussed by Santner et al. [35]. Increased flux through $\mathrm{R} 9$ reduces $\mathrm{H}$ production and increases the importance of the chain terminating R6.

Figures 21a and 21b compare the mole fractions of $\mathrm{H}$ and $\mathrm{HO}_{2}$ computed using Models I and Ia. Although $\mathrm{H}$ concentrations are similar for both models, Model Ia results in less $\mathrm{HO}_{2}$ compared to Model $\mathrm{I}$ at elevated pressures. Differences in $\mathrm{R} 6$ result in notable differences in $\mathrm{HO}_{2}$ radical pools at elevated pressures.

Figures 21c and 21d compare computed reaction rates for reactions involving $\mathrm{HO}_{2}$ against $\mathrm{R} 1$ and $\mathrm{R} 2$ in a $X_{\mathrm{H}_{2}}=0.14$ non-premixed $\mathrm{H}_{2} / \mathrm{N}_{2}$-air flames at near extinction conditions using Models I and Ia. Model I results in a smaller net rate of R6 than Model Ia. Comparing $p=2$ atm and 6 atm, it can be seen clearly that differences caused by R6 are more profound at elevated pressures. In Model $\mathrm{I}, \mathrm{HO}_{2}$ is consumed to a much larger degree via R5 at 6 atm compared to Model Ia. Sheen [13] concluded that there is a significant coupling between $\mathrm{R} 2$, with $\mathrm{H}_{2} \mathrm{O}$ as the third body, and $\mathrm{R} 6$ that has a strong effect on the ability of $\mathrm{H}_{2} / \mathrm{CO}$ models to accurately capture the pressure dependency of the mass-burning rate.

In Fig. 22a predictions using Model Ia are compared against data for $X_{\mathrm{H}_{2}}=0.135,0.140$, and 0.145. As $X_{\mathrm{H}_{2}}$ decreases, the pressure at which turn over occurs shifts to lower pressures. Model Ia captures closely the experimental results and trends. Figure $22 \mathrm{~b}$ depicts $T_{\mathrm{c}}$ and $T_{f, \max , \mathrm{E}}$ as a function of pressure for various $X_{\mathrm{H}_{2}}$ computed by Model Ia. The pressure at which $T_{\mathrm{c}}$ exceeds $T_{f, \text { max,E }}$ corresponds to the pressure at the turning point of $\rho_{\mathrm{u}} K_{\mathrm{ext}}$ for various $X_{\mathrm{H}_{2}}$ using Model Ia.

Therefore, accurately capturing the pressure dependent characteristic of extinction limits requires an accurate representation of $\mathrm{HO}_{2}$ consumption pathways including R6. Sheen [13] discussed the importance of R6 to accurately capture the transition to negative pressure dependence. In addition, Sheen noted that constraining the uncertainty in R6 would have the largest impact in reducing the model uncertainties. Clearly $\rho_{\mathrm{u}} K_{\mathrm{ext}}$ of non-premixed $\mathrm{H}_{2}$ flames provides good targets to minimize the uncertainty associated with R6. 


\subsection{Pressure effects on extinction limits of 'wet' non-premixed $\mathrm{H}_{2}$ flames}

Figure 23 depicts the experimental and computed $K_{\text {ext }}$ 's for a non-premixed $\mathrm{H}_{2}$ flames with $\mathrm{H}_{2} \mathrm{O}$ added to the oxidizer stream at $X_{\mathrm{H}_{2}}=0.15, p=4 \mathrm{~atm}, T_{\mathrm{H}_{2} / \mathrm{N}_{2}}=298 \mathrm{~K}$, and $T_{\text {air } / \mathrm{H}_{2} \mathrm{O}}=393 \mathrm{~K}$. The $x$-axis values correspond to the mole fraction of $\mathrm{H}_{2} \mathrm{O}$ in the oxidizer stream. Predictions obtained using Model II show good agreement with current experimental data at $p=1 \mathrm{~atm}$ but notably over-predict the data at $p=4 \mathrm{~atm}$. Predictions using Models I and III slightly under-predict the data at $p=1 \mathrm{~atm}$ but provide good agreements at $p=4 \mathrm{~atm}$. Predictions using Model Ia under-predict the data to a larger degree compared to Models I and III at elevated pressures. Comparing the trends between numerical calculations observed in Fig. 15 with those in Fig. 23 it becomes clear that the same set of kinetics is sensitized in both types of flames.

\section{8. $\mathrm{CO}_{2}$ third body effects on premixed $\mathrm{H}_{2} / \mathrm{CO} / \mathrm{O}_{2}$ flames}

The goal of these experiments is to sensitize the extinction limits to the main termination reaction involving $\mathrm{CO}_{2}$ as the third body collisional molecule, i.e.,

$$
\mathrm{H}+\mathrm{O}_{2}+\mathrm{CO}_{2} \rightarrow \mathrm{HO}_{2}+\mathrm{CO}_{2}
$$

The complication in achieving such a system is the large concentration of $\mathrm{H}_{2} \mathrm{O}$. Typically the sensitivity to R2a will overwhelm any sensitivity to R2b. Secondly, performing experiments using air as the oxidizer will result in large sensitivities to the main termination reaction involving $\mathrm{N}_{2}, \mathrm{R} 2$. To overcome these two complications the extinction limits of $\mathrm{H}_{2} / \mathrm{CO} / \mathrm{CO}_{2} / \mathrm{O}_{2}$ flames was experimentally determined and compared with numerical calculations. In order to minimize the sensitivity three body reactions involving $\mathrm{H}_{2} \mathrm{O}$, the $\mathrm{H}_{2}$ : $\mathrm{CO}$ ratio was adjusted such that chain branching was achieved while simultaneously minimizing $\mathrm{H}_{2} \mathrm{O}$ production. By using $\mathrm{O}_{2}$ as the oxidizer (instead of air), sensitivity to three body reactions involving $\mathrm{N}_{2}$ was removed. This also allowed for the presence of notably large quantities of $\mathrm{CO}_{2}$.

The results are shown in Fig. 24 and the reported mole fraction of $\mathrm{CO}_{2}$ is that in the $\mathrm{CO} / \mathrm{H}_{2} / \mathrm{O}_{2} / \mathrm{CO}_{2}$ mixture. All experiments were performed at $T_{\mathrm{u}}=298 \mathrm{~K}$ and $p=1 \mathrm{~atm}$. The first series of experiments was for $\mathrm{H}_{2} / \mathrm{CO}=0.15, \phi=0.45$, and the mole fraction of $\mathrm{CO}_{2}$ in the $\mathrm{H}_{2} / \mathrm{CO} / \mathrm{O}_{2} / \mathrm{CO}_{2}$ mixture was varied from 0.32 to 0.43 (Fig. 24a). The second series of experiments was for $\mathrm{H}_{2} / \mathrm{CO}=0.05, \phi=0.23$, and the mole fraction of $\mathrm{CO}_{2}$ in the $\mathrm{H}_{2} / \mathrm{CO} / \mathrm{O}_{2} / \mathrm{CO}_{2}$ mixture was varied from 0.07 and 0.35 (Fig. 24b), with $1700<T_{\mathrm{ad}}<2500 \mathrm{~K}$. There is excellent agreement between predictions obtained using Models I and II and the data. 
Figure 25 depicts the sensitivity analysis of $K_{\text {ext }}$ for to kinetics. For $\mathrm{H}_{2} / \mathrm{CO} / \mathrm{O}_{2} / \mathrm{CO}_{2}$ flames there is notable sensitivity to $\mathrm{CO}$ oxidation via R12. Additionally there is notable negative sensitivity to R2b. Although there are slight differences between the rate parameters for these two aforementioned reactions, their net reaction rates are identical.

\subsection{Effect of binary diffusion coefficients on extinction limits of non-premixed $\mathrm{H}_{2}$ flames}

Figure 26 compares the experimental and computed $K_{\text {ext }}$ 's for two sets of non-premixed $\mathrm{H}_{2}$ flames using Models II and IIa. Model II uses a different formulation for its transport parameters when compared to Models I and III. Models I and III implement the transport parameters developed by Wang and coworkers $[8,24,60]$. In the trial model Model IIa the transport parameters of Model II were replaced by those used in Models I and III. Figures 26a and 26b compare computed $K_{\text {ext }}$ 's using Model II and Model IIa to the data for selected non-premixed $\mathrm{H}_{2}$ flames. In both cases, using Model IIa results in lower $K_{\text {ext }}$ 's by 10-20\% compared to Model II, and which are in closer agreement with the data.

To better understand the results of Fig. 26, Fig. 27 compares the $\mathrm{H}_{-} \mathrm{N}_{2}$ and $\mathrm{H}_{2}-\mathrm{N}_{2}$ binary diffusion coefficients, $D_{\mathrm{H}, \mathrm{N}_{2}}$ and $D_{\mathrm{H}_{2}, \mathrm{~N}_{2}}$ respectively, of Model II and IIa at $p=1 \mathrm{~atm}$ as a function of temperature. Above $\sim 1400 \mathrm{~K}$ there is a clear difference between both $D_{\mathrm{H}_{,} \mathrm{N}_{2}}$ and $D_{\mathrm{H}_{2}, \mathrm{~N}_{2}}$ used in Model II compared to Model IIa with the diffusivities of both pairs being larger in Model IIa. Figure 28 depicts the logarithmic sensitivity coefficients of $K_{\text {ext }}$ to binary diffusion coefficients, $D_{\mathrm{ij}}$, computed using Models II and IIa. The key observation from this figure is the positive sensitivity of the $K_{\mathrm{ext}}$ to $D_{\mathrm{H}_{2}, \mathrm{~N}_{2}}$ and its negative sensitivity to $D_{\mathrm{H}_{\mathrm{N}} \mathrm{N}_{2}}$. Increasing $D_{\mathrm{H}_{2}, \mathrm{~N}_{2}}$ leads to a larger net flux of reactant, $\mathrm{H}_{2}$, into the reaction zone therefore increasing reactivity and making the flame more resistant to extinction. Conversely, increasing $D_{\mathrm{H}, \mathrm{N}_{2}}$ leads to a net 'loss' of $\mathrm{H}$ from the reaction zone making the flame less resistant to extinction [24]. It is important to note that this is not always the case. For example, in Ref. 24 it was observed that in the case of vigorously burning $\mathrm{H}_{2}$ flames the sensitivity of extinction to $D_{\mathrm{H}, \mathrm{N}_{2}}$ is positive.

In summary, in Model II the $D_{\mathrm{H}, \mathrm{N}_{2}}$ is lower compared to Model IIa resulting in a larger $\mathrm{H}$ radical pool within the reaction zone and thus increased resistance to extinction. 


\section{Concluding remarks}

Although the oxidation of hydrogen has been extensively studied, there exist notable discrepancies between data sets and kinetic model predictions for propagation and extinction of hydrogen flames. Additionally, there remain significant uncertainties in the individual rate expressions in $\mathrm{H}_{2}$ kinetic models. In the present study a wide range of fundamental flame data for premixed and non-premixed hydrogen flames were with well-quantified uncertainties were determined, and can be used towards constraining the uncertainties of kinetic models.

The first part of this study focused on premixed $\mathrm{H}_{2}$ /oxidizer flames. It was observed that there exists a large variation in existing literature laminar flame speeds of $\mathrm{H}_{2}$ /air flames. To better resolve this issue, the laminar flame speeds of $\mathrm{N}_{2}$-diluted $\mathrm{H}_{2}$ flames were measured in the counterflow configuration. The extra inert dilution was implemented in order to reduce the mixture reactivity and increase thus the experimental accuracy. Although these data are useful for model validation, there are differences in the detailed flame structure between $\mathrm{N}_{2}$-diluted and $\mathrm{H}_{2}$ /air flames. Furthermore, in order to alleviate any ambiguities caused by extrapolation methodologies to zero stretch, directly measured reference flame speeds at various strain rates were compared against computed results.

To probe the kinetics of ultra-lean $\mathrm{H}_{2}$ /air flames that are thermo-diffusionally unstable at the limit of zero stretch, extinction strain rates of premixed $\mathrm{H}_{2} /$ air flames were investigated. The ratio of rates of the main branching $\left(\mathrm{H}+\mathrm{O}_{2} \rightarrow \mathrm{H}+\mathrm{OH}\right)$ to main termination $\left(\mathrm{H}+\mathrm{O}_{2}+\mathrm{M} \rightarrow \mathrm{HO}_{2}+\mathrm{M}\right)$ reactions dictated the ability of the kinetic model to reproduce experimental results. To supplement these results, extinction strain rates of non-premixed $\mathrm{H}_{2}$ flames were measured at atmospheric and elevated pressures. The computed results did not capture the pressure dependence satisfactorily. While the aforementioned competition between the main branching and termination reactions controls to great extent the extinction behavior, the chain terminating reaction $\mathrm{HO}_{2}+\mathrm{OH} \rightarrow \mathrm{H}_{2} \mathrm{O}+\mathrm{O}_{2}$ was determined also to play an important role at elevated pressures.

Experiments were designed also to specifically to sensitize three-body reactions involving $\mathrm{H}_{2} \mathrm{O}$ and $\mathrm{CO}_{2}$ as the third body. Such data are needed to constrain the large uncertainty in three-body termination reactions.

Finally, the importance of accurately formulating and modeling binary diffusion coefficients and their effect on the prediction of flame propagation and specially extinction has been demonstrated through detailed numerical calculations and sensitivity analysis. 


\section{Acknowledgements}

This material is based upon work supported as part of the CEFRC, an Energy Frontier Research Center funded by the U.S. Department of Energy, Office of Science, Office of Basic Energy Sciences under Award Number DE-SC0001198. Discussions with Drs. David Sheen and Enoch Dames are greatly appreciated. 


\section{References}

[1] M. Chaos, F.L. Dryer, Combust. Sci. Tech. 180 (2008) 1053-1096.

[2] M. P. Burke, M. Chaos, F.L. Dryer, Y. Ju, Combust. Flame 157 (2010) 618-631.

[3] J.M. Anderlohr, A.P. da Cruz, R. Bounaceur, F. Battin-Leclerc, Combust. Sci. Tech. 182 (2010) 39-59.

[4] S.M. Correa, Proc. Combust. Inst. 27 (1998) 1793-1813.

[5] A. Bhargava, M. Colket, W. Sowa, K. Casleton, D. Maloney, J. Eng. Gas Turbines Power, ASME, 122 (2000) 405-411.

[6] B. de Jager, J.B.W. Kok, G. Skevis, Proc. Combust. Inst. 31 (2007) 3123-3130.

[7] J.Li, Z.Zhao, A. Kazakov, M. Chaos, F.L. Dryer, J.J. Scire Jr., Int. J. Chem. Kinet. 39 (2007) 109136.

[8] H. Wang, X. You, A.V. Joshi, S. G. Davis, A. Laskin, F. Egolfopoulos, C.K. Law, USC Mech Version II. High Temperature combustion Reaction Model of $\mathrm{H}_{2} / \mathrm{CO} / \mathrm{C}_{1}-\mathrm{C}_{4}$ Compound. http://ignis.usc.edu/USC_Mech_II.htm, May 2007.

[9] M. O’Connaire, H.J. Curran, J.M. Simmie, W.J. Pitz, C.K. Westbrook, Int. J. Chem. Kinet. 36 (2004) 603-622.

[10] S.C. Davis, A.V. Joshi, H. Wang, F. Egolfopoulos, Proc. Combust. Inst. 30 (2005) 1283-1292.

[11] A.A. Konnov, Combust. Flame 152 (2008) 507-528.

[12] M.P. Burke, M. Chaos, Y. Ju, F.L. Dryer, S.J. Klippenstein, Int. J. Chem. Kinet. 44 (2012) 444474.

[13] D.A. Sheen, Spectral Optimization and Uncertainty Quantification in Combustion Modeling, Chapter 5, Ph.D. Thesis, University of Southern California, 2011.

[14] D.R. Dowdy, D.B. Smith, S.C. Taylor, A. Williams, Proc. Combust. Inst. 23 (1990) 325-332.

[15] K.T. Aung, M.I. Hassan, G.M. Faeth, Combust. Flame 109 (1997) 1-24.

[16] S.D. Tse, D.L. Zhu, C.K. Law, Proc. Combust. Inst. 28 (2000) 1793-1800.

[17] N. Lamoureux, N. Djebaili-Chaumeix, C.-E. Paillard, Exp. Therm. Fluid Sci. 27 (2003) 385-393.

[18] Z. Huang, Y, Zhang, K. Zenga, B. Liu, Q. Wang, D. Jiang, Combust. Flame 146 (2006) 302-311.

[19] C. Tang, Z. Huang, C. Jin, J. He, J. Wang, X. Wang, H. Miao, Int. J. Hydrogen Energ. (2008), 33, 4906-4914.

[20] E. Hu, Z. Huang, J. He, C. Jin, J. Zheng, Int. J. Hydrogen Energ. 34 (2009) 4876-4888.

[21] G.I. Sivashinsky, C.K. Law, G. Joulin, G., Combust. Sci. Tech. 28 (1982), 155-159. 
[22] J.D. Buckmaster, G.S.S. Ludford, Lectures on Mathematical Combustion, Society for Industrial and Applied Mathematics, p. 62-65, Philadelphia, 1983.

[23] C. Kaiser, J.-B. Liu, Paul D. Ronney, Paper No. 2000-0576, 38th AIAA Aerospace Sciences Meeting, Reno, NV, January 11-14, 2000.

[24] Y. Dong, A.T. Holley, M.G. Andac, F.N. Egolfopoulos, S.G. Davis, P. Middha, H.Wang, Combust. Flame 142 (2005) 374-387.

[25] G.L. Pellett, G.B., Northam, L.G., Wilson, AIAA-89-2522, AIAA/ASME/SAE/ASEE 25th Joint Propulsion Conference, Monterey, CA, July 10-12, 1989.

[26] G.L. Pellett, G.B. Northam, AIAA-92-0877, 30 ${ }^{\text {th }}$ Aerospace Sciences Meeting and Exhibit, Reno, NV, January 6, 1992.

[27] G.L. Pellett, K.M. Isaac, W.M. Humphreys, Jr., L.R. Gartrell, W.L. Roberts, C.L. Dancey, G.B. Northam, Combust. Flame 112 (1998) 575-592.

[28] P. Papas, I. Glassman, C.K. Law, Proc. Combust. Inst. 25 (1994) 1333-1339.

[29] G. Balakrishnan, M.D. Smooke, F.A. Williams, Combust. Flame 102 (1995) 329-340.

[30] C.H. Sohn, S.H. Chung, Combust. Flame 121 (2000) 288-300.

[31] R. Seiser, K. Seshardri, Proc. Combust. Inst. 30 (2005) 407-414

[32] U. Niemann, K. Seshadri, F.A. Williams, Proc. Combust. Inst. 34 (2013) 881-886.

[33] A.K. Das, K. Kumar, C.-J. Sung, Combust. Flame 158 (2011) 345-353.

[34] D. Singh, T. Nishiie, S. Tanvir, L. Qiao, Fuel 94 (2012) 448-456.

[35] J. Santner, F.L. Dryer, Y. Ju, Proc. Combust. Inst. 34 (2013) 719-726.

[36] Z.M. Nikolaou, J.Y. Chen, N. Swaminathan, Combust. Flame 160 (2013) 56-75.

[37] J. Natarajan, T. Lieuwen, J. Seitzman, Combust. Flame 151 (2007) 104-119.

[38] V.R. Rishore, M.R. Ravi, A. Ray, Combust. Flame 158 (2011) 2149-164.

[39] C. Prathap, A. Ray, M.R. Ravi, Combust. Flame 159 (2012) 482-492.

[40] C.K. Wu, C.K. Law, Proc. Combust. Inst. 20 (1984) 1941-1949.

[41] J.-Y. Ren, T.Y. Tsotsis, F.N. Egolfopoulos, Combust. Sci. Tech. 174 (2002) 181-1205.

[42] Y.L. Wang, A.T. Holley, C. Ji, F.N. Egolfopoulos, T.T. Tsotsis, H.J. Curran, Proc. Combust. Inst. 32 (2009) 1035-1042.

[43] C. Ji, E. Dames, Y.L. Wang, H. Wang, F.N. Egolfopoulos, Combust. Flame 157 (2010) 277-287.

[44] O. Park, P.S. Veloo, F.N. Egolfopoulos, Proc. Combust. Inst. 33 (2011) 887-894.

[45] C. Ji, F.N. Egolfopoulos, Proc. Combust. Inst. 33 (2011) 955-961.

[46] C. Ji, E. Dames, B. Sirjean, H. Wang, F.N. Egolfopoulos, Proc. Combust. Inst. 33 (2011) 971-978. 
[47] P.S. Veloo, F.N. Egolfopoulos, Combust. Flame 158 (2011) 501-510.

[48] C. Ji, E. Dames, H. Wang, F.N. Egolfopoulos, Combust. Flame 159 (2012) 1070-1081.

[49] C. Ji, S.M. Sarathy, P.S. Veloo, C.K. Westbrook, F.N. Egolfopoulos, Combust. Flame 159 (2012) 1426-1436.

[50] A.T. Holley, Y. Dong, M.G. Andac, F.N. Egolfopoulos, Combust. Flame 144 (2006) 448-460.

[51] R.J. Kee, J.F. Grcar, M.D. Smooke, J.A. Miller, A FORTRAN Program for Modeling Steady Laminar One-Dimensional Premixed Flames, Report No. SAND85-8240, Sandia National Laboratories, 1985.

[52] J.F. Grcar, R.J. Kee, M.D. Smooke, J.A. Miller, Proc. Comb. Inst. 21 (1986) 1773-1782.

[53] R.J. Kee, J.A. Miller, G.H. Evans, G. Dixon-Lewis, Proc. Combust. Inst. 22 (1988) 1479-1494.

[54] F.N. Egolfopoulos, Proc. Combust. Inst. 25 (1994) 1375-1381.

[55] H. Zhang, F.N. Egolfopoulos, Proc. Combust. Inst. 28 (2000) 1875-1882.

[56] R.J. Kee, F.M. Rupley, J.A. Miller, Chemkin-II: A Fortran Chemical Kinetics Package for the Analysis of Gas-Phase Chemical Kinetics, Report No. SAND89-8009, Sandia National Laboratories, 1989.

[57] R.J. Kee, J. Warnatz, J.A. Miller, A FORTRAN Computer Code Package for the Evaluation of Gas-Phase Viscosities, Conductivities and Diffusion Coefficients, Report No. SAND83-8209, Sandia National Laboratories, 1983.

[58] F.N. Egolfopoulos, P.E. Dimotakis, Proc. Combust. Inst. 27 (1998) 641-648.

[59] M. Nishioka, C.K. Law, T. Takeno, Combust. Flame 104 (1996) 328-342.

[60] P. Middha, H. Wang, Combust. Theor. Model. 9 (2005) 353-363.

[61] F.N. Egolfopoulos, C.K. Law, Proc. Combust. Inst. 23 (1991) 333-340.

[62] C.Ji, Y.L. Wang, F.N. Egolfopoulos, J. Propul. Power 27 (2011) 856-863.

[63] R.T.E. Hermanns, A.A. Konnov, R.J.M. Bastiaans, L.P.H. de Goey, Energ. Fuel 21 (2007) 19771981.

[64] Z. Hong, D.F. Davidson, R.K. Hanson, Combust. Flame 158 (2011) 633-644.

[65] J.V. Michael, M.-C. Su, J.W. Sutherland, J.J. Carroll, A.F. Wagner, J. Phys. Chem. A 106 (2002) 5297-5313.

[66] J. Troe, Proc. Combust. Inst. 28 (2000) 1463-1469.

[67] C.J. Cobos, H.Hippler, J. Troe, J. Phys. Chem. 89 (1985) 342-349.

[68] R. Sivaramakrishnan, A.Comandini, R.S. Tranter, K. Brezinsky, S.G. Davis, and H. Wang, Proc. Combust. Inst. 31 (2007) 429-437. 
[69] L.F. Keyser, J. Phys. Chem. 92 (1988) 1193-1200.

[70] H. Hippler, H. Neunaber, J. Troe, J. Chem. Phys. 103 (1995) 3510-3516.

[71] M.P. Burke, S.J. Klippenstein, L.B. Harding, Proc. Combust. Inst. 34 (2013) 547-555.

[72] Z. Hong, K-Y. Lam, R. Sur, S. Wang, D.F. Davidson, R.K. Hanson, Proc. Combust. Inst. 34 (2013) 565-571.

[73] H.K. Chelliah, C.K. Law, T. Ueda, M.D. Smooke, F.A. Williams, Proc. Combust. Inst. 23 (1990) 503-511.

[74] C.K. Law, Mathematical Modeling in Combustion Science (J.D. Buckmaster and T. Takeno Eds., p. 47, Springer-Verlag, New York, 1987.

[75] M.A. Birkan, C.K. Law, Combust. Flame 73 (1988) 127-146.

[76] F.N. Egolfopoulos, C.K. Law, Combust. Flame 80 (1990) 7-16.

[77] F.N. Egolfopoulos, C.K. Law, Proc. Combust. Inst. 23 (1990) 333-340.

[78] G. Balakrishnan, C. Treviño, F. Mauss, Combust. Flame 91 (1992) 246-256. 


\section{Table and figures}

\begin{tabular}{|c|c|c|c|c|c|c|}
\hline $\begin{array}{c}\text { Lower } \\
\text { Jet }\end{array}$ & $\begin{array}{l}\text { Upper } \\
\text { Jet }\end{array}$ & $\begin{array}{c}P \\
{[\mathrm{~atm}]}\end{array}$ & $\begin{array}{c}T_{\mathrm{u}} \\
{[\mathrm{K}]}\end{array}$ & $\begin{array}{l}T_{\mathrm{N}_{2}} \\
{[\mathrm{~K}]}\end{array}$ & $\begin{array}{c}\mathrm{D} \\
{[\mathrm{mm}]}\end{array}$ & $\begin{array}{c}\mathrm{L} \\
{[\mathrm{mm}]}\end{array}$ \\
\hline $\begin{array}{c}\mathrm{H}_{2} / \\
\left(9.5 \% \mathrm{O}_{2}+90.5 \% \mathrm{~N}_{2}\right)\end{array}$ & $\mathrm{N}_{2}$ & 1 & 298 & 298 & 10 & 11 \\
\hline $\mathrm{H}_{2} /$ air & $\mathrm{N}_{2}$ & 1 & 298 & 298 & $\begin{array}{l}10\left(K_{\text {ext }}>400 \mathrm{~s}^{-1}\right) \\
14\left(K_{\text {ext }} \leq 400 \mathrm{~s}^{-1}\right)\end{array}$ & $\begin{array}{l}10 \\
14\end{array}$ \\
\hline $\mathrm{H}_{2} /$ air/ $\mathrm{H}_{2} \mathrm{O}$ & $\mathrm{N}_{2}$ & 1 & 343 & 298 & $\begin{array}{l}10\left(K_{e x t}>400 \mathrm{~s}^{-1}\right) \\
14\left(K_{\text {ext }} \leq 400 \mathrm{~s}^{-1}\right)\end{array}$ & $\begin{array}{l}10 \\
14\end{array}$ \\
\hline $\mathrm{H}_{2} / \mathrm{CO} / \mathrm{O}_{2} / \mathrm{CO}_{2}$ & $\mathrm{~N}_{2}$ & 1 & 298 & 298 & $\begin{array}{l}10\left(K_{\text {ext }}>400 \mathrm{~s}^{-1}\right) \\
20\left(K_{\text {ext }} \leq 300 \mathrm{~s}^{-1}\right)\end{array}$ & $\begin{array}{l}10 \\
20\end{array}$ \\
\hline
\end{tabular}

Table 1. Experimental configuration and conditions (premixed flames). 


\begin{tabular}{ccccccc}
\hline $\begin{array}{c}\text { Lower } \\
\text { Jet }\end{array}$ & $\begin{array}{c}\text { Upper } \\
\text { Jet }\end{array}$ & $\begin{array}{c}p \\
{[\mathrm{~atm}]}\end{array}$ & $\begin{array}{c}T_{\text {lower }} \\
{[\mathrm{K}]}\end{array}$ & $\begin{array}{c}T_{\text {upper }} \\
{[\mathrm{K}]}\end{array}$ & $\begin{array}{c}\mathrm{D} \\
{[\mathrm{mm}]}\end{array}$ & $\begin{array}{c}\mathrm{L} \\
{[\mathrm{mm}]}\end{array}$ \\
\hline \multirow{2}{*}{ Air } & \multirow{2}{*}{$\mathrm{H}_{2} / \mathrm{N}_{2}$} & 1 & 298 & 298 & 10 & 10 \\
& & $2-7$ & 298 & 298 & 7 & 9 \\
\multirow{2}{*}{$\mathrm{Air} / \mathrm{H}_{2} \mathrm{O}$} & $\mathrm{H}_{2} / \mathrm{N}_{2}$ & 1 & 353 & 298 & 10 & 10 \\
& & 4 & 393 & 298 & 7 & 9 \\
\hline
\end{tabular}

Table 2. Experimental configuration and conditions (non-premixed flame). 


\begin{tabular}{ccc}
\hline$p[\mathrm{~atm}]$ & $X_{\mathrm{H}_{2}}$ & $\alpha\left[\mathrm{s}^{-1}\right]$ \\
\hline $1 \mathrm{~atm}$ & 0.135 & $10 \pm 6$ \\
& 0.140 & $20 \pm 8$ \\
& 0.145 & $25 \pm 12$ \\
& 0.135 & $30 \pm 10$ \\
& 0.140 & $50 \pm 10$ \\
& 0.145 & $65 \pm 15$ \\
& & \\
& 0.135 & $35 \pm 10$ \\
& 0.140 & $41 \pm 10$ \\
& 0.145 & $60 \pm 15$ \\
\hline
\end{tabular}

Table 3. The axial velocity gradient at the burner exit, $\alpha$, for the extinction experiments. 


\begin{tabular}{cl}
\hline Model & \multicolumn{1}{c}{ Reference } \\
\hline I & USC Mech II [8] \\
Ia & Davis et al. [10] \\
II & Li et al. [7] \\
IIa & Li et al. + Model I transport \\
III & Burke et al. [12] \\
\hline
\end{tabular}

Table 4. Kinetic models used. 


\begin{tabular}{ll}
\hline & List of reactions \\
\hline (R1) & $\mathrm{H}+\mathrm{O}_{2} \rightarrow \mathrm{O}+\mathrm{OH}$ \\
(R2) & $\mathrm{H}+\mathrm{O}_{2}+\mathrm{M} \rightarrow \mathrm{HO}_{2}+\mathrm{M}$ \\
(R2a) & $\mathrm{H}+\mathrm{O}_{2}+\mathrm{H}_{2} \mathrm{O} \rightarrow \mathrm{HO}_{2}+\mathrm{H}_{2} \mathrm{O}$ \\
(R2b) & $\mathrm{H}+\mathrm{O}_{2}+\mathrm{CO}_{2} \rightarrow \mathrm{HO}_{2}+\mathrm{CO}_{2}$ \\
(R3) & $\mathrm{O}+\mathrm{H}_{2} \rightarrow \mathrm{OH}+\mathrm{H}$ \\
(R4) & $\mathrm{H}_{2}+\mathrm{OH} \rightarrow \mathrm{H}_{2} \mathrm{O}+\mathrm{H}$ \\
(R5) & $\mathrm{HO}_{2}+\mathrm{H} \rightarrow \mathrm{OH}+\mathrm{OH}$ \\
(R6) & $\mathrm{HO}_{2}+\mathrm{OH} \rightarrow \mathrm{H}_{2} \mathrm{O}+\mathrm{O}_{2}$ \\
(R7) & $\mathrm{HO}_{2}+\mathrm{O} \rightarrow \mathrm{O}_{2}+\mathrm{OH}$ \\
(R8) & $\mathrm{HO}_{2}+\mathrm{H} \rightarrow \mathrm{H}_{2}+\mathrm{O}_{2}$ \\
(R9) & $\mathrm{O}+\mathrm{H}_{2} \mathrm{O} \rightarrow \mathrm{OH}^{\mathrm{O}} \mathrm{OH}$ \\
(R10) & $\mathrm{H}+\mathrm{OH}+\mathrm{M} \rightarrow \mathrm{H}_{2} \mathrm{O}+\mathrm{M}$ \\
(R11) & $\mathrm{H}+\mathrm{H}+\mathrm{M} \rightarrow \mathrm{H}_{2}+\mathrm{M}$ \\
(R12) & $\mathrm{CO}+\mathrm{OH} \rightarrow \mathrm{CO}_{2}+\mathrm{H}$ \\
\hline
\end{tabular}

Table 5. Reaction labels. 


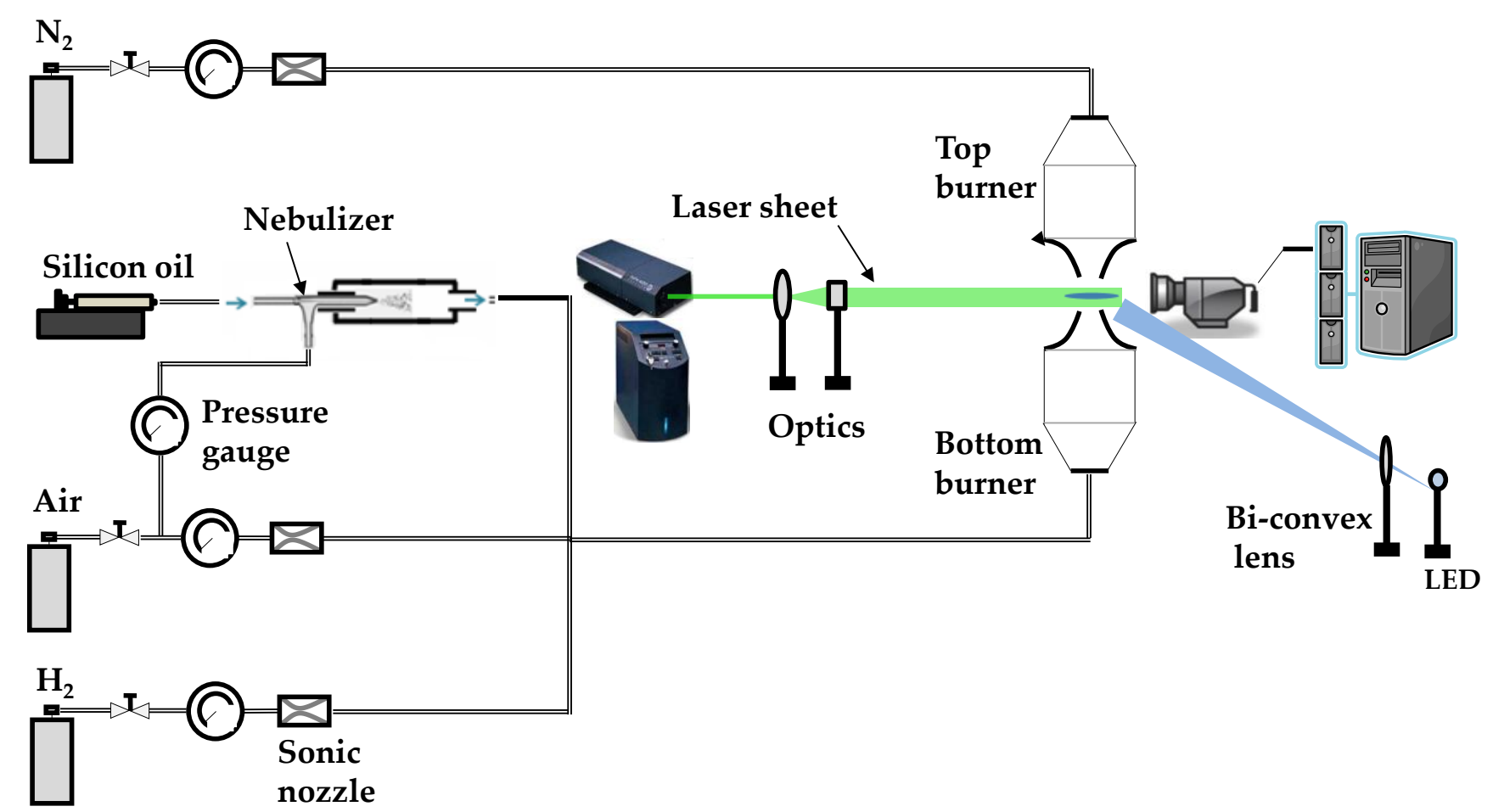

Figure 1. Schematic of the atmospheric pressure experimental configuration (single flame configuration). 


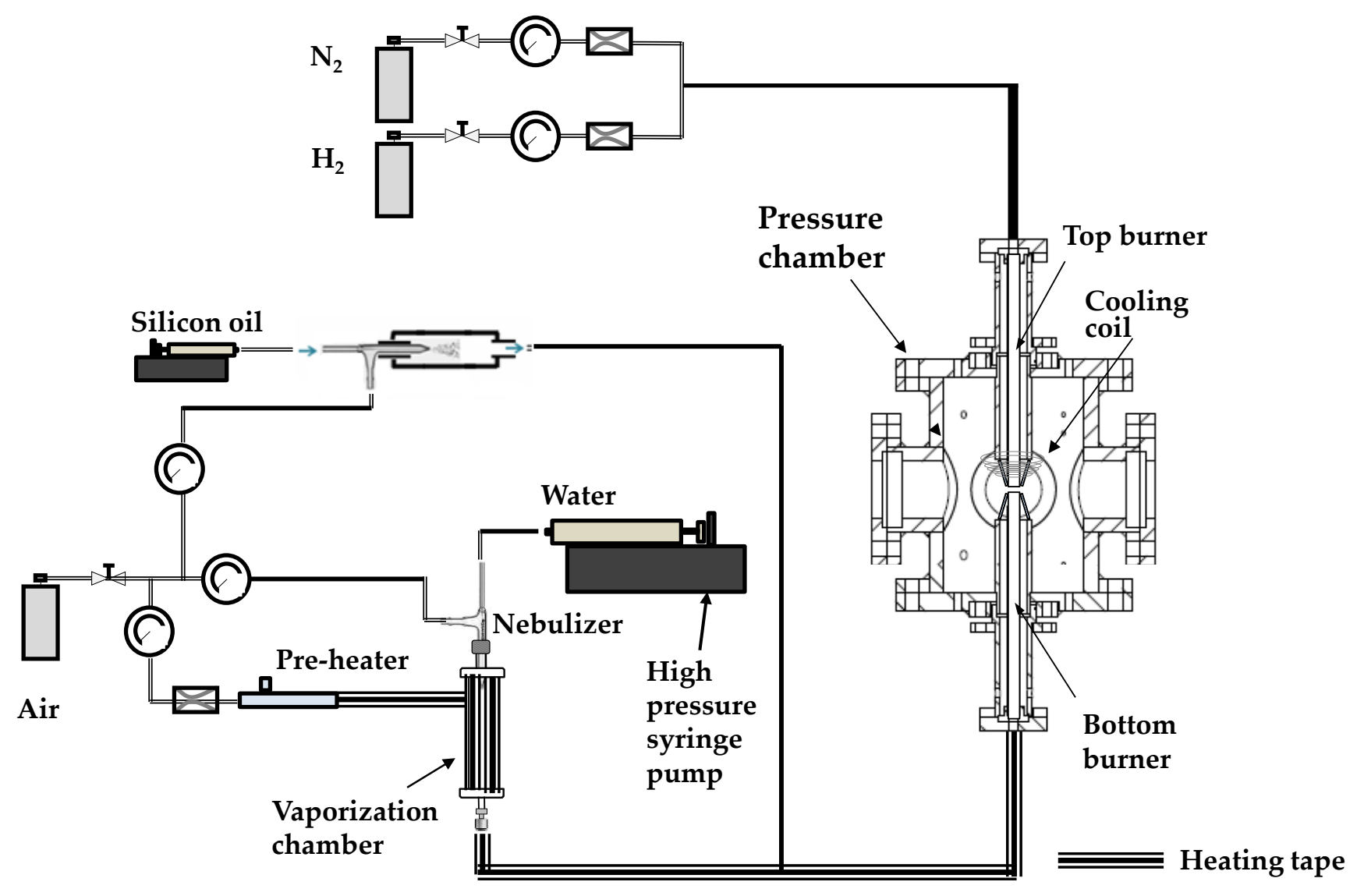

Figure 2. A schematic of the high-pressure experimental configuration, including the vaporization system. 

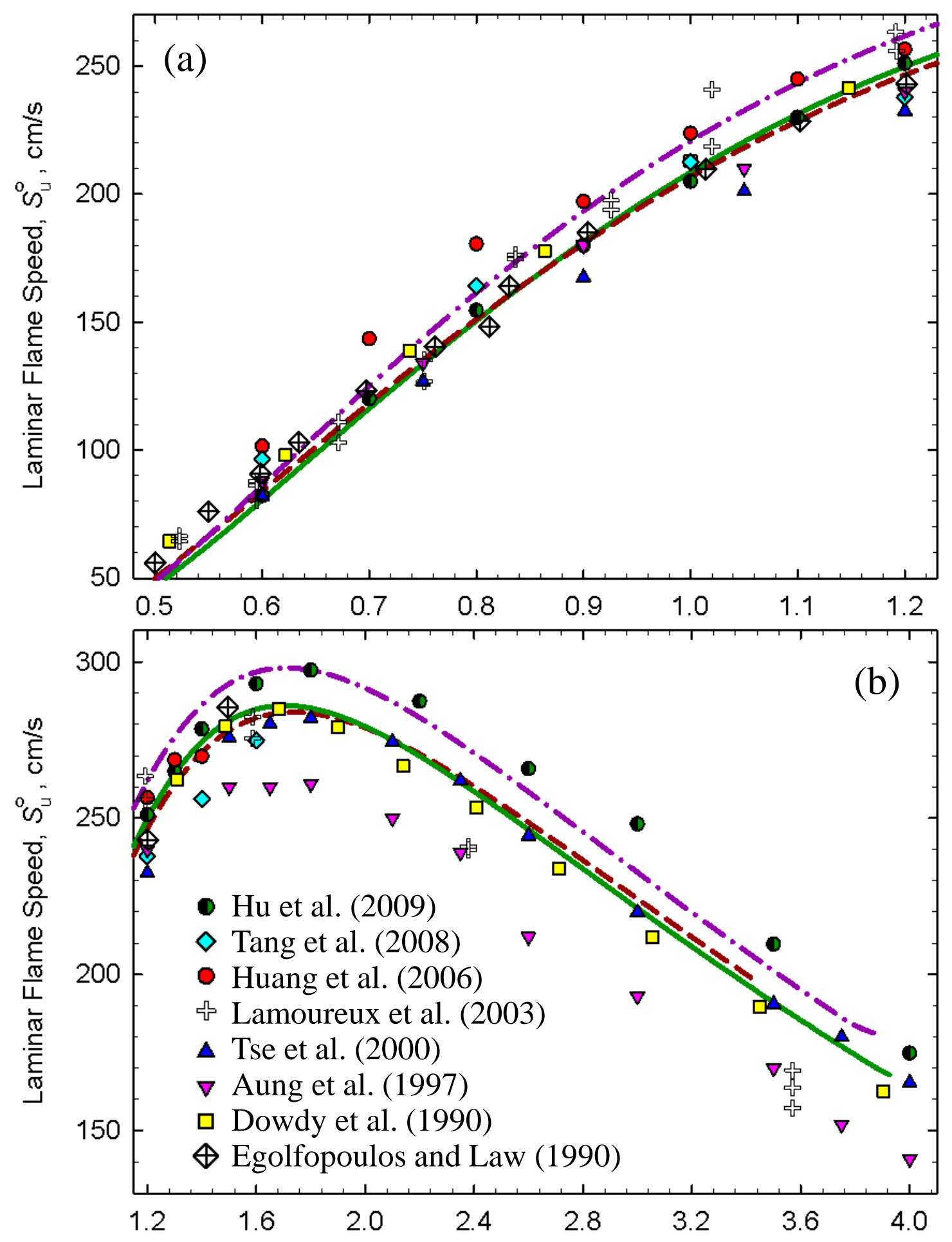

Equivalence Ratio, $\phi$

Figure 3. Comparison of measured and computed $S_{\mathrm{u}}^{\mathrm{o}}$ 's for $\mathrm{H}_{2} /$ air flames at $T_{\mathrm{u}}=298 \mathrm{~K}$ and

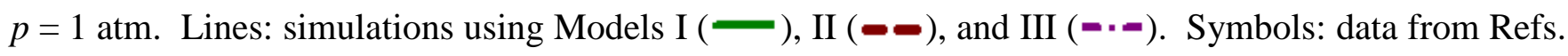
14( $\square), 15(\nabla), 16(\triangle), 17(+), 18(0), 19(\diamond), 20(\bullet)$, and 61( $\diamond)$. All data except Ref. 61 $(\oplus$, counterflow technique) were determined by spherically expanding flame technique. 

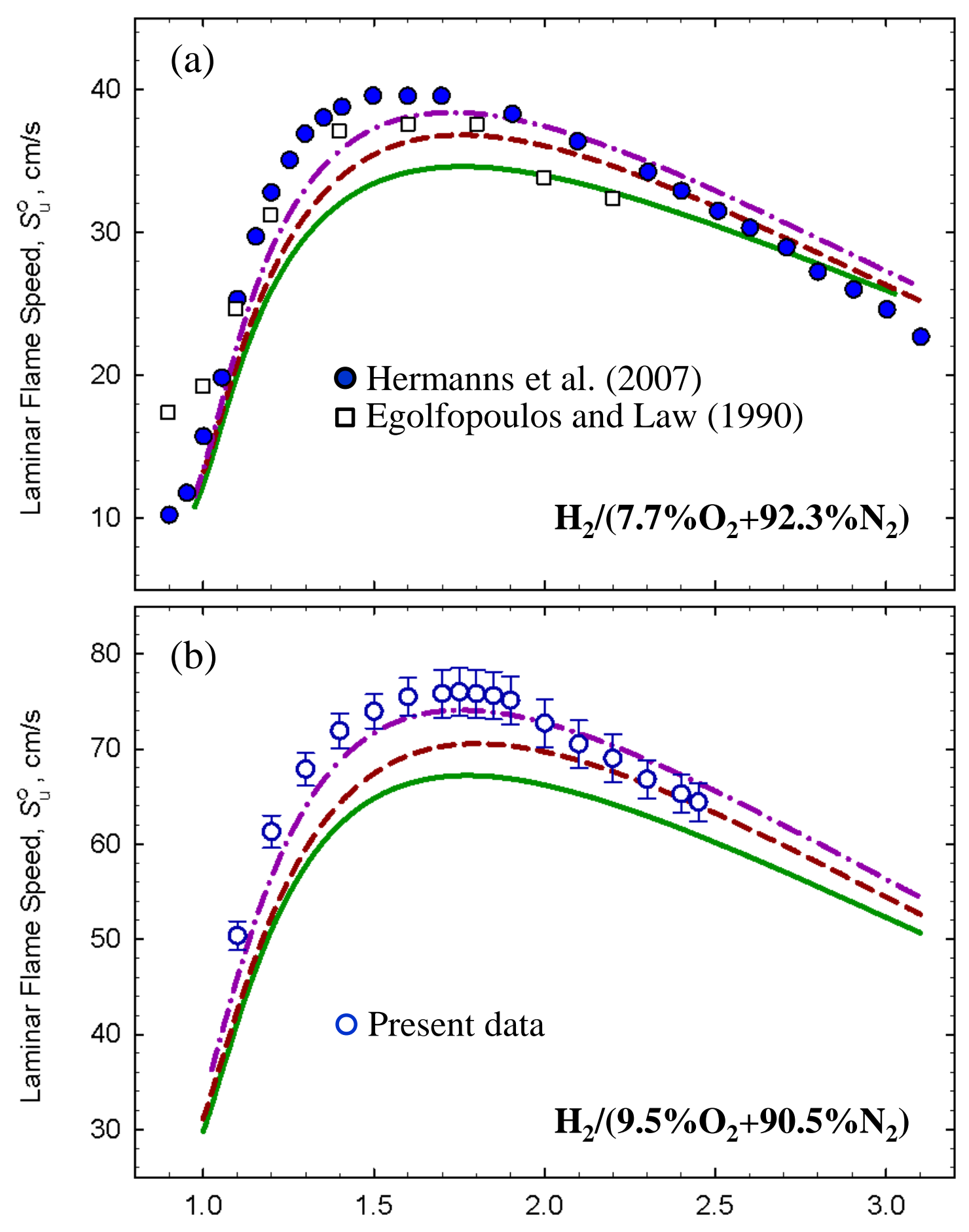

Equivalence Ratio, $\phi$

Figure 4. Comparison of measured and computed $S_{\mathrm{u}}^{\mathrm{o}}$ 's of (a) $\mathrm{H}_{2} /\left(7.7 \% \mathrm{O}_{2}+92.3 \% \mathrm{~N}_{2}\right)$ flames and (b) $\mathrm{H}_{2} /\left(9.5 \% \mathrm{O}_{2}+90.5 \% \mathrm{~N}_{2}\right)$ flames, at $T_{\mathrm{u}}=298 \mathrm{~K}$ and $p=1 \mathrm{~atm}$. Lines: simulations using Models I (

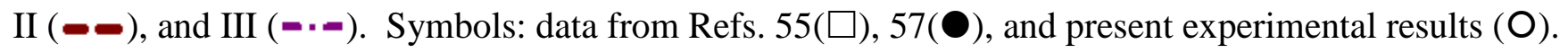


(a) $\phi=1.1$

$\mathrm{H}_{2} /$ air

$$
\begin{aligned}
\text { (R4) } \mathrm{OH}+\mathrm{H}_{2} & \rightarrow \mathrm{H}+\mathrm{H}_{2} \mathrm{O} \\
\text { (R1) } \mathrm{H}_{+} \mathrm{O}_{2} & \rightarrow \mathrm{O}+\mathrm{OH} \\
\text { (R3) } \mathrm{O}+\mathrm{H}_{2} & \rightarrow \mathrm{H}+\mathrm{OH}
\end{aligned}
$$

(R5) $\mathrm{HO}_{2}+\mathrm{H} \rightarrow \mathrm{OH}+\mathrm{OH}$

$$
\begin{aligned}
& (\mathrm{R} 8) \mathrm{HO}_{2}+\mathrm{H} \rightarrow \mathrm{H}_{2}+\mathrm{O}_{2} \\
& (\mathrm{R} 6) \mathrm{HO}_{2}+\mathrm{OH} \rightarrow \mathrm{H}_{2} \mathrm{O}+\mathrm{O}_{2}
\end{aligned}
$$

(R2) $\mathrm{H}+\mathrm{O}_{2}+\mathrm{M} \rightarrow \mathrm{HO}_{2}+\mathrm{M}$
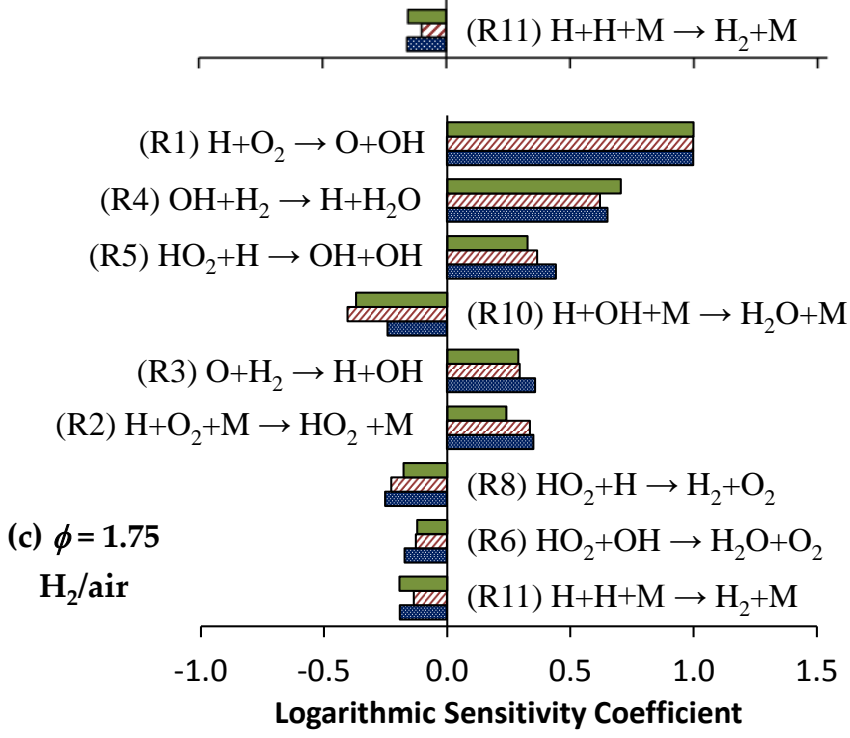

$\frac{A_{i}}{S_{u}^{o}} \frac{\partial S_{u}^{o}}{\partial A_{i}} \quad A_{\mathrm{i}}:$ pre-exponential factor (b) $\phi=1.1$

$\mathrm{H}_{2} /\left(9.5 \% \mathrm{O}_{2}+90.5 \% \mathrm{~N}_{2}\right)$

$$
\begin{aligned}
& \text { (R4) } \mathrm{OH}+\mathrm{H}_{2} \rightarrow \mathrm{H}+\mathrm{H}_{2} \mathrm{O} \\
& \text { (R1) } \mathrm{H}+\mathrm{O}_{2} \rightarrow \mathrm{O}+\mathrm{OH}
\end{aligned}
$$

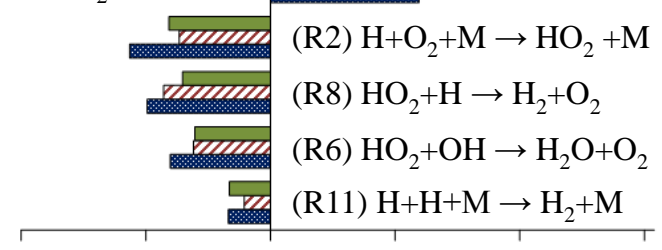

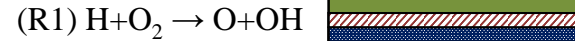

(R4) $\mathrm{OH}+\mathrm{H}_{2} \rightarrow \mathrm{H}+\mathrm{H}_{2}$

(R5) $\mathrm{HO}_{2}+\mathrm{H} \rightarrow \mathrm{OH}+\mathrm{OH}$

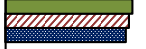

ग101070

(R10) $\mathrm{H}+\mathrm{OH}+\mathrm{M} \rightarrow \mathrm{H}_{2} \mathrm{O}+\mathrm{M}$

(R8) $\mathrm{HO}_{2}+\mathrm{H} \rightarrow \mathrm{H}_{2}+\mathrm{O}_{2}$

(R3) $\mathrm{O}+\mathrm{H}_{2} \rightarrow \mathrm{H}+\mathrm{OH}$

(d) $\phi=1.75$

$\mathrm{H}_{2} /\left(9.5 \% \mathrm{O}_{2}+90.5 \% \mathrm{~N}_{2}\right)$

$$
\text { (R11) } \mathrm{H}+\mathrm{H}+\mathrm{M} \rightarrow \mathrm{H}_{2}+\mathrm{M}
$$

(R6) $\mathrm{HO}_{2}+\mathrm{OH} \rightarrow \mathrm{H}_{2} \mathrm{O}+\mathrm{O}_{2}$

$\begin{array}{cccccc} & & & \text { (R2) } \mathrm{H}+\mathrm{O}_{2}+\mathrm{M} \rightarrow & \mathrm{HO}_{2}+\mathrm{M} \\ -1 & -0.5 & 0 & 0.5 & 1 & 1.5\end{array}$

Logarithmic Sensitivity Coefficient

$\square$ Model I

च Model II

옹 Model III

Figure 5. Logarithmic sensitivity coefficients of $S_{\mathrm{u}}^{\mathrm{o}}$ to kinetics at $\phi=1.1$ and 1.75 for $\mathrm{H}_{2}$ /air flames and $\mathrm{H}_{2} /\left(9.5 \% \mathrm{O}_{2}+90.5 \% \mathrm{~N}_{2}\right)$ flames at $T_{\mathrm{u}}=298 \mathrm{~K}$, and $p=1$ atm computed using Models I, II, and III. 

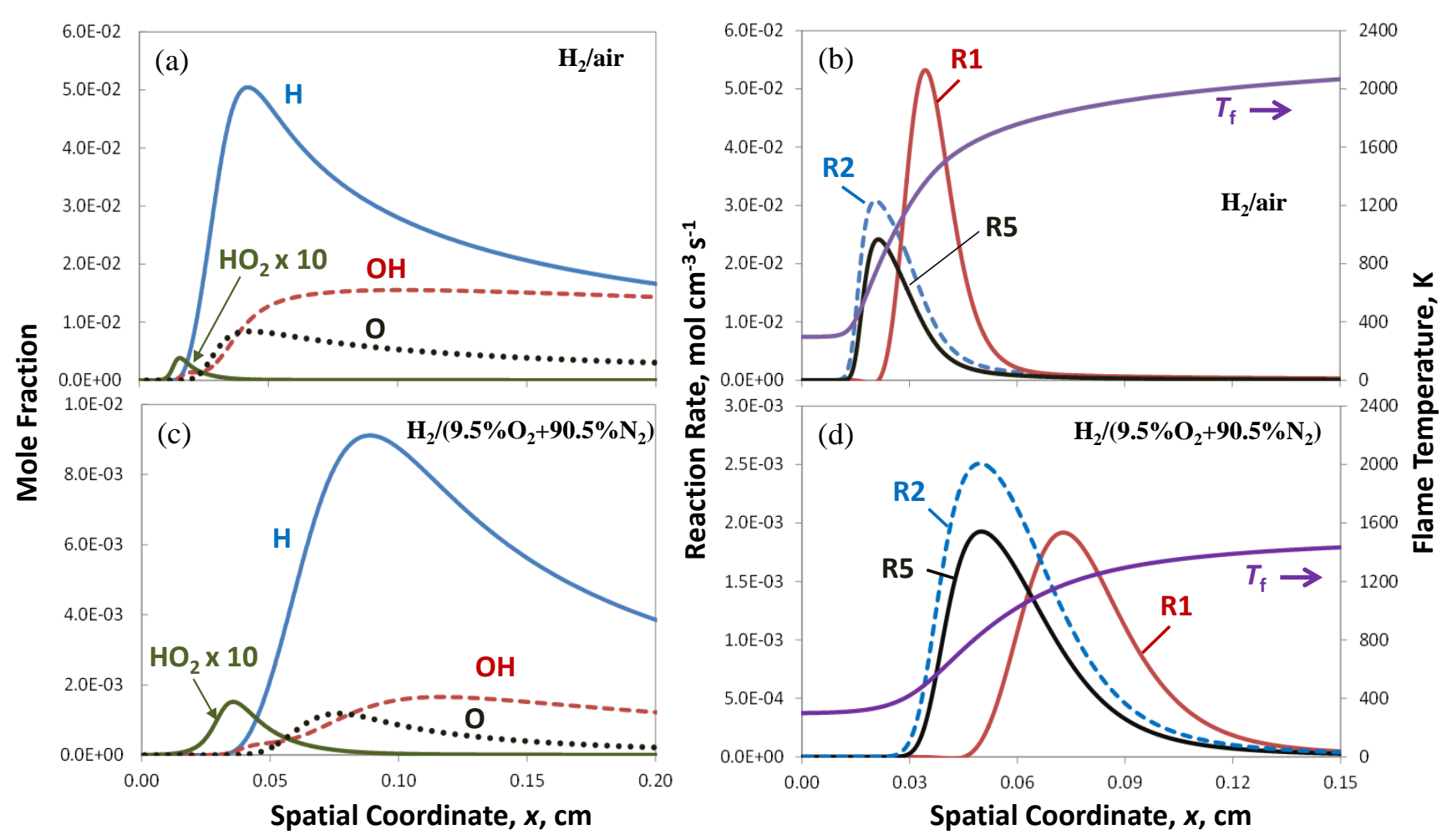

Figure 6. Computed species mole fraction profiles, reaction rates, and flame temperatures for flames of $\mathrm{H}_{2} /$ air and $\mathrm{H}_{2} /\left(9.5 \% \mathrm{O}_{2}+90.5 \% \mathrm{~N}_{2}\right)$ at $\phi=1.1, T_{\mathrm{u}}=298 \mathrm{~K}$, and $p=1 \mathrm{~atm}$ computed using Model III. 

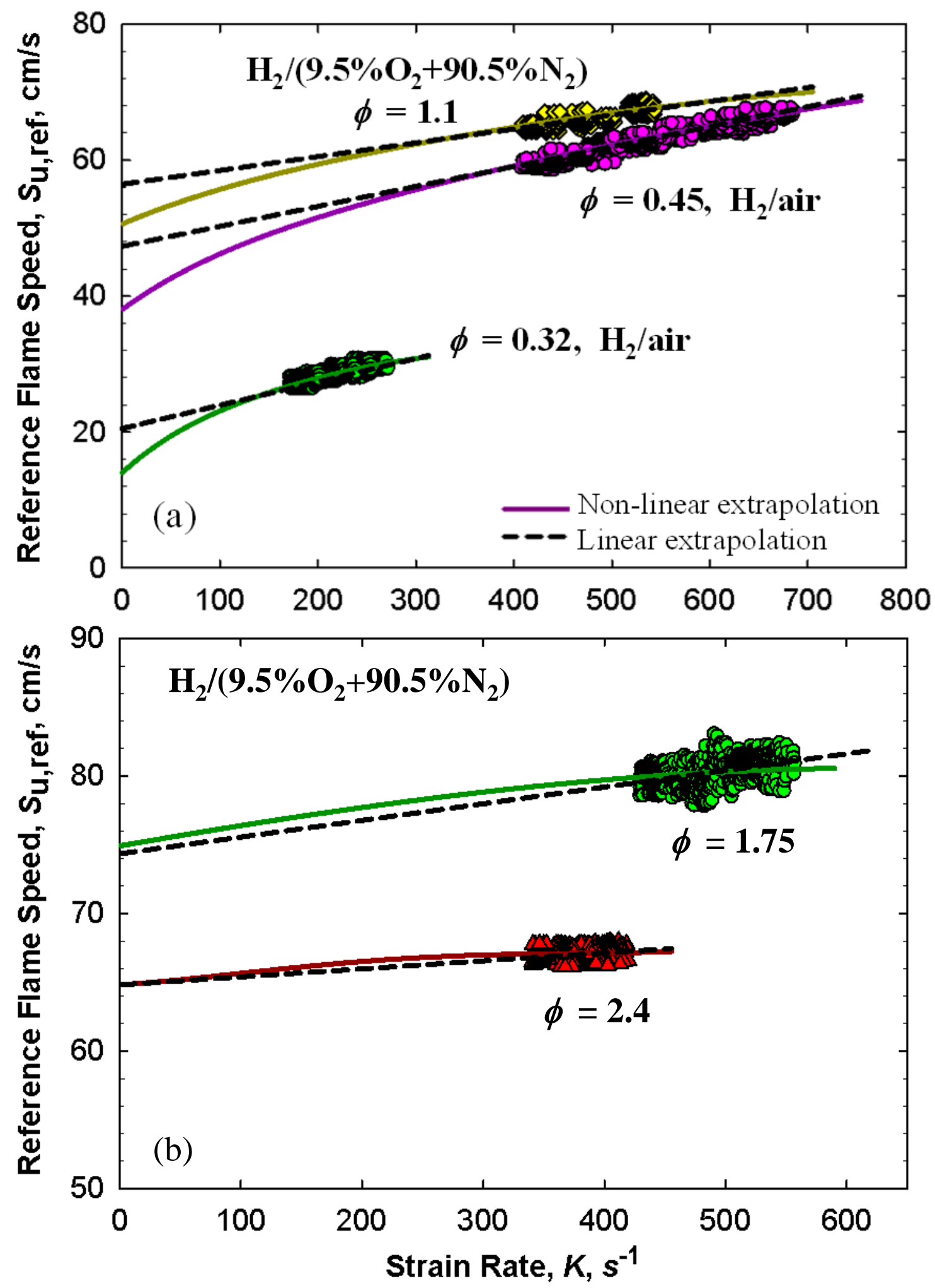

Figure 7. Comparison of non-linear and linear extrapolation techniques for the experimental determination of $S_{\mathrm{u}}^{\mathrm{o}}$ 's of $\mathrm{H}_{2} /$ air and $\mathrm{H}_{2} /\left(9.5 \% \mathrm{O}_{2}+90.5 \% \mathrm{~N}_{2}\right)$ flames at $T_{\mathrm{u}}=298 \mathrm{~K}$ and $p=1 \mathrm{~atm}$. Lines: extrapolation curves. Symbols: present experimental data. 

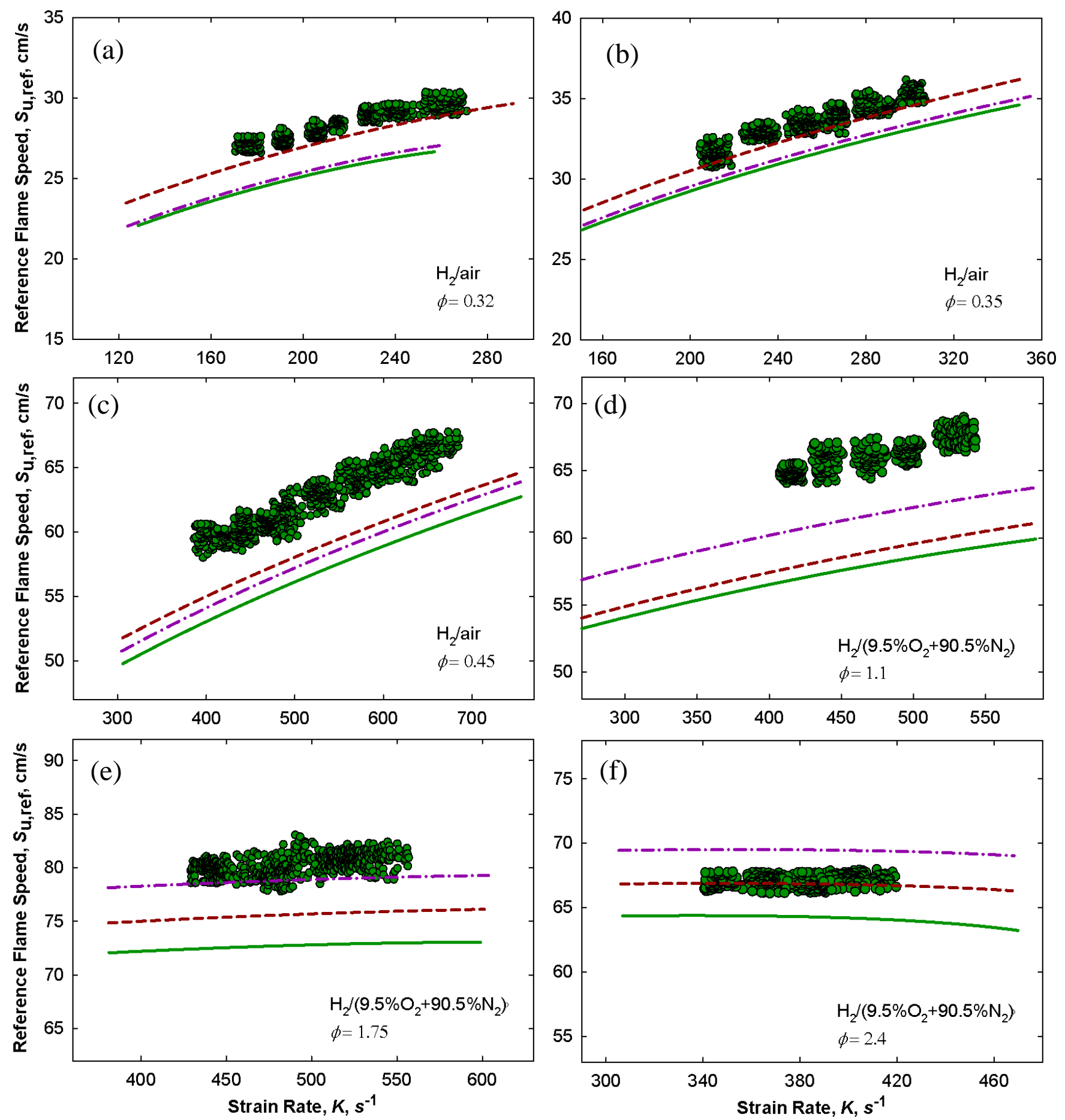

Figure 8. Experimental and computed reference flame speeds for $\mathrm{H}_{2} /$ air and $\mathrm{H}_{2} /\left(9.5 \% \mathrm{O}_{2}+90.5 \% \mathrm{~N}_{2}\right)$ mixtures at $\phi=0.32,0.35,0.45,1.1,1.75$, and 2.4 at $T_{\mathrm{u}}=298 \mathrm{~K}$ and $p=1 \mathrm{~atm}$. Lines: simulations using

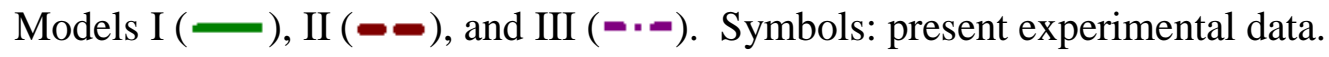




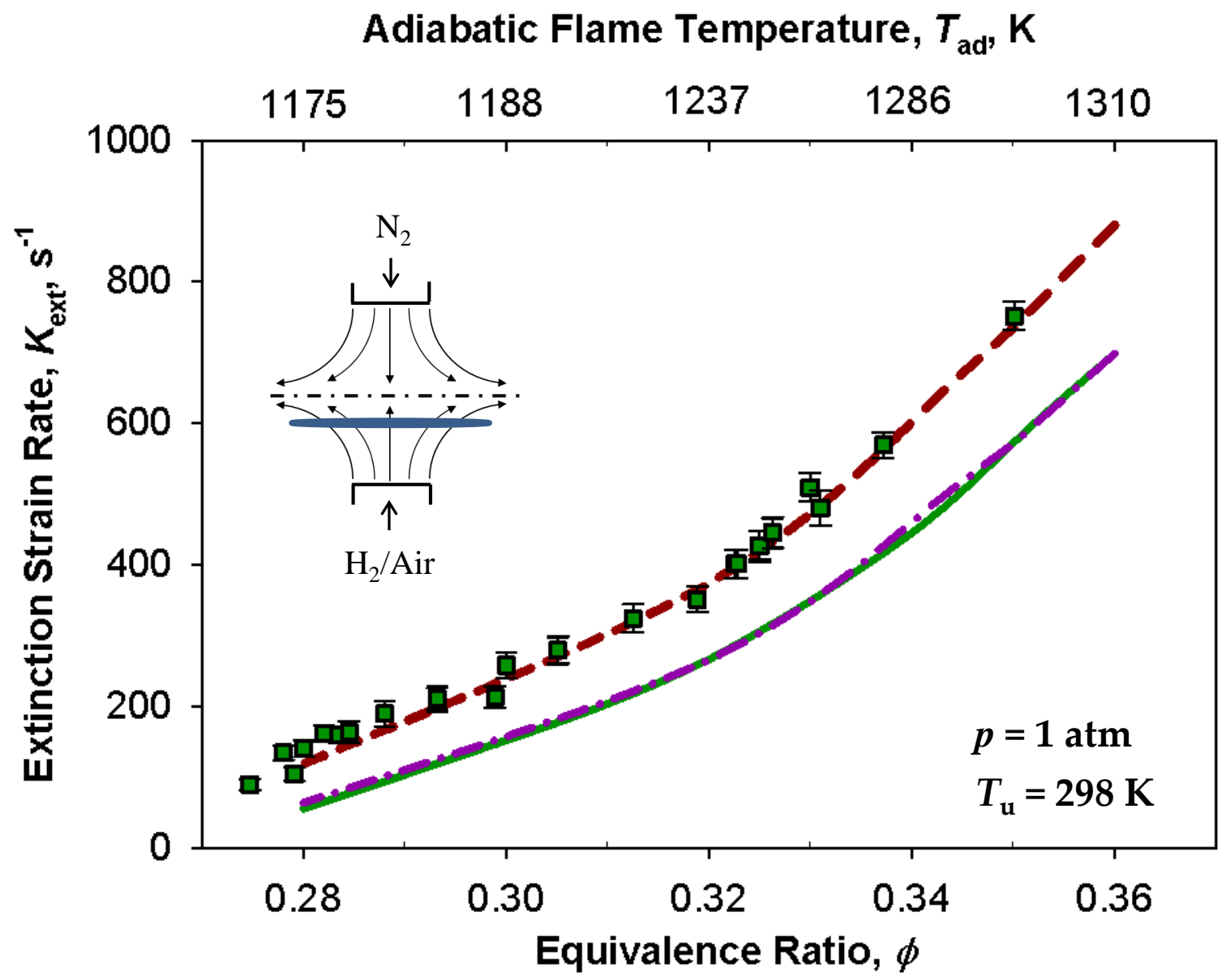

Figure 9. Experimental and computed $K_{\text {ext }}$ 's of opposed-jet premixed $\mathrm{H}_{2} /$ air flames at $T_{\mathrm{u}}=298 \mathrm{~K}$ and $p=1$ atm. Lines: simulations using Models I ( - ), II ( $\boldsymbol{-})$, and III (- $\cdot \boldsymbol{-})$. 


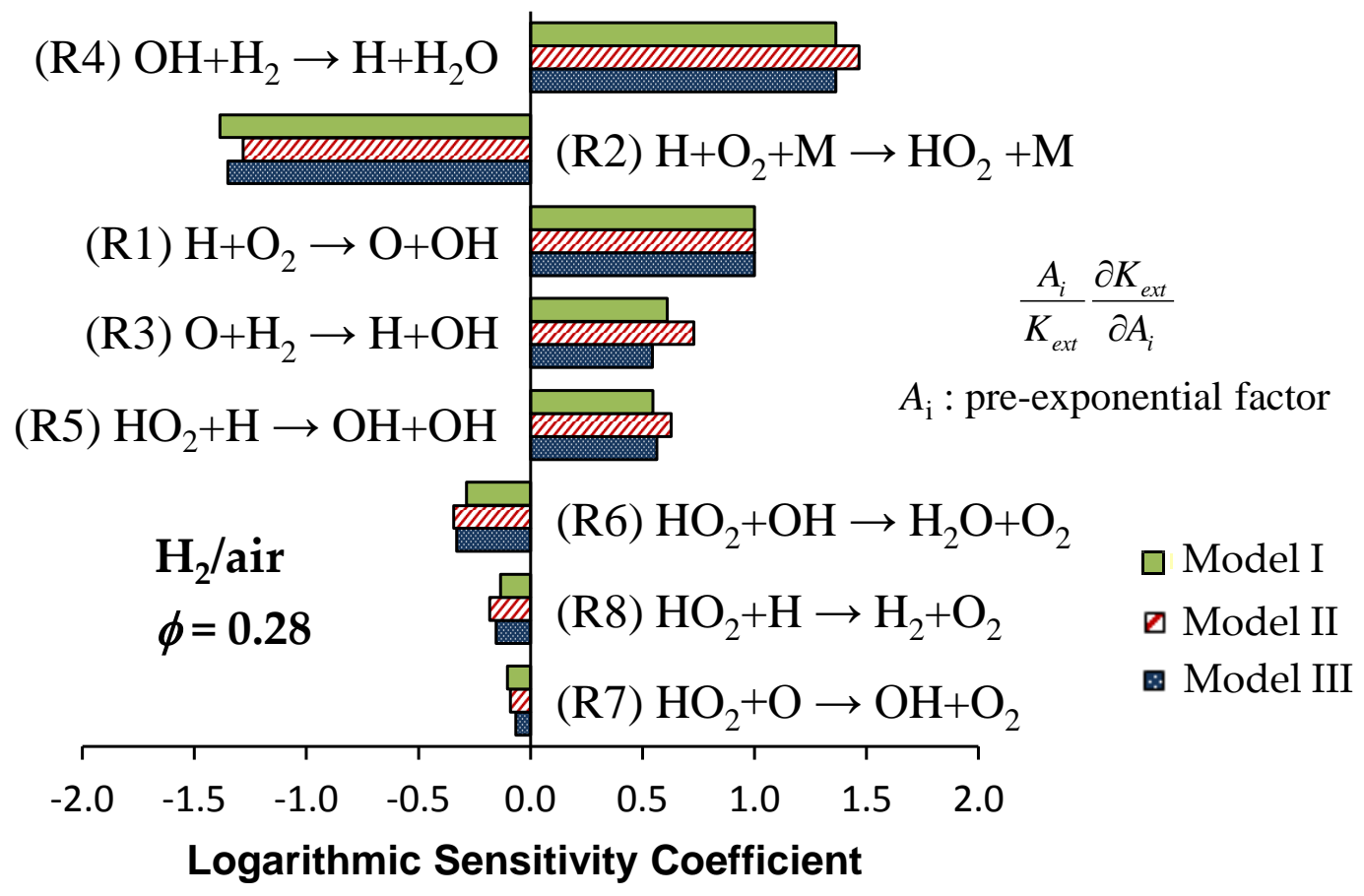

Figure 10. Logarithmic sensitivity coefficients of (a) $K_{\text {ext }}$ to kinetics for opposed-jet premixed $\mathrm{H}_{2} /$ air flames at $\phi=0.28, T_{\mathrm{u}}=298 \mathrm{~K}$, and $p=1$ atm computed using Models I, II, and III. 

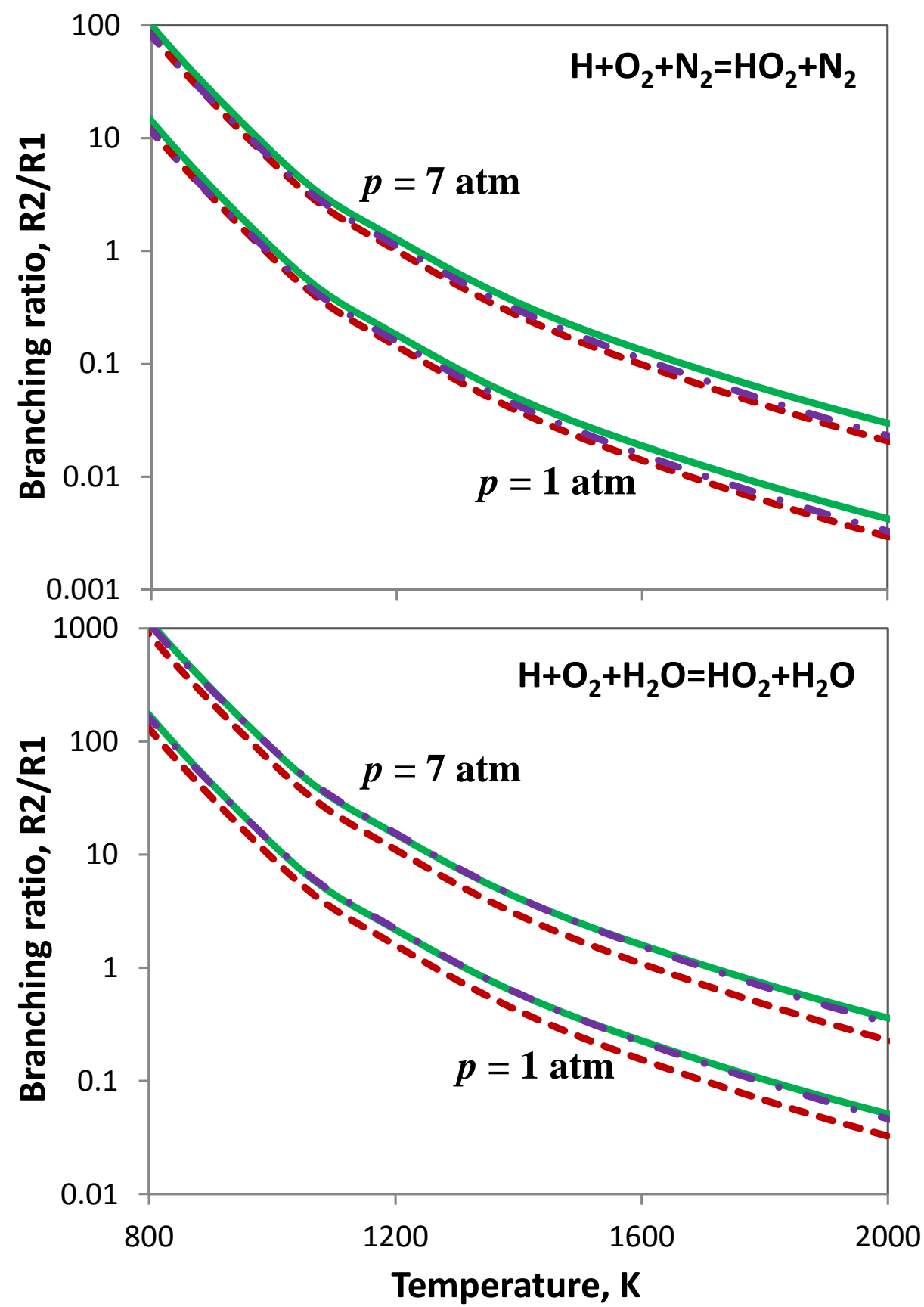

Figure 11. Branching R2/R1 ratios, computed using Models I ( - ), II (- $)$ ), and III ( - - $)$ ). 


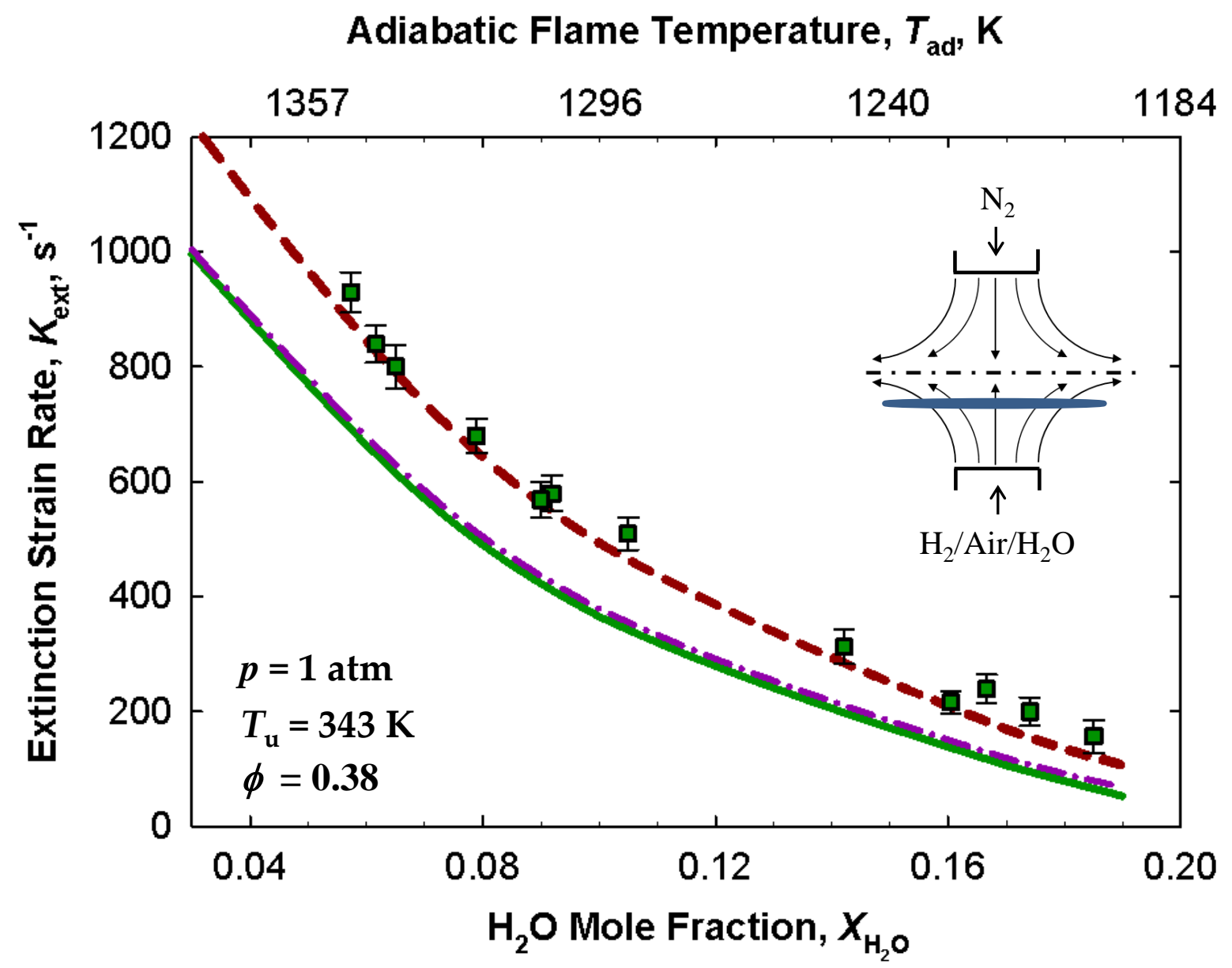

Figure 12. Experimental and computed $K_{\text {ext }}$ 's of opposed-jet premixed $\mathrm{H}_{2} / \mathrm{H}_{2} \mathrm{O} /$ air flames at $\phi=0.38$, $T_{\mathrm{u}}=343 \mathrm{~K}$, and $p=1 \mathrm{~atm}$. Lines: simulations using Models I ( - ), II (- $\left.\mathbf{-}\right)$, and III (- $\left.\cdot \boldsymbol{-}\right)$. 


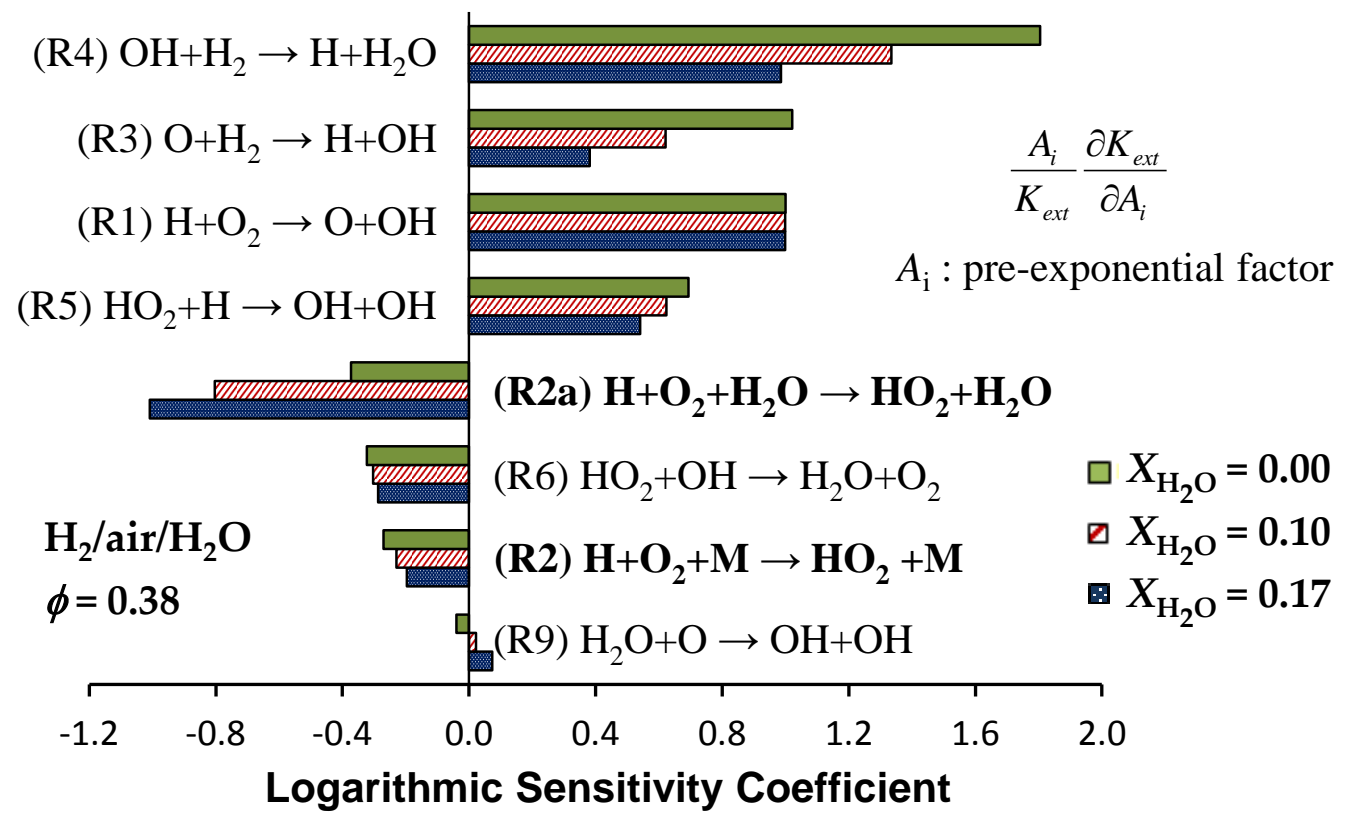

Figure 13. Logarithmic sensitivity coefficients of $K_{\text {ext }}$ 's to kinetics for opposed-jet premixed $\mathrm{H}_{2} /$ air/ $\mathrm{H}_{2} \mathrm{O}$ flames at $\phi=0.38, T_{\mathrm{u}}=343 \mathrm{~K}$, and $p=1 \mathrm{~atm}$ computed using Model $\mathrm{I}$. 

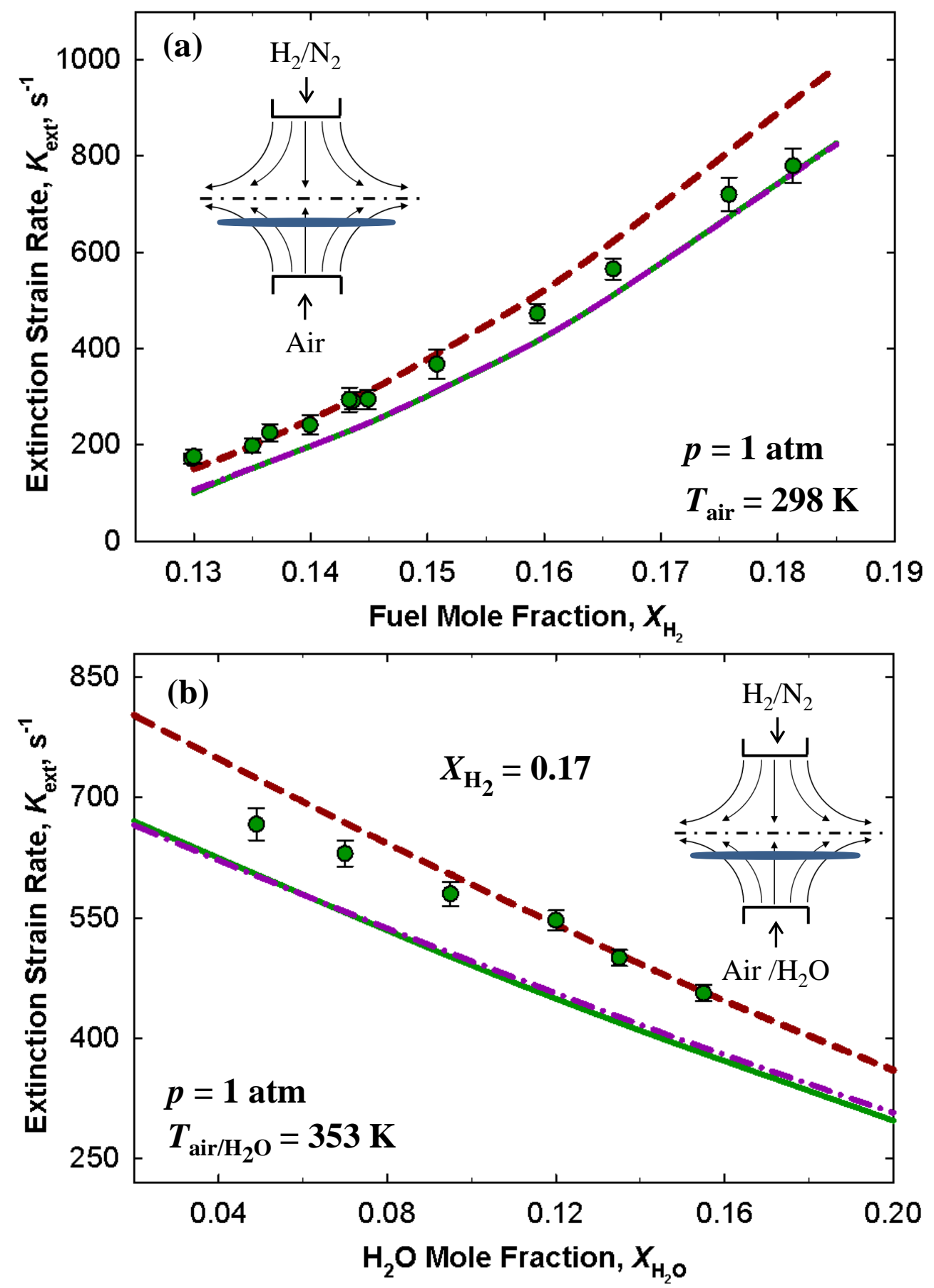

Figure 14. Experimental and computed $K_{\text {ext }}$ 's of opposed-jet non-premixed (a) $\mathrm{H}_{2}$ flames at $T_{\text {air }}=298 \mathrm{~K}$ and $p=1 \mathrm{~atm}$, and (b) $\mathrm{H}_{2}$ flames with $\mathrm{H}_{2} \mathrm{O}$ added to air jet at $X_{\mathrm{H}_{2}}=0.17, T_{\mathrm{air} / \mathrm{H}_{2} \mathrm{O}}=353 \mathrm{~K}$, and $p=1 \mathrm{~atm}$.

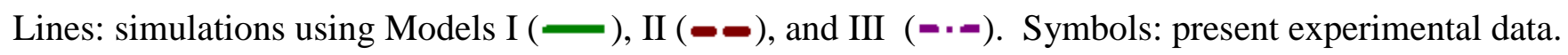



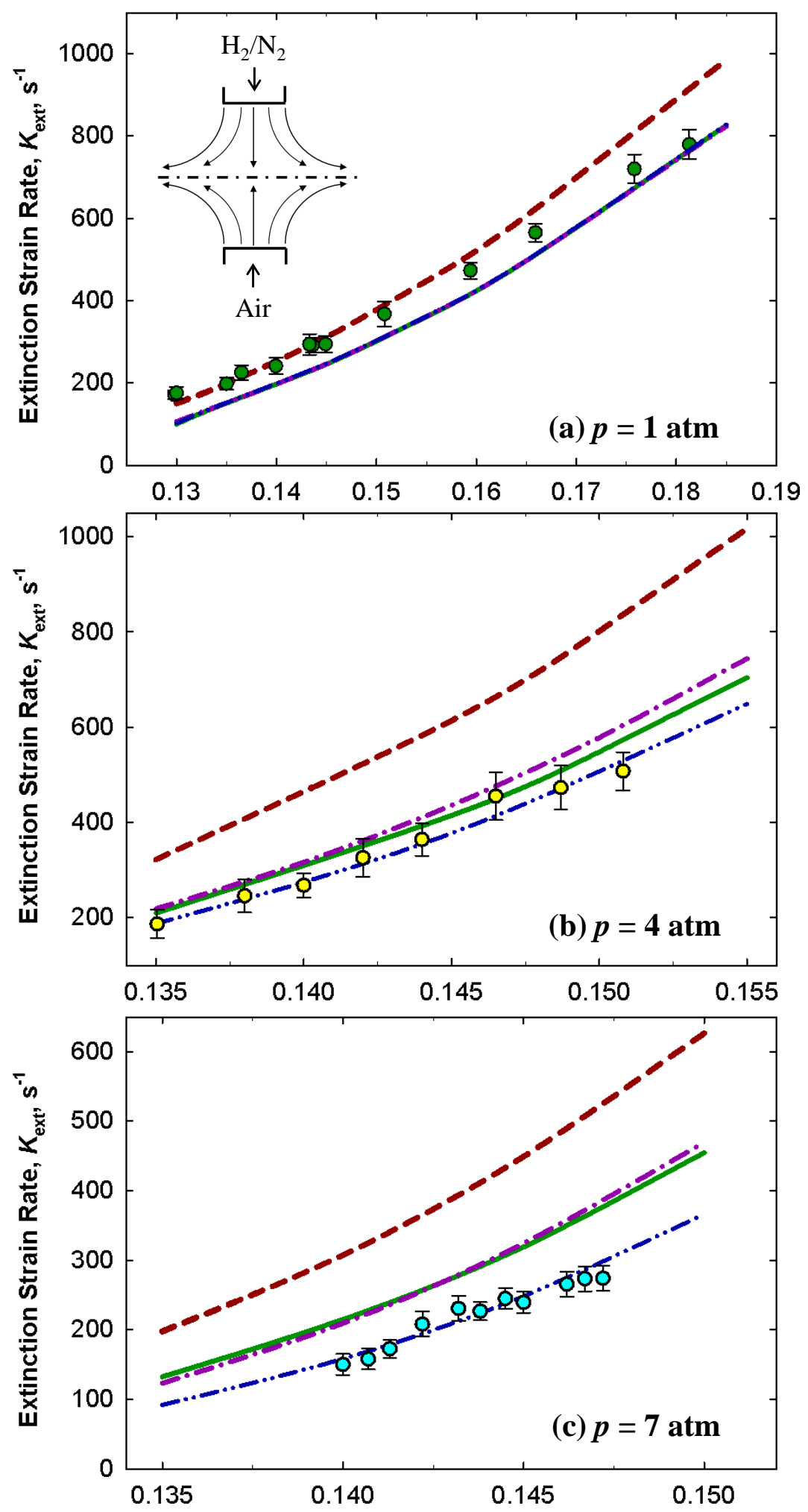

Fuel Mole Fraction, $\boldsymbol{X}_{\mathbf{H}_{2}}$

Figure 15. Experimental and computed $K_{\text {ext }}$ 's of opposed-jet non-premixed $\mathrm{H}_{2}$ flames at $T_{\text {air }}=298 \mathrm{~K}$, and $p=1,4$, and 7 atm. Lines: simulations using Models I (-), II (--), III (-・- ), and Ia ( $-\cdots-)$. Symbols: present experimental data. 


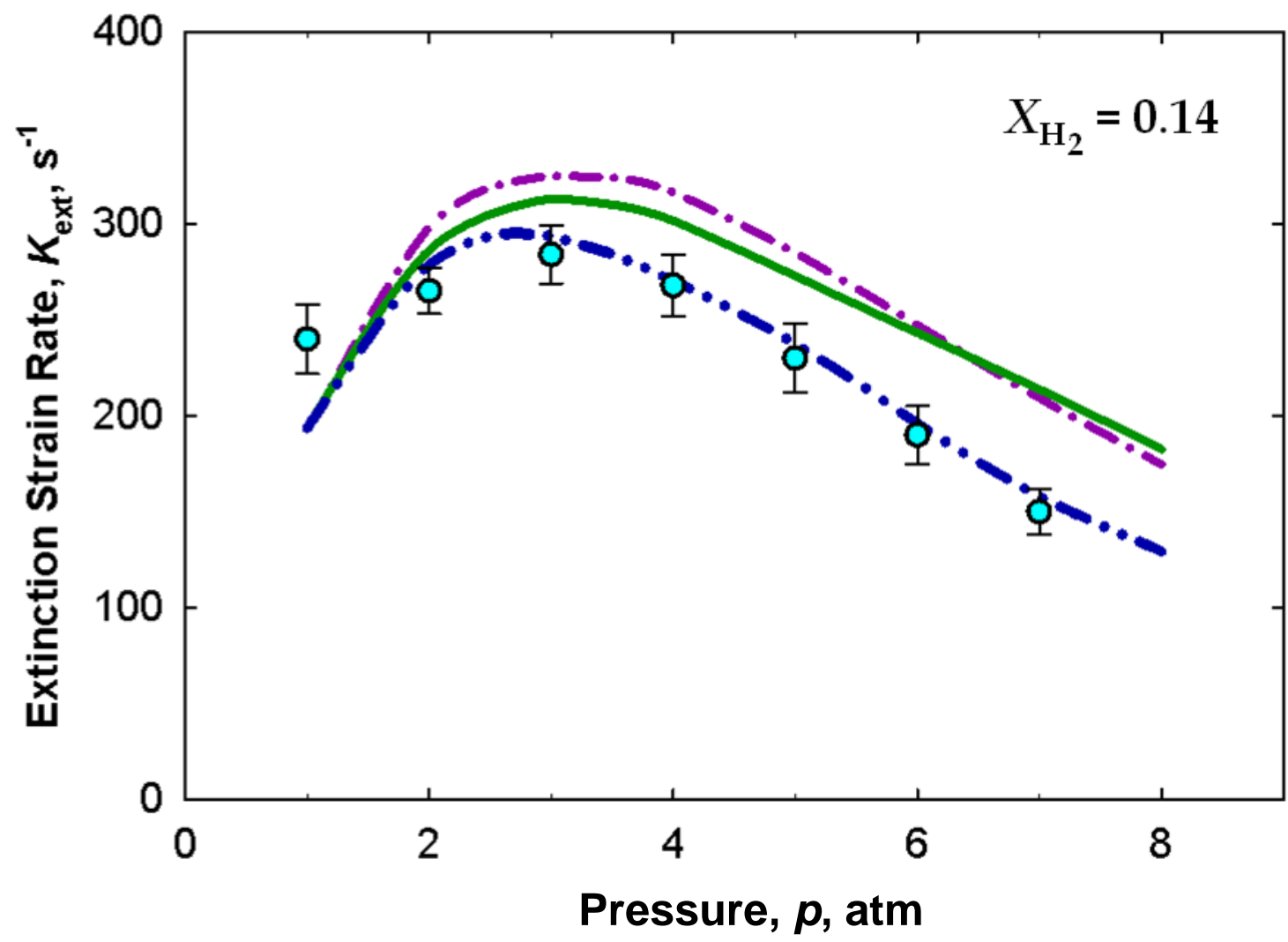

Figure 16. Experimental and computed $K_{\text {ext }}$ 's of opposed-jet non-premixed $\mathrm{H}_{2}$ flames as a function of ambient pressure at $X_{\mathrm{H}_{2}}=0.14$ and $T_{\text {air }}=298 \mathrm{~K}$. Lines: simulations using Models I (- $)$, Ia ( $\left.-\cdots\right)$, and III ( $-\cdot-$ ). Symbols: present experimental data. 


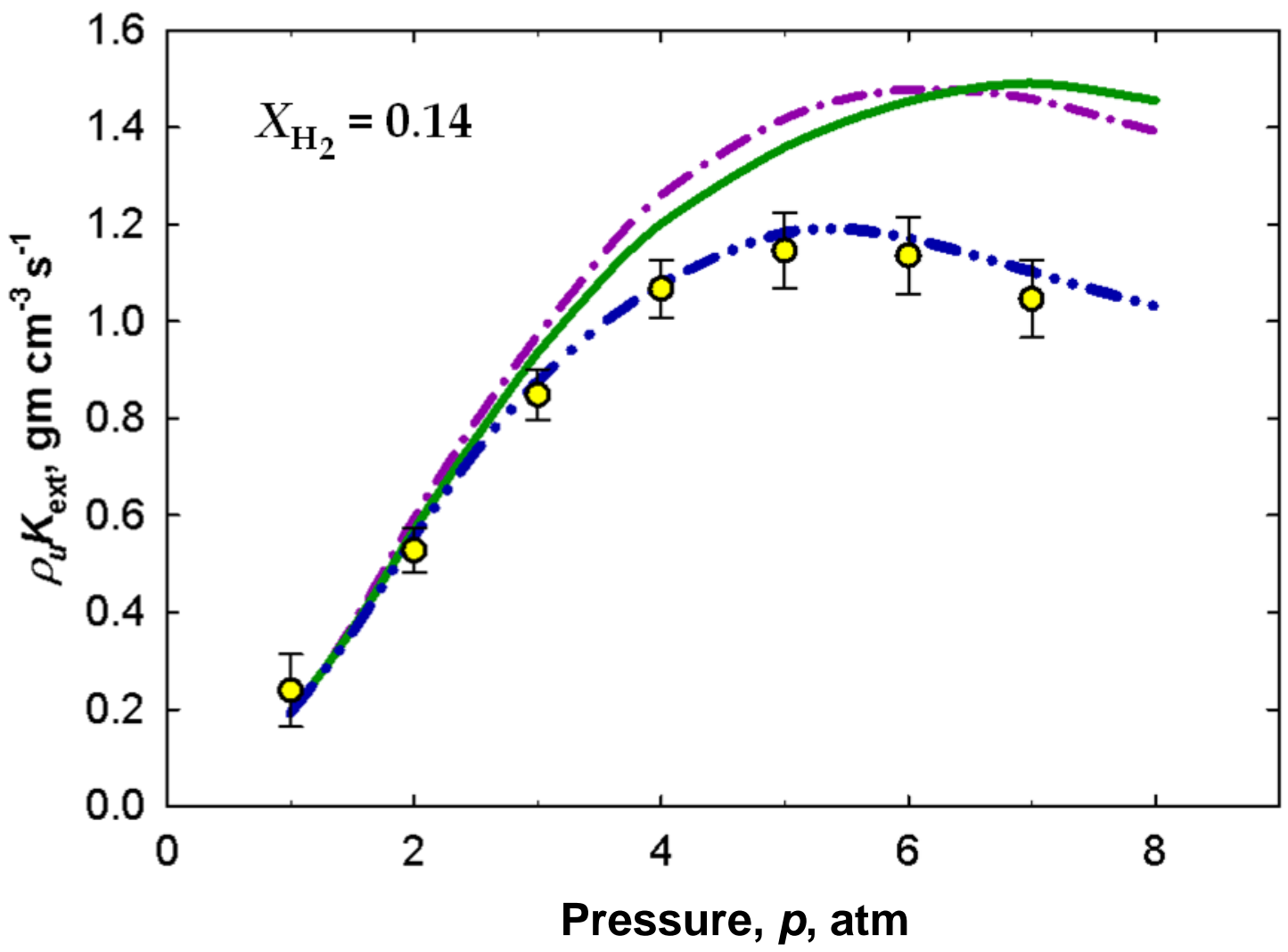

Figure 17. Experimental and computed $\rho_{\mathrm{u}} K_{\mathrm{ext}}$ 's of opposed-jet non-premixed $\mathrm{H}_{2}$ flames as a function of ambient pressure at $X_{\mathrm{H}_{2}}=0.14$ and $T_{\text {air }}=298 \mathrm{~K}$. Lines: simulations using Models I ( $(\mathbf{C})$, Ia (-・-), and III ( $-\cdot \boldsymbol{-})$. Symbols: present experimental data. 


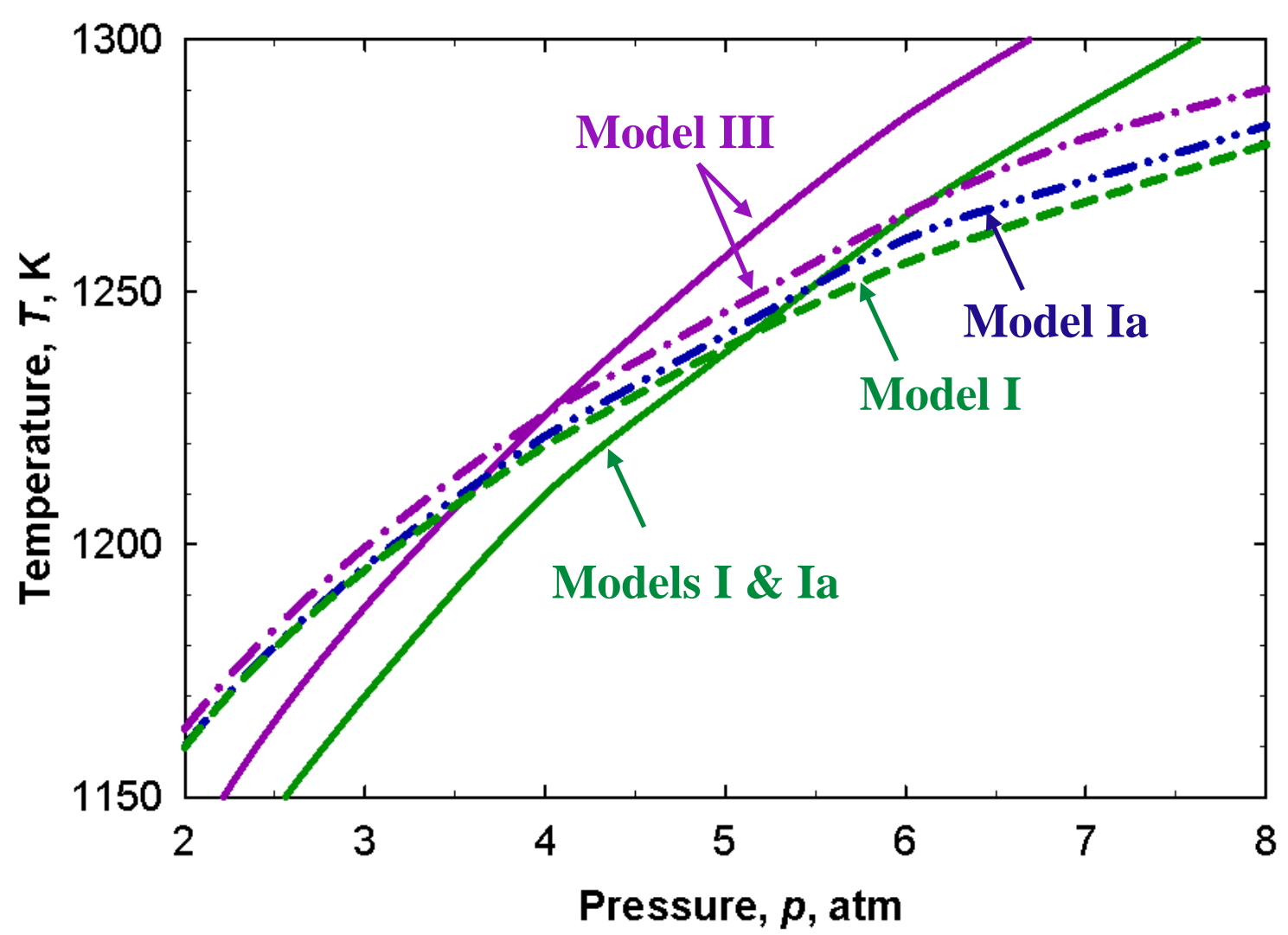

Figure 18. Variation of computed peak flame temperature at extinction, $T_{f, \max , \mathrm{E}}$ and the crossover temperature, $T_{\mathrm{c}}$ as a function of pressure computed with detailed chemistry. Solid lines are $T_{\mathrm{c}}$ 's computed by Models I and Ia ( - ), and Model III ( - ). Dashed lines are $T_{f, \text { max,E' }}$; computed by

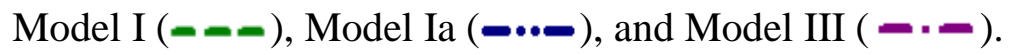




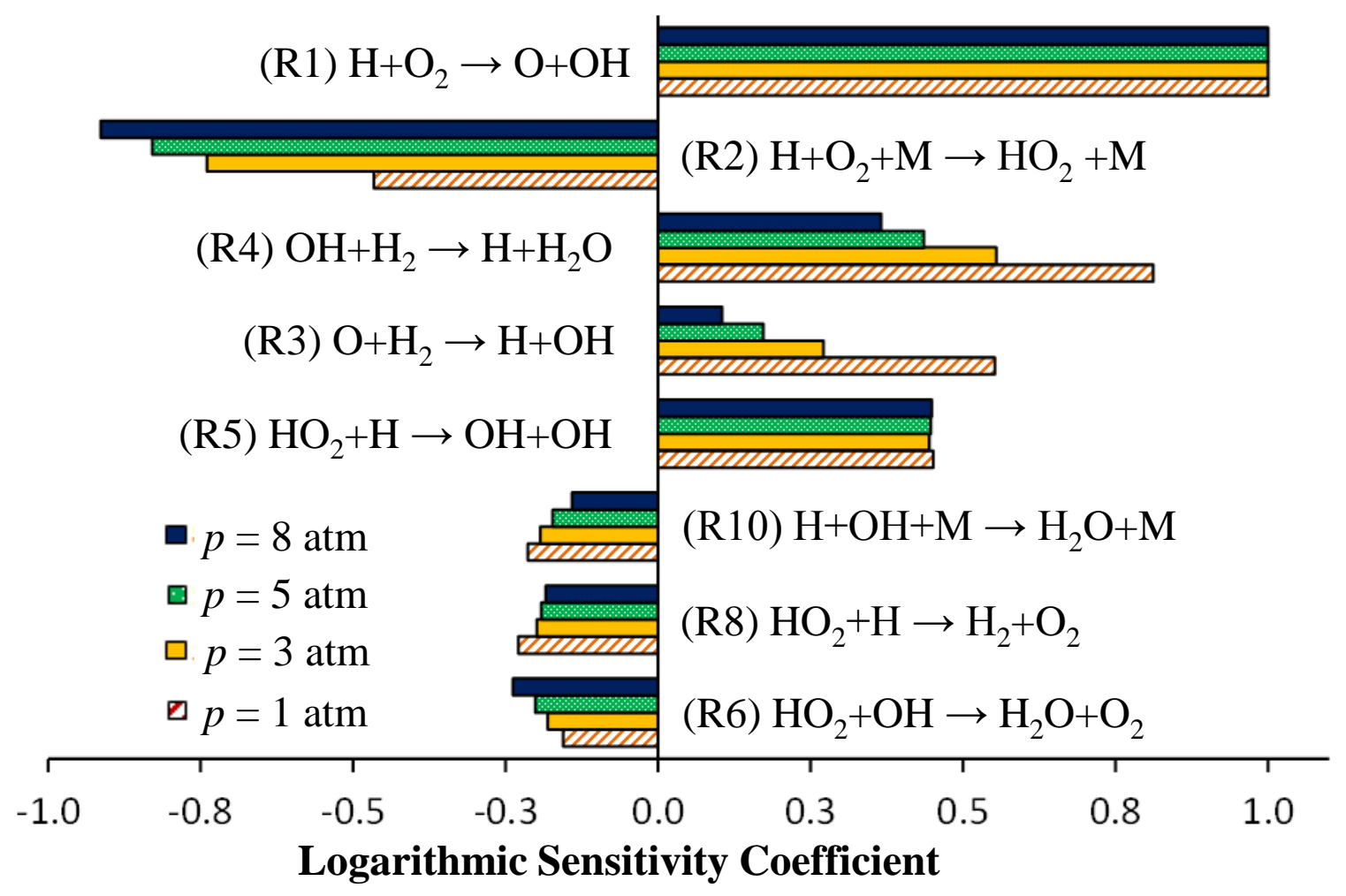

Figure 19. Logarithmic sensitivity coefficients of $K_{\text {ext }}$ to kinetics for opposed-jet non-premixed $\mathrm{H}_{2}$ flames at $p=1,3,5$, and 8 atm, $X_{\mathrm{H}_{2}}=0.14$, and $T_{\text {air }}=298 \mathrm{~K}$ computed using Model Ia. 


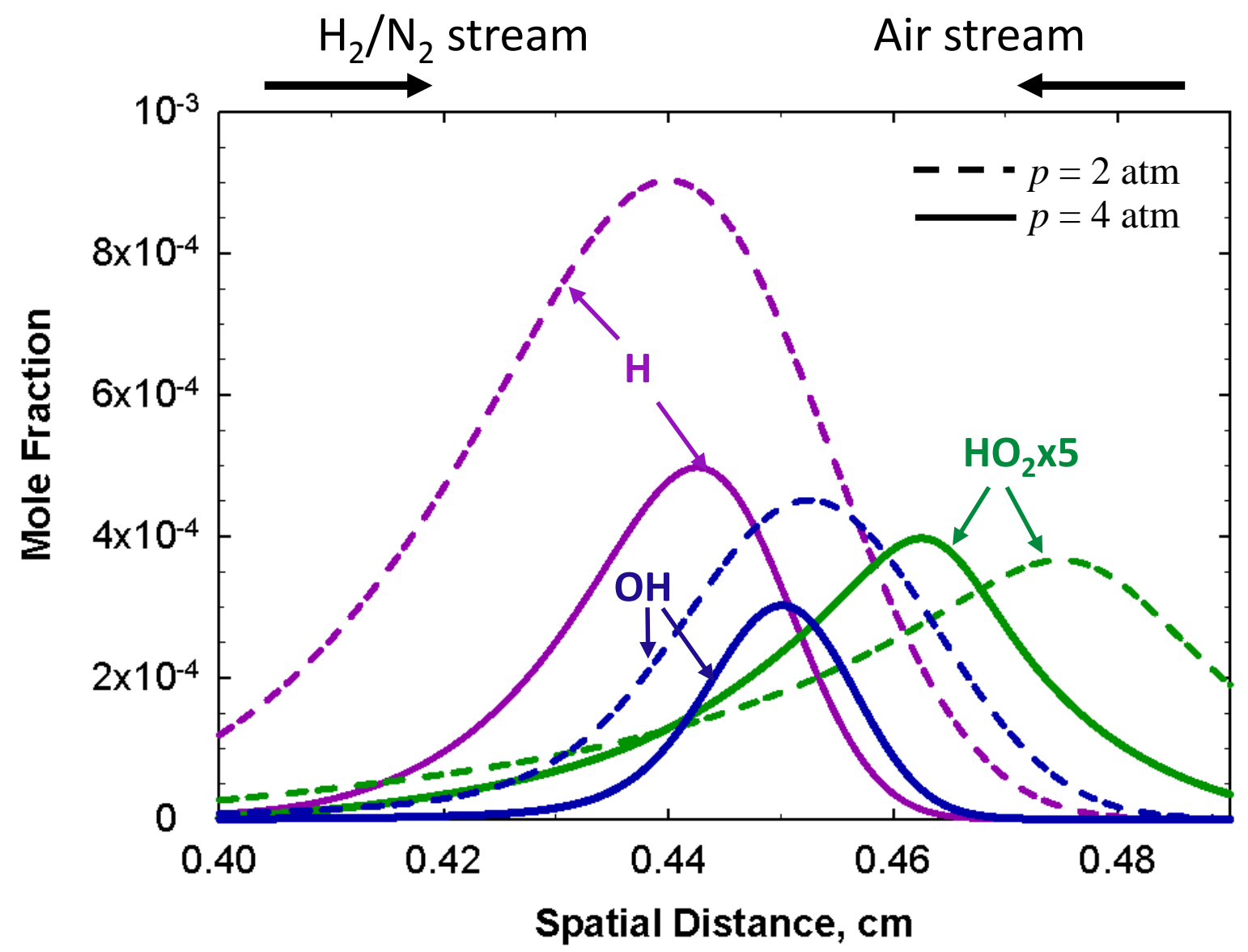

Figure 20. Mole fraction of $\mathrm{H}, \mathrm{OH}$, and $\mathrm{HO}_{2}$ for $X_{\mathrm{H}_{2}}=0.14$ at $p=2$ and 4 atm computed using Model Ia. 

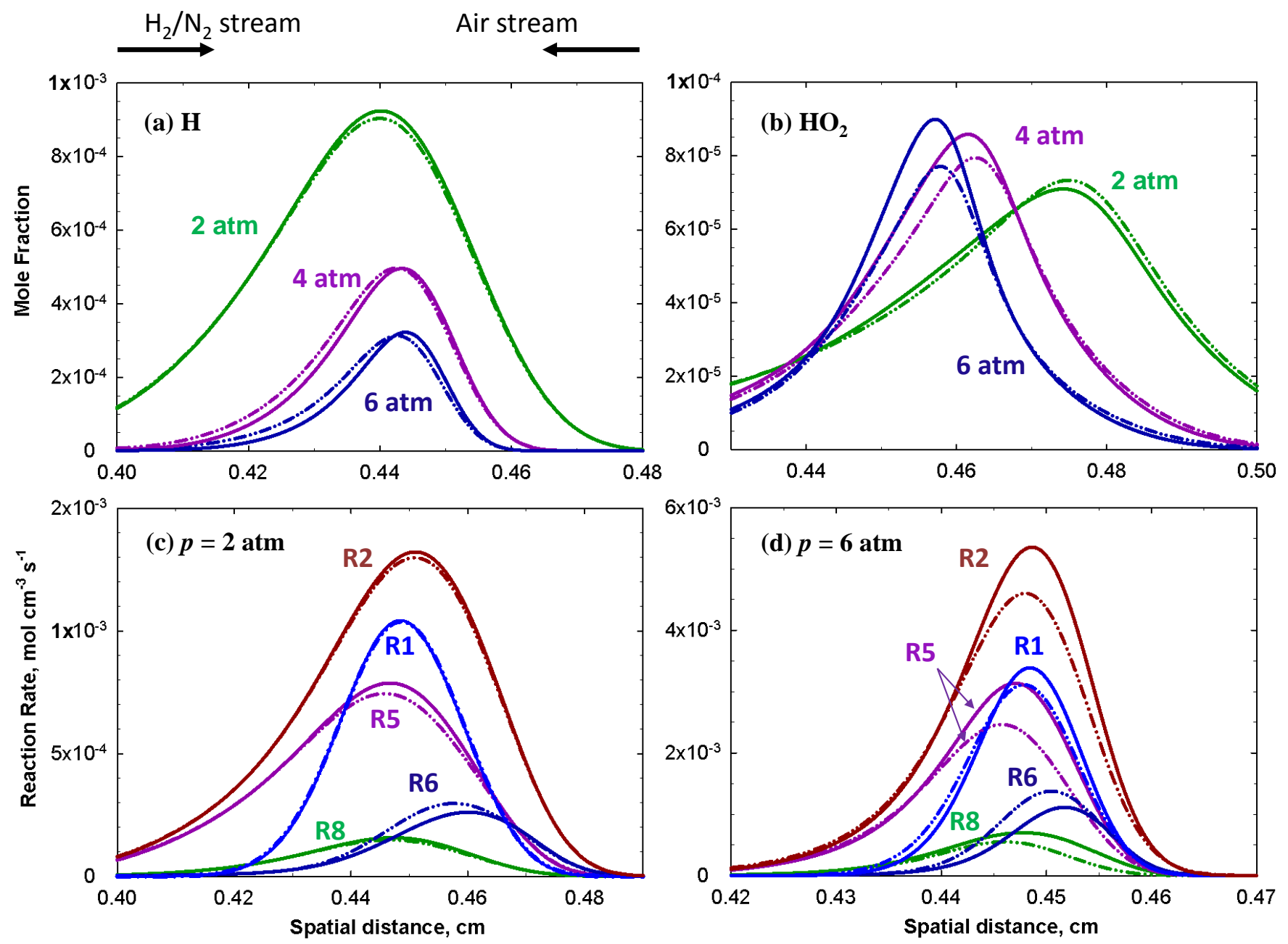

Figure 21. Mole fraction of (a) $\mathrm{H}$ and (b) $\mathrm{HO}_{2}$ with various pressures, $X_{\mathrm{H}_{2}}=0.14$. Net reaction rates of $\mathrm{H}+\mathrm{O}_{2} \rightarrow \mathrm{OH}+\mathrm{O} \quad(\mathrm{R} 1), \quad \mathrm{H}+\mathrm{O}_{2}+\mathrm{M} \rightarrow \mathrm{HO}_{2}+\mathrm{M} \quad(\mathrm{R} 2), \quad \mathrm{HO}_{2}+\mathrm{H} \rightarrow \mathrm{OH}+\mathrm{OH} \quad$ (R5) $\mathrm{HO}_{2}+\mathrm{OH} \rightarrow \mathrm{H}_{2} \mathrm{O}+\mathrm{O}_{2}$ (R6), and $\mathrm{HO}_{2}+\mathrm{H} \rightarrow \mathrm{H}_{2}+\mathrm{O}_{2}$ (R8) for non-premixed $\mathrm{H}_{2} / \mathrm{N}_{2}$-air flames at $X_{\mathrm{H}_{2}}=0.14$ for (c) $p=2 \mathrm{~atm}$ and (d) $p=6$ atm computed using model I(solid line) and Ia (dashed line). 


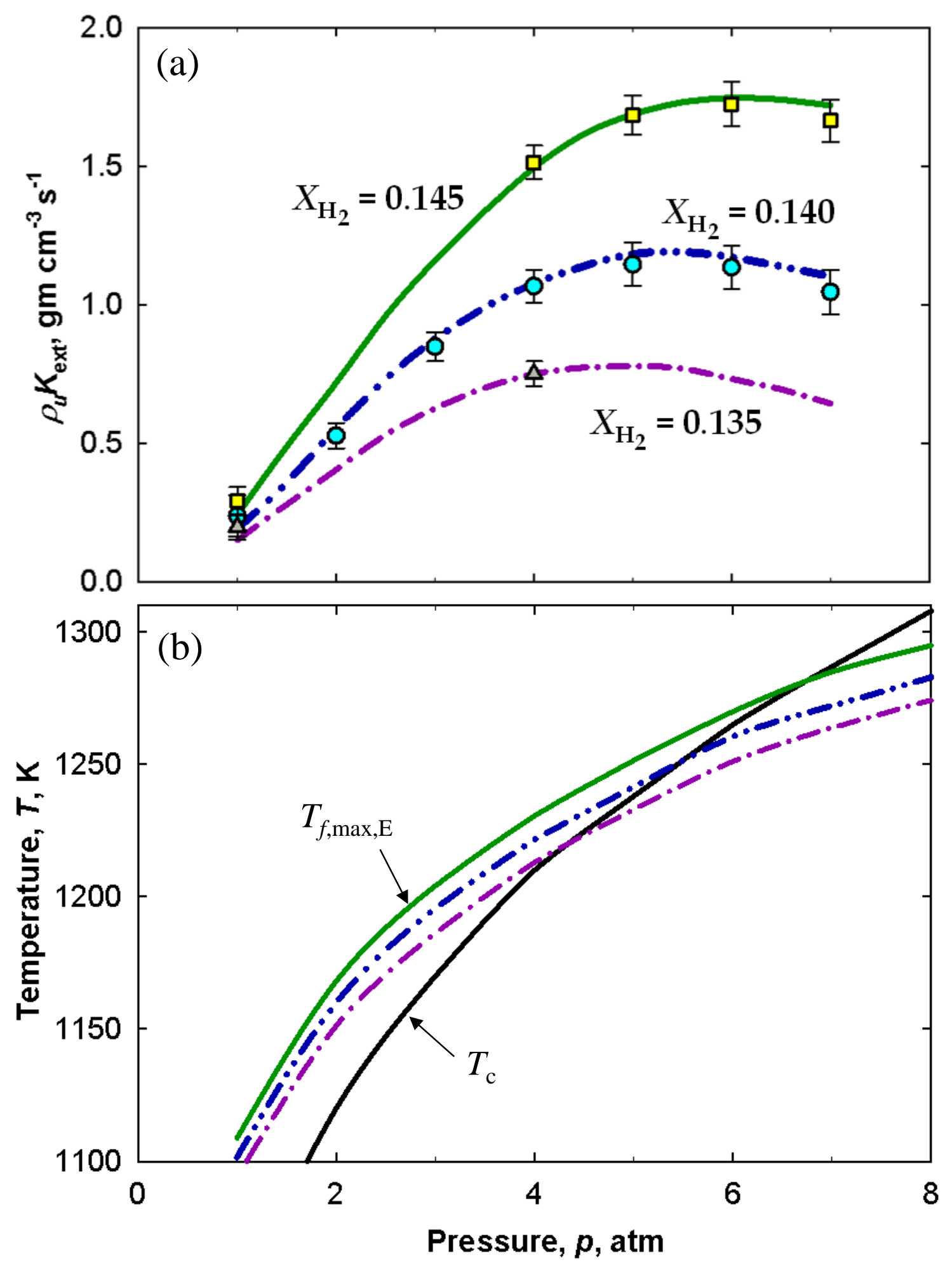

Figure 22. (a) Experimental and computed $\rho_{\mathrm{u}} K_{\text {ext }}$ 's of opposed-jet non-premixed $\mathrm{H}_{2}$ flames (b) Computed $T_{f, \max , \mathrm{E}}$ and $T_{\mathrm{c}}$ as a function of ambient pressure at and $T_{\mathrm{air}}=298 \mathrm{~K} . X_{\mathrm{H}_{2}}=0.135(\sim \cdot-, \triangle)$, $0.140(\boldsymbol{-}, \mathbf{O})$, and $0.145(-, \square)$. Lines: simulations using Model Ia. Symbols: present experimental data. 

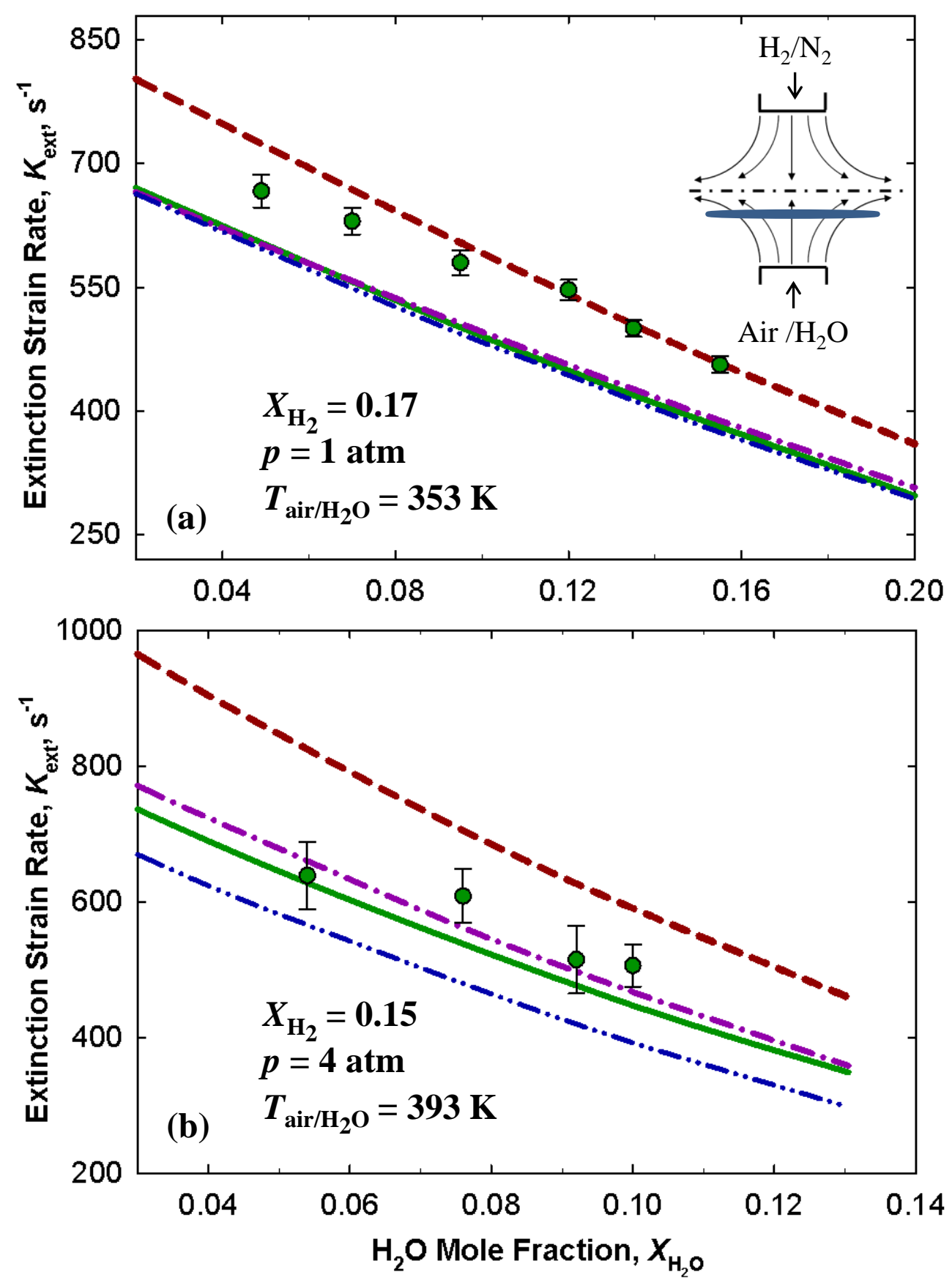

Figure 23. Experimental and computed $K_{\text {ext }}$ 's of opposed-jet non-premixed $\mathrm{H}_{2}$ flames with $\mathrm{H}_{2} \mathrm{O}$ added to the oxidizer jet at (a) $T_{\text {air/ } H_{2} \mathrm{O}}=353 \mathrm{~K}, p=1 \mathrm{~atm}$, and $X_{\mathrm{H}_{2}}=0.17$ and (b) $T_{\mathrm{air} / \mathrm{H}_{2} \mathrm{O}}=393 \mathrm{~K}$,

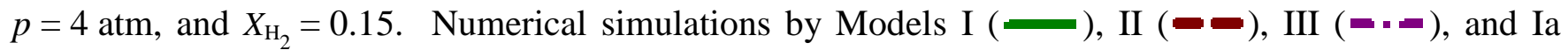
(-.-) . Symbols: present experimental data. 

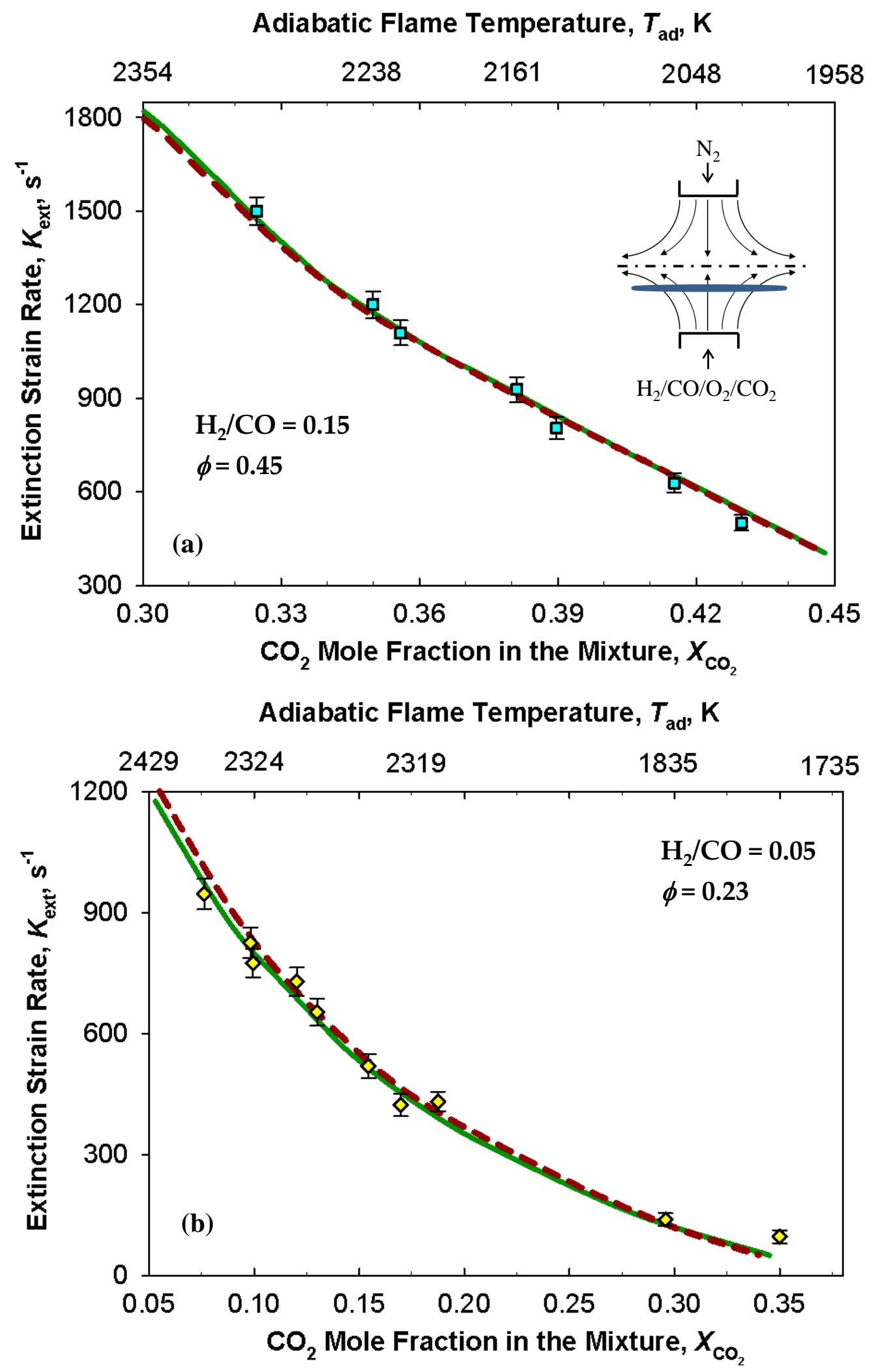

Figure 24. Experimental and computed $K_{\text {ext }}$ 's of opposed-jet premixed $\mathrm{CO} / \mathrm{H}_{2} / \mathrm{CO}_{2} / \mathrm{O}_{2}$ flames at (a) $\phi=0.45, \mathrm{H}_{2} / \mathrm{CO}=0.15$ (b) $\phi=0.23, \mathrm{H}_{2} / \mathrm{CO}=0.05 . T_{\mathrm{u}}=298 \mathrm{~K}$, and $p=1 \mathrm{~atm}$. Lines: simulations using Models I ( $)$ and II ( $-\boldsymbol{C})$. Symbols: present experimental data. 


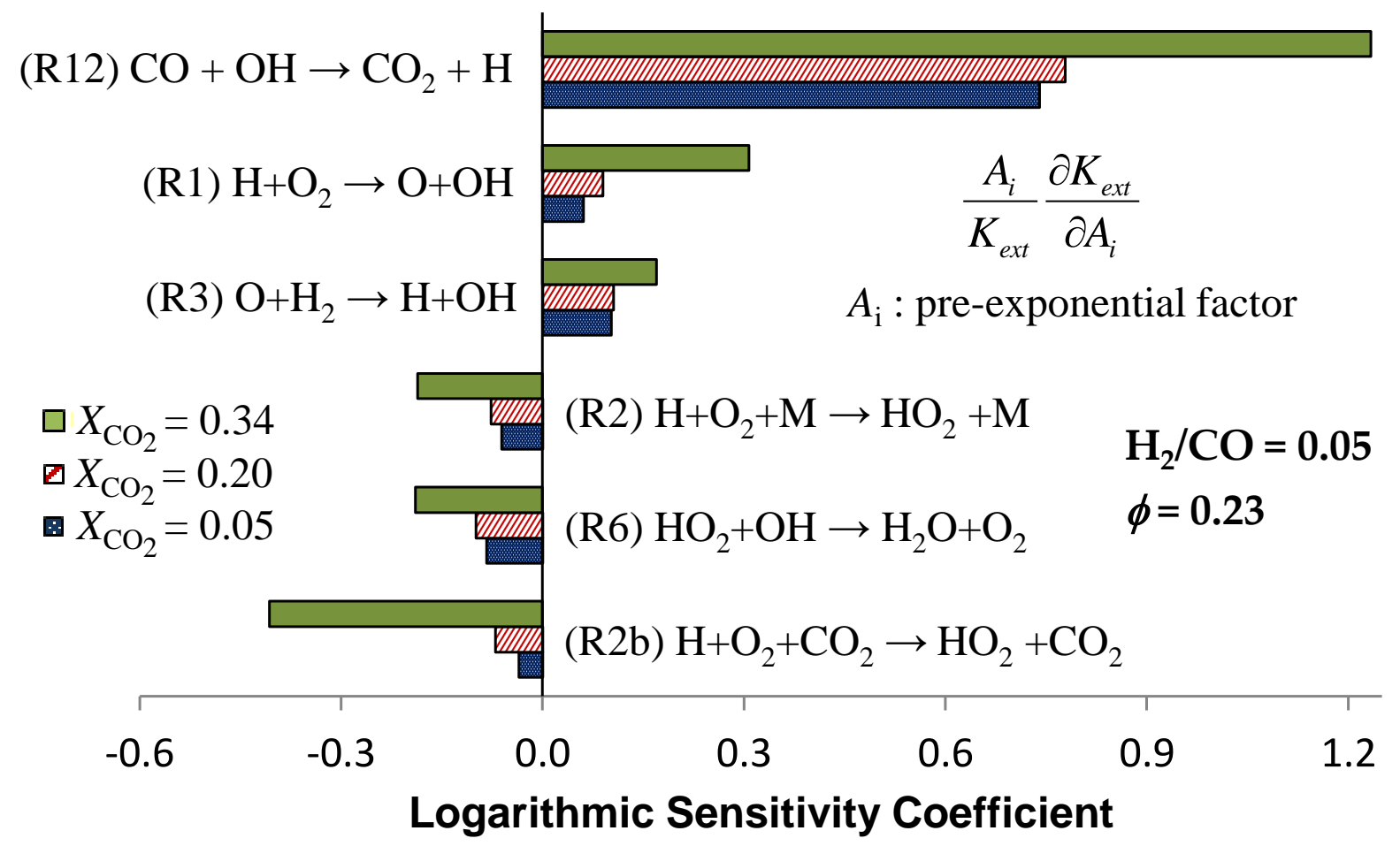

Figure 25. Logarithmic sensitivity coefficients of $K_{\text {ext }}$ with respect to kinetics for $\mathrm{H}_{2} / \mathrm{CO} / \mathrm{CO}_{2} / \mathrm{O}_{2}$ flames with $\mathrm{CO} / \mathrm{H}_{2}=0.05$ at $\phi=0.23, T_{\mathrm{u}}=298 \mathrm{~K}$, and $p=1$ atm computed using Model $\mathrm{I}$. 


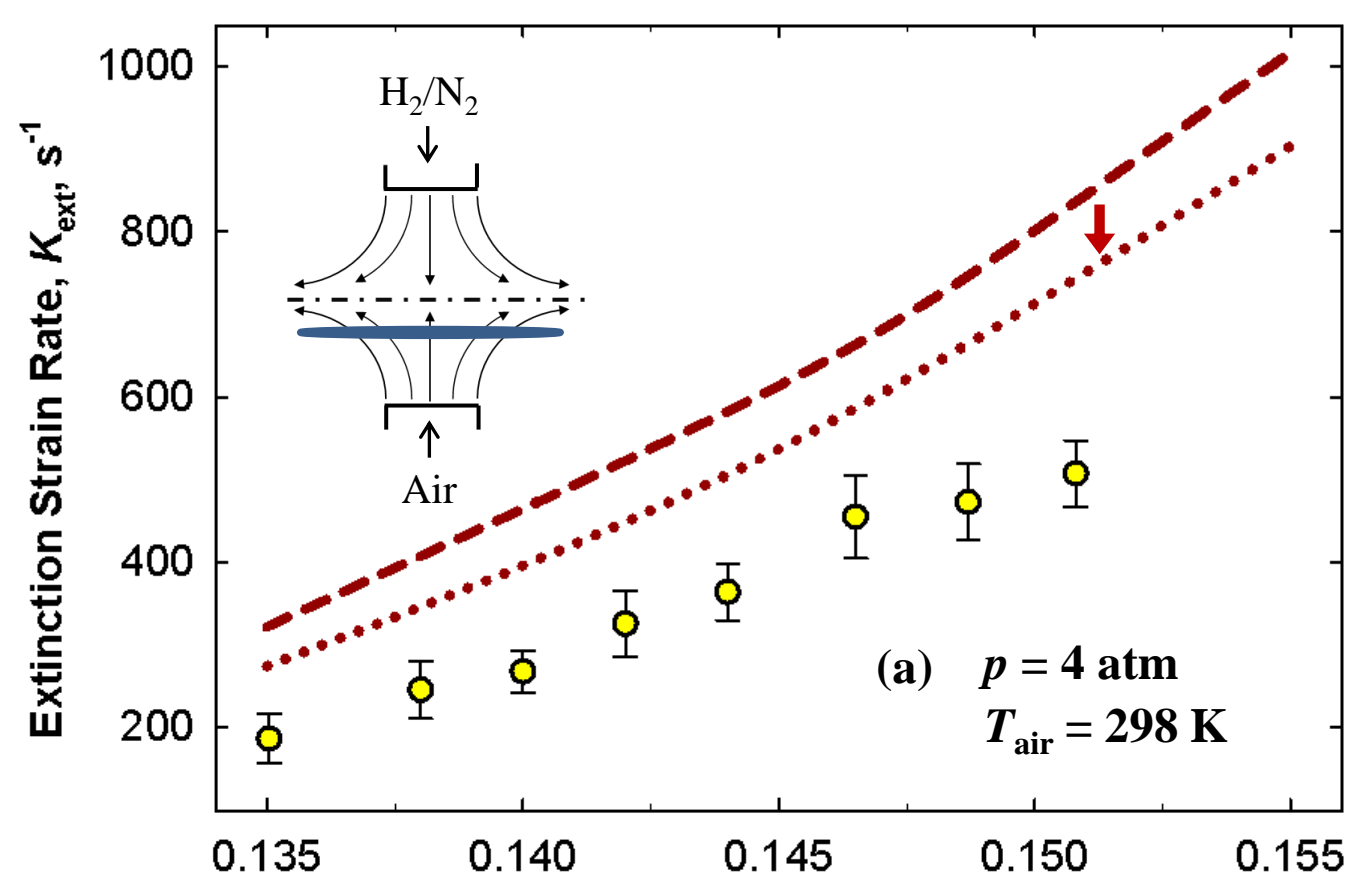

Fuel Mole Fraction, $\boldsymbol{X}_{\mathrm{H}_{2}}$

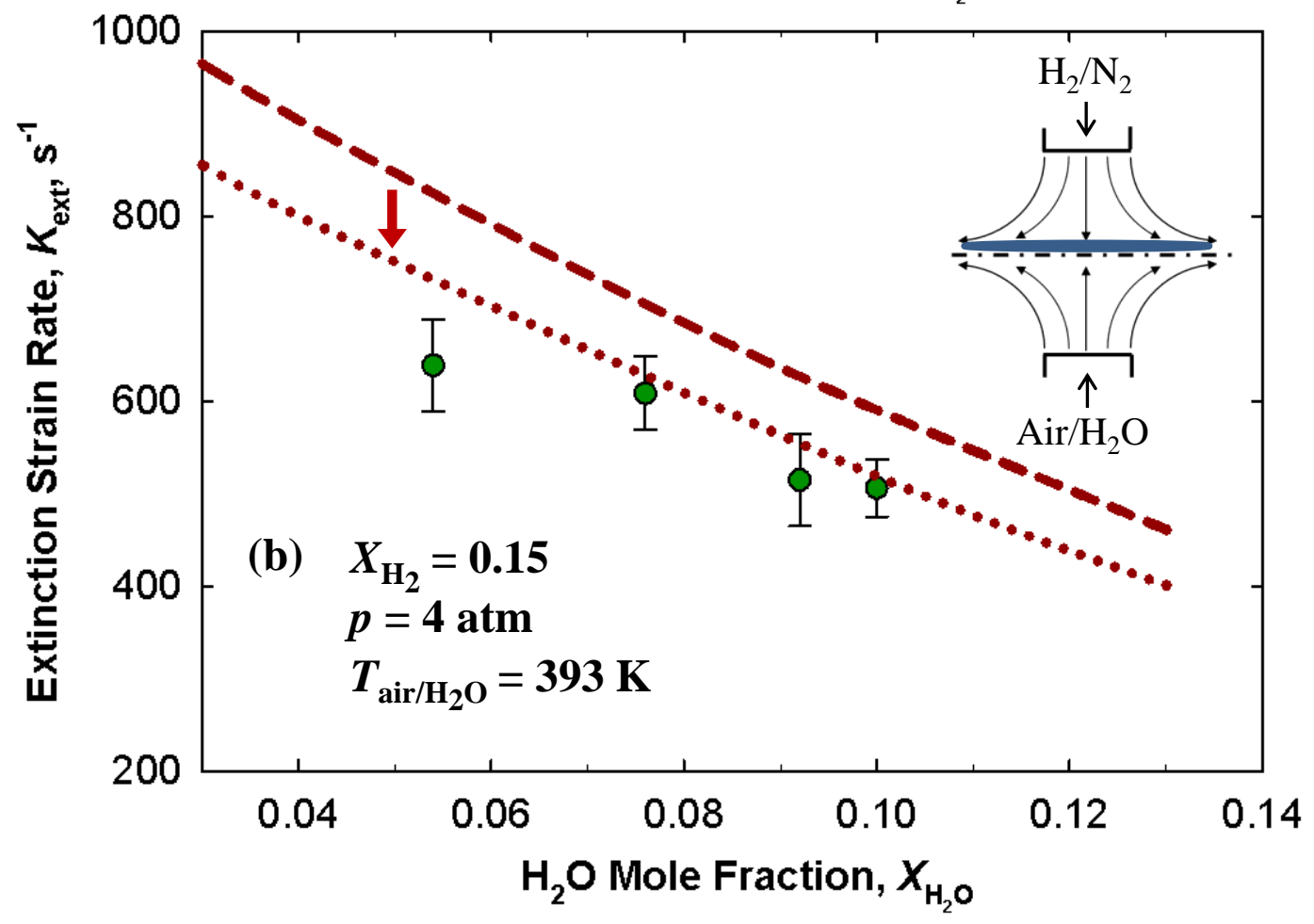

Figure 26. Experimental and computed $K_{\text {ext }}$ 's of non-premixed $\mathrm{H}_{2} / \mathrm{N}_{2}$-Air flames at $T_{\text {air }}$ and $T_{\mathrm{N}_{2} / \mathrm{H}_{2}}=298 \mathrm{~K}$ and $p=1,4$, and $7 \mathrm{~atm}$. Lines: simulations using Models II (-) and IIa $(\cdots)$ ). Symbols: present experimental data. 


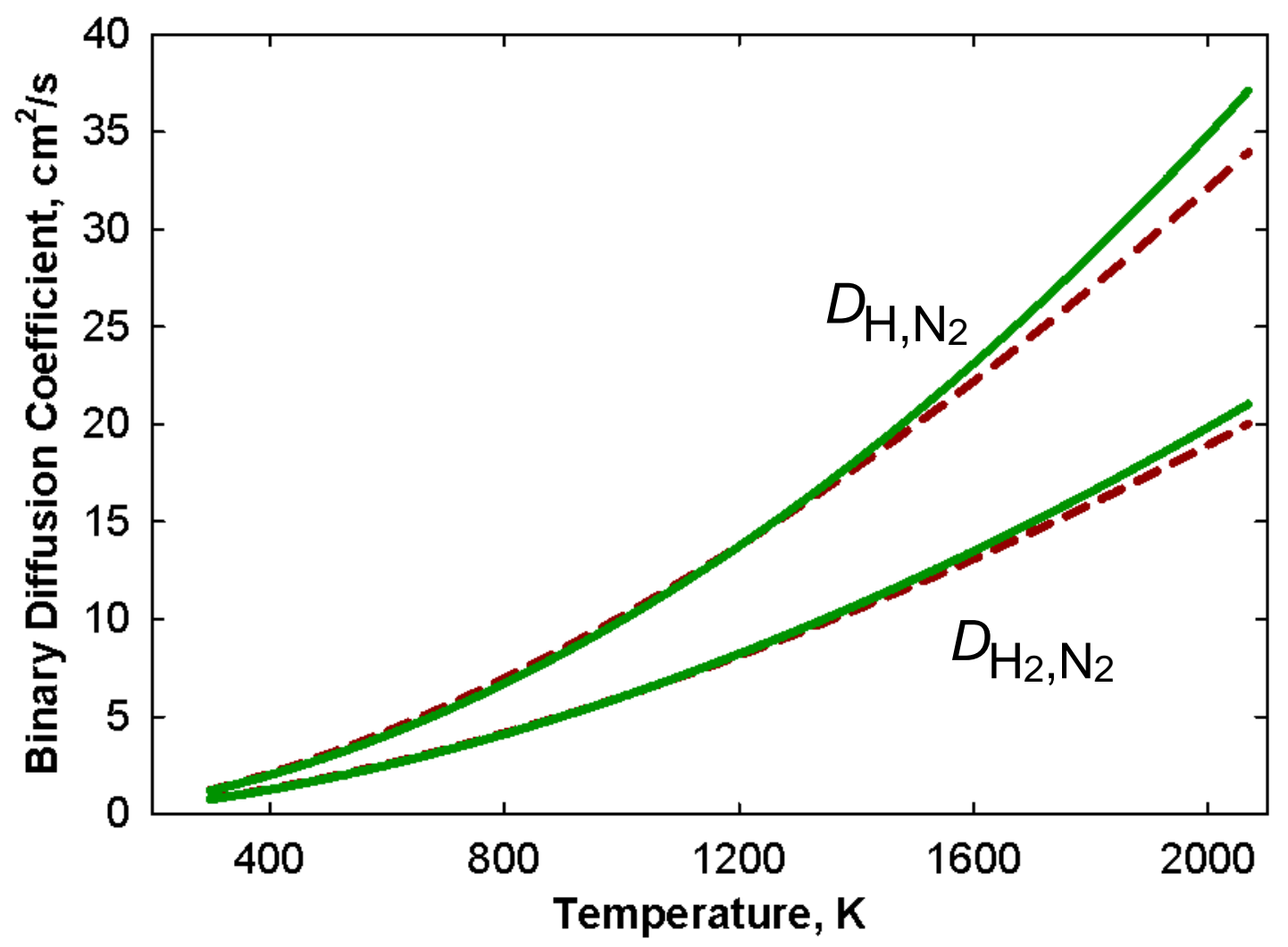

Figure 27. Binary diffusion coefficients of pairs $\left(\mathrm{H}, \mathrm{N}_{2}\right)$ and $\left(\mathrm{H}_{2}, \mathrm{~N}_{2}\right)$ as a function of temperature computed using Models IIa ( $(-)$ and II (- $)$ at $p=1 \mathrm{~atm}$. 


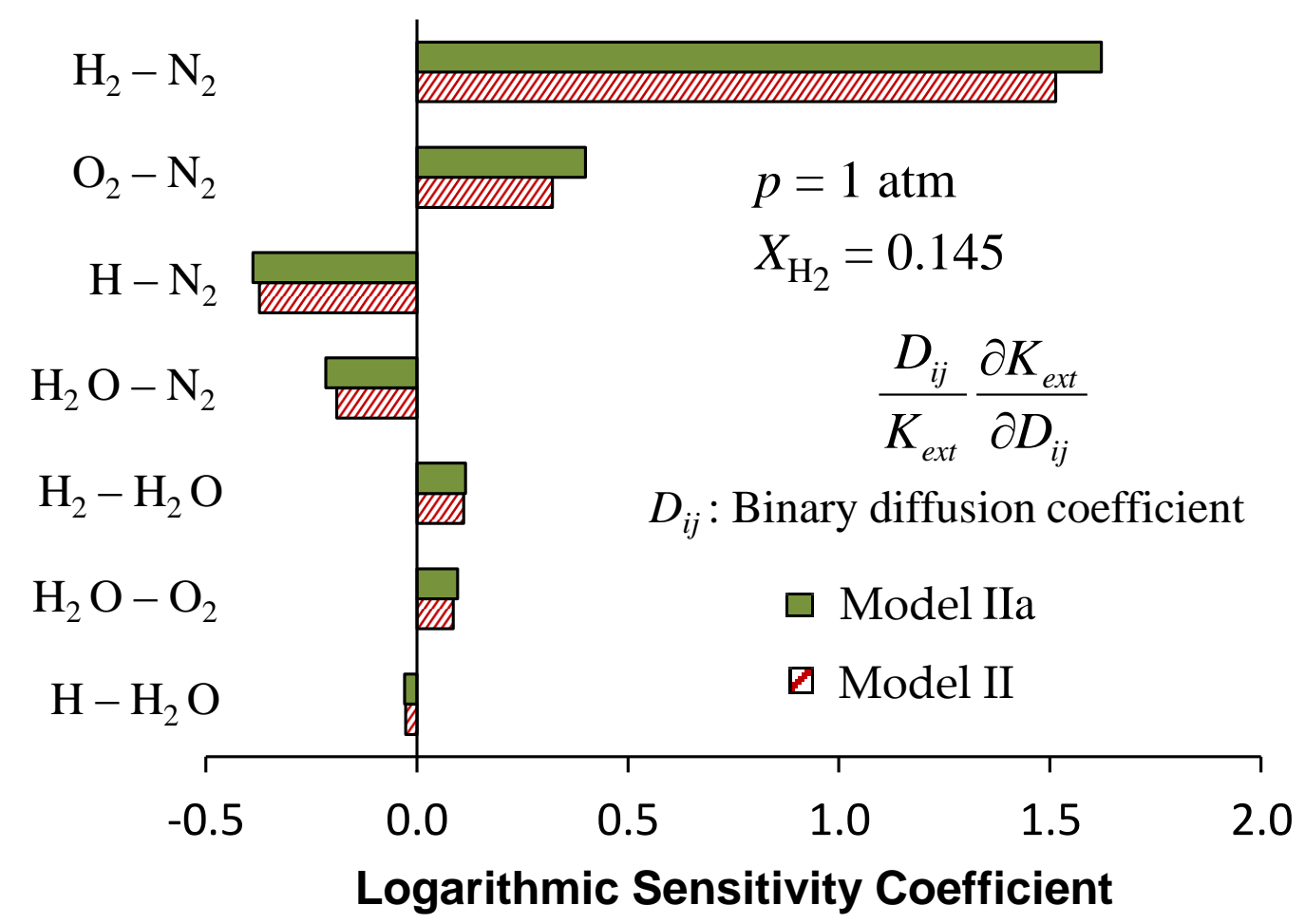

Figure 28. Logarithmic sensitivity coefficients of $K_{\text {ext }}$ to binary diffusion coefficients for opposed-jet non-premixed $\mathrm{H}_{2}$ flames at $X_{\mathrm{H}_{2}}=0.145, T_{\text {air }}=298 \mathrm{~K}$, and $p=1 \mathrm{~atm}$ computed using Models II and IIa. 